\title{
STRUCTURAL UNEMPLOYMENT, UNDEREMPLOYMENT, AND SECULAR STAGNATION
}

\author{
Ken-ichi Hashimoto \\ Yoshiyasu Ono \\ Matthias Schlegl
}

May 2020

The Institute of Social and Economic Research

Osaka University

6-1 Mihogaoka, Ibaraki, Osaka 567-0047, Japan 


\title{
Structural unemployment, underemployment, and secular stagnation*
}

\author{
Ken-ichi Hashimoto ${ }^{\dagger}$ Yoshiyasu Ono ${ }^{\ddagger}$ Matthias Schlegl ${ }^{\S}$
}

May 2020

\begin{abstract}
We introduce a preference for wealth into the standard search and matching model to analyze the labor market when there is persistent demand shortage. We show that, under some conditions, a secular stagnation steady state exists in which the economy permanently operates below capacity due to both structural unemployment and underemployment. The latter is a direct consequence of the lack of aggregate demand. Our findings are as follows. In the absence of demand shortage, the preference for wealth creates a new transmission channel for shocks and policy measures due to induced changes in the real interest rate, in addition to the job creation channel of the standard matching model. Turning to the stagnation equilibrium, the effects of demand and supply shocks are opposite to those of the standard case and result in a co-movement of unemployment and underemployment. In contrast, the effects of wage and cost shocks depend on the degree of aggregate demand shortage, but they can explain movements of unemployment and underemployment in opposite directions. Finally, we show that fluctuations in the total employment gap under stagnation are primarily driven by fluctuations in underemployment instead of structural unemployment. Our analysis helps to understand why the unemployment rate in Japan has been surprisingly low during its lost decades and highlights the need for further policy interventions in support of aggregate demand despite a seemingly decent employment record.
\end{abstract}

Keywords: demand shortage, unemployment, underemployment, labor market frictions, secular stagnation

JEL Classification: E24, E31, E44, J20, J64

\footnotetext{
${ }^{*}$ We are grateful to Eiichi Miyagawa, Akihisa Shibata, Takashi Shimizu, Mototsugu Shintani, Daishin Yasui, Kaz Yugami, to seminar participants at Kobe University and Tokyo Institute of Technology for helpful comments and suggestions, and to Osaka University for its International Joint Research Promotion Program. Financial supports from the Joint Usage Research Center Program at ISER and JSPS KAKENHI Grants (19K23230, 15H05728 and 20K01631) are gratefully acknowledged.

${ }^{\dagger}$ Graduate School of Economics, Kobe University; Email: hashimoto@econ.kobe-u.ac.jp

${ }^{\ddagger}$ Institute of Social and Economic Research, Osaka University; Email: ono@iser.osaka-u.ac.jp

${ }^{\S}$ Department of Economics, Sophia University, Tokyo; Email: m-schlegl-4t5@sophia.ac.jp
} 


\section{Introduction}

Japan's macroeconomic performance in the decades following the burst of its bubble economy is characterized by persistent deflationary tendencies and a shortfall of production below estimates of potential output. As households restrained consumption, firms cut back on investment, and with monetary policy constrained by the binding lower bound on the nominal interest rate, aggregate demand has been insufficient for the economy to produce at full capacity. Japan's economy is stuck in an equilibrium of persistent stagnation without any natural recovery.

Against this background, the country has performed surprisingly well in terms of its unemployment record throughout the stagnation period. Albeit increasing in the immediate aftermath of the asset price crash, the unemployment rate of Japan has remained low by international comparison. As illustrated in panel (a) of Figure 1, it peaked at slightly more than $5 \%$ in 2002 and has since fallen back to its 1980s level, the trend being briefly interrupted by the global financial crisis. ${ }^{1}$ This absence of widespread unemployment is commonly explained by the specific features of the Japanese labor market, most notably the system of life-time employment. ${ }^{2}$ Several studies report that these traditional Japanese practices of long-term employment have eroded remarkably little, at least among core workers, during the stagnation decades (see Shimizutani and Yokoyama, 2009; Kambayashi and Kato, 2011; Hamaaki et al., 2012, among others). The unemployment rate in Japan is then primarily determined by institutional and structural factors of the labor market, as opposed to the United States and other advanced economies, making it less responsive to fluctuations in spending. ${ }^{3}$

But then, how did the lack of demand manifest itself in the labor market, if not in the unemployment rate? During the last decades, there has been a profound change in the structure of employment in Japan; the emergence of underemployment in the form of an increase in parttime and non-regular employment as well as a secular decline in working hours. For illustration, panel (b) of Figure 1 shows the share of part-time employment in Japan in contrast to the OECD average. ${ }^{4}$ Having been less than $12 \%$ in the 1980 s, the share of part-time employees has sharply increased throughout the lost decades starting well before the labor market liberalization policies of the early 2000s. By 2018, this share had doubled compared to the 1980s level whereas it only increased by 3 percentage points over all OECD countries. A similar trend can be observed for other forms of non-regular employment (see Japan Institute for Labour Policy and Training, 2015). And while the rise in part-time employment can partly be attributed

\footnotetext{
${ }^{1}$ In fact, Japan's employment record makes some economists question the existence of a structural demand deficiency. For instance, Homburg (2017) argues that Japan is in a "benign liquidity trap" characterized by a decent performance of output and employment despite deflation and a zero interest rate.

${ }^{2}$ We refer to Hashimoto and Raisian (1985) for a description of the Japanese employment system in comparison to the United States before the lost decades.

${ }^{3}$ This explanation is in line with the findings of Ball et al. (2013), who empirically study Okun's Law for several advanced economies since 1980. They estimate a slope coefficient of only -0.15 for Japan further indicating a weak relationship between unemployment and aggregate demand and attribute this finding to the institutional features of the Japanese labor market.

${ }^{4}$ The OECD defines part-time employment as follows: "Part-time employment is defined as people in employment (whether employees or self-employed) who usually work less than 30 hours per week in their main job. Employed people are those aged 15 and over who report that they have worked in gainful employment for at least one hour in the previous week or who had a job but were absent from work during the reference week while having a formal job attachment."
} 

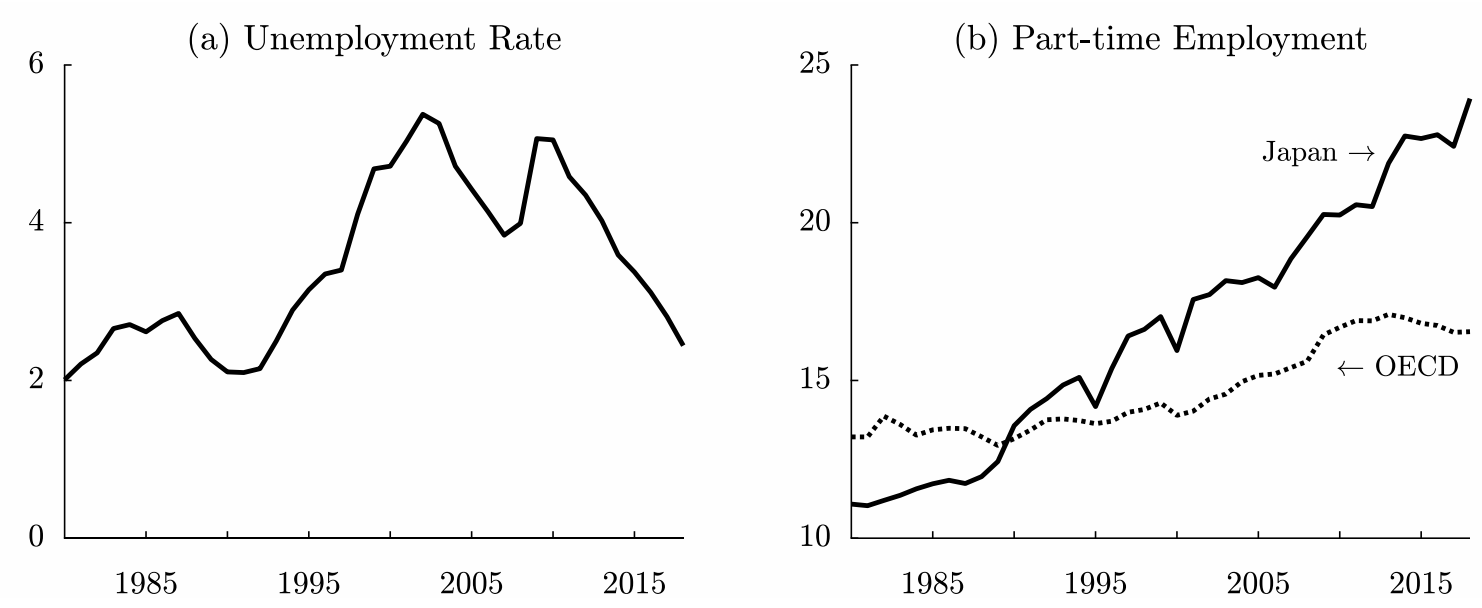

Data sources: (a) Unemployment rate (in percent of the labor force), OECD; (b) Part-time employment rate (in percent of total employment), OECD, Japan (solid) and OECD average (dotted line)

to an increased desire for flexibility by employees, it primarily reflects the lack of alternative employment opportunities. ${ }^{5}$ Finally, the decline in average hours worked in the OCED data is also indicative of the rise of underemployment in Japan since 1990. Average annual hours worked have declined steadily, particularly strongly in the 1990s, and have even fallen below the OECD average. ${ }^{6}$

These observations pose important questions for researchers and policymakers alike: How does a lack of aggregate demand manifest itself in the labor market? Under what conditions does demand-driven underemployment occur in equilibrium? How do structural unemployment and underemployment interact with each other? How do they respond to macroeconomic shocks and various labor market policies? And how do these variables contribute to the total employment gap in the labor market in the presence of demand shortage?

Existing models of secular stagnation are insufficient to address these questions as they do not model the institutional structure of the labor market in detail. In this paper, we offer a richer model of stagnation that allows us to explicitly distinguish between structural unemployment and demand-driven underemployment. Using this model, we examine the effects of macroeconomic demand and supply shocks and various microeconomic labor market policies thereby addressing the aforementioned questions and substantially extending the existing literature.

Specifically, we incorporate a preference for wealth into the standard search and matching model of the labor market. In a setting with infinitely-lived households, such a preference captures the bequest motive within dynasties that is frequently incorporated in overlapping generations models. The preference for wealth creates a strong motive to save in addition to the standard consumption smoothing motive, which can explain why empirically the saving

\footnotetext{
${ }^{5}$ For illustration, non-regular employees consistently emphasize the "lack of regular employment opportunities" as a major reason for their current work style in surveys conducted by the Japan Institute for Labour Policy and Training (see Japan Institute for Labour Policy and Training, 2015).

${ }^{6}$ The secular decline in working hours is also confirmed by data from the Labour Force Survey of the Statistics Bureau of Japan. Average working hours per week have substantially fallen from a stable level of slightly more than 28 hours in the 1980 s to less than 23 hours by the 2010s.
} 
rate of households is increasing in their wealth (see Benhabib and Bisin, 2018; Fagereng et al., 2019). ${ }^{7}$ Importantly, the preference for wealth allows for the possibility of a secular stagnation equilibrium as is well-know from contributions such as Ono (1994, 2001, 2015), Michau (2018) or Schlegl (2018). Households' desire to save can drive the equilibrium or "natural" real interest rate into negative territory. Yet, the effective lower bound, which we model as a rate of zero for simplicity, prevents the nominal interest rate from falling sufficiently. This increases the desire for savings which depresses aggregate demand. Combined with downward nominal wage rigidities in the spirit of Schmitt-Grohé and Uribe $(2016,2017)$, the model economy operates in a secular stagnation equilibrium characterized by deflation and a persistent lack of demand.

The search and matching friction results in structural unemployment in equilibrium as vacancies and job-seekers have to match successfully in a costly process before a position can be filled. In addition, our model allows firms to respond to demand fluctuations by adjusting working hours of employees, which results in demand-driven underemployment. In the absence of demand shortage, our model behaves similar to the standard case. The search friction creates an employment gap, but conditional on being employed, households realize their potential working hours and there is no underemployment. Nevertheless, the preference for wealth offers an interesting new transmission channel as various shocks and labor market policies also affect unemployment and other macroeconomic variables by inducing changes in the real interest rate. In contrast, both structural unemployment and underemployment coexist and mutually affect each other in the stagnation equilibrium. While unemployment is determined by the labor market friction, it is the demand side that determines realized working hours, which fall short of potential hours. The total employment gap then exceeds the unemployment rate.

We use this model to study the effects of macroeconomic supply and demand shocks as well as microeconomic shocks such as wage and cost shocks under stagnation. The effects of demand and supply shocks are reversed under demand shortage. Higher demand, in the form of government spending, increases working hours and lowers unemployment thereby raising consumption and output. In contrast, a positive supply shock via an increase in labor productivity worsens deflation and leads to both higher unemployment and more underemployment. This is the paradox of toil that is common to models of stagnation. Importantly, these macro shocks result in co-movements of the unemployment rate and the degree of underemployment as have been observed in Japan following the burst of the bubble economy and during the global financial crisis. In contrast, the effects of labor market policies depend on the shape of the wealth preference and the substitution elasticity of the matching function both of which also affect the severity of demand shortage. When the economy is sufficiently depressed, these policies result in movements of unemployment and underemployment in opposite directions as has been the case in Japan during labor market liberalization policies in the early 2000s and after 2012.

\footnotetext{
${ }^{7}$ Several recent contributions have analyzed the macroeconomic implications of a preference for wealth in models similar to ours. Kumhof et al. (2015), Michau et al. (2019) and Mian et al. (2019) study the dynamics of wealth and inequality that result from endogenous differences in saving rates based on the wealth preference, while Michau et al. (2018) analyze the dynamics of asset prices and the possibility of rational bubbles in such a framework. Michaillat and Saez (2019) incorporate a preference for wealth (relative to the average wealth level) into a New Keynesian model to study business cycle fluctuations and Saez and Stantcheva (2018) employ a similar framework for the analysis of capital taxation. For the interested reader, we refer to Zou (1994) who provides an in-depth discussion of the idea of a preference for wealth in economic thought.
} 
Finally, we use numerical simulations to quantify the relative importance of search-based unemployment and demand-driven underemployment in the stagnation equilibrium. While the standard search and matching mechanism is still at work in the model - in fact, structural unemployment worsens under stagnation - the effects of shocks are typically reflected in stronger variations in underemployment for reasonable parameter calibrations.

Related Literature: Our paper analyzes the interactions of structural unemployment based on search frictions and underemployment under secular stagnation, thereby contributing to and combining two fields of macroeconomics that have so far been treated fairly independently.

There is a rich literature on unemployment as a consequence of frictions in the labor market. Diamond (1982), Mortensen (1982) and Pissarides (1985) developed search and matching models of unemployment, which scholars have since applied in a wide variety of fields. ${ }^{8}$ Merz (1995) and Andolfatto (1996) introduce these labor market frictions into the standard real business cycle model. In these type of models, all goods are produced by successful matches between workers and firms. Equilibrium unemployment then results from frictions when matching vacancies and job-seekers.

Variations in working hours are introduced into the matching framework by Fang and Rogerson (2009) as households optimally choose their labor supply based on the consumption versus leisure trade-off. While their study focuses on cross-country differences in working hours resulting from differences in employment to population ratios and hours per worker, our paper contrasts the labor market equilibria in the presence and absence of persistent stagnation, abstracting from voluntary variations in the labor supply.

In a related framework, Kudoh et al. (2019) analyze changes in the composition of firms' labor demand over the business cycle. While labor market participation, i.e. the extensive margin of the labor supply, is chosen by each individual, working hours conditional on employment are adjusting in response to demand-driven fluctuations in production, which is a features similar to our model. However, these fluctuations occur over the business cycle and are hence purely temporarily in nature. This is in stark contrast to our framework which allows for the possibility of good market disequilibrium and demand-driven underemployment as a steady state phenomenon.

Finally, Michaillat and Saez (2015) apply a matching framework to both the labor market and the product market, such that the equilibrium level of sales is determined by a matching process between sellers and buyers. This implies that the price level and labor market tightness, i.e. the ratio of vacancies to job-seekers, have to adjust in order to balance demand and supply in both markets simultaneously. Thus, there are feedback effects from demand fluctuations into the labor market. Under fixed prices, an increase in aggregate demand increases labor demand which leads to a rise in working hours and lower unemployment. The authors then discuss the effects of macroeconomic shocks on labor and product market tightness focusing on the special cases of fixed prices as well as an equilibrium with competitive prices and Nash bargaining. ${ }^{9}$

\footnotetext{
${ }^{8}$ Pissarides (2000) provides the standard textbook for an introduction to models of search and matching frictions in the labor market. Rogerson et al. (2007) survey the related literature.

${ }^{9}$ Landais et al. (2015b,a) use the same framework to study the effects of various labor market policies.
} 
While the above-mentioned contributions model structural unemployment based on the search friction and allow for voluntary variations in working hours, they do not consider the possibility of involuntary underemployment in equilibrium. ${ }^{10}$ In our model, this phenomenon emerges as a result of good market disequilibrium under persistent stagnation.

The secular stagnation hypothesis has been revived by Summers (2013) against the background of the weak recovery following the Great Recession, based on the original idea of Hansen (1939). Proponents of this hypothesis argue that an oversupply of savings at full employment permanently depresses aggregate demand as the zero lower bound on the nominal rate prevents the real interest rate from falling sufficiently to stimulate spending. In the presence of downward nominal wage rigidity, this results in an equilibrium characterized by deflation, a shortfall of output below potential and involuntary underemployment. The oversupply of savings has been modelled among others as a consequence of demographics (Eggertsson et al., 2019), a shortage of safe assets (Caballero and Farhi, 2018) or strong liquidity preferences (Ono, 2001; Illing et al., 2018). ${ }^{11}$ In this paper, we model the secular stagnation equilibrium based on a preference for wealth in line with the contributions of Ono (1994, Chapter 11; 2015) and Michau (2018). ${ }^{12}$

These models, however, do not consider structural unemployment and abstract from labor market frictions. The labor market gap is either entirely ignored, in case the analysis is based on an endowment economy, or it consists of a demand-driven shortfall of realized working hours only. Hence, these models do not allow for potential interactions of unemployment and underemployment. In contrast, this paper treats both phenomena in an integrated framework, thereby showing that they are inherently interrelated. In our model, structural unemployment increases under stagnation, a feature which is also consistent with the idea of hysteresis in the labor market.

Our analysis concludes that it is primarily demand-driven underemployment instead of structural unemployment that responds to economic disturbances and labor market policies under stagnation, which is in line with the developments in Japan since the 1990s. It thus highlights the need for further policy intervention in support of aggregate demand despite the seemingly decent employment situation in terms of the unemployment rate.

The remainder of this paper is organized as follows. Section 2 outlines the features of the model. Section 3 focuses on the standard equilibrium without aggregate demand shortage, but with a preference for wealth, and examines the effects of labor market policies and macroeconomic shocks on unemployment, output and consumption. Section 4 considers the case where aggregate demand shortage occurs in steady state and shows that the effects of these policies and shocks are just opposite to those in the standard case. We also provide a decomposition of the total employment gap. The final section summarizes our findings and concludes.

\footnotetext{
${ }^{10}$ An exception is Michaillat (2012) who introduces involuntary unemployment based on rationing into the search and matching model. Rationing unemployment results from a wage above market clearing level and coexists with structural unemployment. Yet, it is not related to a persistent shortage of demand.

${ }^{11}$ For the open economy versions of these models, see Eggertsson et al. (2016), Caballero et al. (2016) and Ono (2014).

${ }^{12}$ In addition, Schlegl (2018) provides a treatment of secular stagnation in an economy with land while Michau (2019a) carefully analyzes the effects of helicopter drops of money under stagnation based on a preference for wealth. Michaillat and Saez (2014) also rely on a preference for wealth to obtain an equilibrium with a permanent liquidity trap.
} 


\section{The Model}

\subsection{Households}

Time is continuous and denoted by $t$. There is a mass one of infinitely-lived households. To eliminate any uncertainty regarding employment, the model assumes that each household consists of a large number of individuals normalized to unity, with $u_{t}$ unemployed and $1-u_{t}$ employed ones. Each individual is endowed with one unit of labor $l_{t}=1$, which is supplied inelastically, and one unit of time. Let $x_{t} \in[0,1]$ denote realized working hours per individual. In case of aggregate demand shortage, realized working hours fall short of potential working hours, i.e. $x_{t}<1$. Each household receives wage income of $w_{t}\left(1-u_{t}\right) x_{t}$ and unemployment benefits of $z u_{t}$, where $w_{t}$ is the real wage rate and $z$ denotes unemployment benefits. We follow Merz (1995) and Andolfatto (1996) and assume that the household provides perfect consumption insurance for its members such that consumption is the same for employed and unemployed individuals.

Household assets $a_{t}$, in real terms, consist of interest bearing assets (bonds or equities) $b_{t}$ and real money holdings $m_{t}$ that do not pay interest:

$$
a_{t}=b_{t}+m_{t}
$$

Let $r_{t}$ denote the real interest rate and $R_{t} \geq 0$ the nominal interest rate, which are related via the Fisher Equation by $R_{t}=r_{t}+\pi_{t}$, where $\pi_{t}$ denotes the rate of inflation. Then, real wealth evolves as: ${ }^{13}$

$$
\dot{a}_{t}=r_{t} a_{t}+w_{t}\left(1-u_{t}\right) x_{t}+z u_{t}-c_{t}-R_{t} m_{t}-\tau_{t},
$$

where $\tau_{t}$ is a real lump-sum tax, and $\left(1-u_{t}\right) x_{t} \in[0,1]$ is effective employment. Note that the household faces opportunity costs $R_{t}$ when holding money due to the foregone interest earnings.

As in Michaillat and Saez (2015) and Michau (2018), the lifetime utility of the household is given by

$$
\mathcal{U}_{0}=\int_{0}^{\infty}\left[\phi\left(c_{t}\right)+\mu\left(m_{t}\right)+\omega\left(a_{t}-m_{t}^{S}\right)\right] e^{-\rho t} d t
$$

where $\rho>0$ is the subjective discount rate. At any point in time, the household derives utility $\phi\left(c_{t}\right)$ from consuming $c_{t}$ with $\phi^{\prime}(\cdot)>0$ and $\phi^{\prime \prime}(\cdot)<0$ and utility $\mu\left(m_{t}\right)$ from holding real money balances $m_{t}$, with $\mu^{\prime}(\cdot)>0, \mu^{\prime \prime}(\cdot)<0$, and $\mu^{\prime}\left(m_{t}\right)=0$ for all $m_{t} \geq \bar{m}$. At $\bar{m}$, the household is satiated with real money balances and does not derive any utility from holding more money for transaction purposes. In addition, we introduce a preference for net wealth $\omega\left(a_{t}-m_{t}^{S}\right)$ with $\omega^{\prime}(\cdot)>0$ and $\omega^{\prime \prime}(\cdot) \leq 0$, where $m_{t}^{S}$ denotes the real money supply. This specification implies that households collectively consider the money stock a government liability that eventually needs to be redeemed and hence not part of aggregate net wealth, even though each household considers his personal money holdings as part of his wealth. As there is no heterogeneity on the household level in our model, it is only wealth from equity holdings (as bonds are in zero net supply) that affects the wealth preference in steady state. ${ }^{14}$

\footnotetext{
${ }^{13}$ The nominal flow budget equation is $\dot{A}_{t}=R_{t} P_{t} b_{t}+W_{t}\left(1-u_{t}\right) x_{t}+Z u_{t}-P_{t} c_{t}-P_{t} \tau_{t}$, where $A_{t}\left(\equiv P_{t} a_{t}\right)$ denotes total asset holdings. Using $a_{t}=m_{t}+b_{t}$ and $r_{t} \equiv R_{t}-\pi_{t}$, where $\pi_{t} \equiv \dot{P}_{t} / P_{t}$, we obtain (2).

${ }^{14}$ Michau (2019b) discusses and justifies the preference for net wealth in contrast to alternative specifications.
} 
The household maximizes lifetime utility subject to the asset constraint (1) and the flow budget constraint (2). Optimal household behavior is described by the Euler Equation, the money demand function and the transversality condition as

$$
\begin{gathered}
\eta_{c} \frac{\dot{c_{t}}}{c_{t}}=r_{t}-\rho+\frac{\omega^{\prime}\left(b_{t}+m_{t}-m_{t}^{S}\right)}{\phi^{\prime}\left(c_{t}\right)}, \\
R_{t}=\frac{\mu^{\prime}\left(m_{t}\right)}{\phi^{\prime}\left(c_{t}\right)} \geq 0, \\
\lim _{t \rightarrow \infty} \phi^{\prime}\left(c_{t}\right) a_{t} e^{-\rho t}=0,
\end{gathered}
$$

where $\eta_{c} \equiv-\phi^{\prime \prime}\left(c_{t}\right) c_{t} / \phi^{\prime}\left(c_{t}\right)$ is the elasticity of the marginal utility with respect to consumption (and the inverse of the intertemporal elasticity of substitution), which we assume constant. ${ }^{15}$

The preference for wealth affects the intertemporal allocation of consumption in the Euler Equation (3). Households have stronger incentives to save since accumulation of wealth becomes an end in itself, representing the bequest motive within dynasties, rather than a mere means to smooth consumption. This creates a wedge between the real interest rate and the time preference rate of the household.

Optimal money demand in (4) requires the marginal rate of substitution between money and consumption to equal the opportunity cost of holding money, which are given by the nominal interest rate. The nominal rate equals zero whenever $m_{t} \geq \bar{m}$, which allows for the possibility of a liquidity trap in our framework.

\section{$2.2 \quad$ Firms}

The supply side of the economy consists of a large number of identical firms that produce the consumption good using labor as the only input factor. Production requires exactly one worker. Each firm therefore offers one position, which can be filled, in which case the firm is operating, or vacant. Before operating their business, firms have to search for workers in the labor market to fill this position. During the matching process, a search cost $k$ occurs. The government might however subsidies the searching process at rate $s \in[0,1)$ such that the effective search costs for the firm are given by $(1-s) k$. Firms that successfully match hire $l_{t}=1$ workers and produce output $y_{t}$ with the linear production function:

$$
y_{t}=x_{t} \bar{y} l_{t}=x_{t} \bar{y}
$$

where $\bar{y}$ denotes labor productivity and $x_{t}$ hours per worker. The operating profit of each producing firm is then simply given by $\left(\bar{y}-w_{t}\right) x_{t}$. In equilibrium, the number of operating firms equals $1-u_{t}$ and the number of vacant firms is denoted by $v_{t}$. Total output is therefore determined as

$$
Y_{t}=\left(1-u_{t}\right) x_{t} \bar{y}
$$

\footnotetext{
${ }^{15}$ These equations are obtained from the standard current value Hamiltonian function $\mathcal{H}_{t}=\phi\left(c_{t}\right)+\mu\left(m_{t}\right)+$ $\omega\left(a_{t}-m_{t}^{S}\right)+\lambda_{t}\left[r_{t} a_{t}+w_{t}\left(1-u_{t}\right) x_{t}+z u_{t}-c_{t}-R_{t} m_{t}-\tau_{t}\right]$, where $\lambda_{t}$ is the costate variable for $a_{t}$.
} 
Firms face frictions when setting their prices. Specifically, we follow Ono (1994, 2001) and introduce sluggish nominal price adjustment in the goods market via a reduced-form Phillips curve for the inflation rate $\pi_{t}$. Importantly, the dynamics of the price level in the presence of aggregate demand shortage differ from those with no aggregate demand shortage as follows:

$$
\pi_{t}=\frac{\dot{P}_{t}}{P_{t}}=\left\{\begin{array}{l}
g_{m} \text { if } x_{t}=1, \\
\alpha\left(x_{t}-1\right) \text { if } x_{t}<1,
\end{array}\right.
$$

where $\alpha$ represents the adjustment speed of nominal prices. In the absence of aggregate demand shortage, the dynamics of the price level are similar to the standard Money-in-the-Utility framework where the inflation rate is determined by the money growth rate $g_{m}$ and the price level adjusts to clear the money market. In contrast, we impose a limit on price declines under aggregate demand shortage in order to prevent deflationary wage-price-spirals and to allow for the possibility of a disequilibrium in the goods market in steady state.

The asymmetry in the inflation process is a fundamental element of stagnation models including among others the contributions of Schmitt-Grohé and Uribe (2016, 2017), Michau (2018), Illing et al. (2018) and Eggertsson et al. (2019) and typically results from some form of downward nominal wage rigidity that becomes binding in case of unemployment. ${ }^{16}$

\subsection{Government}

The government runs a balanced budget to provide total benefits $z u_{t}$ to unemployed, to subsidise a fraction $s$ of search costs $k$ of vacant firms and to finance government spending $g$ such that

$$
\tau_{t}+g_{m} m_{t}^{S}=z u_{t}+s k v_{t}+g
$$

where $g_{m}$ denotes the growth rate of the nominal money supply and $v_{t}$ represent the number of vacant firms. Expenditures are financed by the revenue from lump-sum taxation $\tau_{t}$ and seignorage $g_{m} m_{t}^{S}$. As a consequence, government bonds are in zero net supply and interestbearing assets of households $b_{t}$ solely consist of equity holdings in firms.

\subsection{Labor market}

\subsubsection{Matching mechanism}

As workers and firms face matching frictions, structural (or frictional) unemployment occurs in equilibrium, although each agent inelastically supplies one unit of labor. The number of successful matches between firms and workers is given by the matching function $F\left(u_{t}, v_{t}\right)$, which is a function of unemployment $u_{t}$ and the number of firms with a vacancy $v_{t}$ where

$$
0 \leq F\left(u_{t}, v_{t}\right) \leq \min \left\{u_{t}, v_{t}\right\} ; \quad F\left(0, v_{t}\right)=0 ; \quad F\left(u_{t}, 0\right)=0 .
$$

\footnotetext{
${ }^{16}$ Otherwise, the possibility of unemployment due to demand shortage is intrinsically avoided. Note that under this assumption, the possibility of no aggregate demand shortage is not eliminated. Ono and Ishida (2014) provide a micro-foundation for such an adjustment process.
} 
The function $F\left(u_{t}, v_{t}\right)$ is continuously differentiable, concave, homogeneous of degree one, and increasing with respect to both $u_{t}$ and $v_{t}$. Let $\theta_{t}$ denote the jobs-to-applicants ratio, i.e.,

$$
\theta_{t} \equiv \frac{v_{t}}{u_{t}} \in[0, \infty)
$$

which measures the tightness of the labor market. A higher value of $\theta$ implies more vacancies per job-seeker, which we will refer to as a tighter labor market.

Then, the probability that a vacant firm matches with a worker $q\left(\theta_{t}\right)$ is simply given by the relative frequency of matches among all vacancies and satisfies

$$
q\left(\theta_{t}\right) \equiv \frac{F\left(u_{t}, v_{t}\right)}{v_{t}}=F\left(\frac{1}{\theta_{t}}, 1\right), \quad q^{\prime}(\cdot)<0, \quad q^{\prime \prime}(\cdot)>0, \quad q(0)=1, \quad q(\infty)=0 .
$$

Similarly, the probability that a worker matches with a firm with a vacancy $p\left(\theta_{t}\right)$ is given by the relative frequency of matches among all unemployed and satisfies

$$
p\left(\theta_{t}\right) \equiv \frac{F\left(u_{t}, v_{t}\right)}{u_{t}}=F\left(1, \theta_{t}\right)=\theta_{t} q\left(\theta_{t}\right), \quad p^{\prime}(\cdot)>0, \quad p^{\prime \prime}(\cdot)<0, \quad p(0)=0, \quad p(\infty)=1 .
$$

Equations (12) and (13) imply that firms are less likely to fill vacancies and that unemployed workers are more likely to find employment the tighter the labor market as measured by $\theta .{ }^{17}$

In each period a fraction $\delta$ of workers become unemployed, where $\delta$ constitutes an exogenous separation rate. Hence, the flow into unemployment is given by $\delta\left(1-u_{t}\right)$. At the same time, the number of successful matches between vacant firms and unemployed workers is given by $F\left(u_{t}, v_{t}\right)=p\left(\theta_{t}\right) u_{t}$, which follows from (13). Therefore, the dynamics of the unemployment rate are determined by the following law of motion:

$$
\dot{u}_{t}=\delta\left(1-u_{t}\right)-p\left(\theta_{t}\right) u_{t}=\delta-\left(\delta+p\left(\theta_{t}\right)\right) u_{t} .
$$

\subsubsection{Value functions and Nash bargaining}

A set of value functions describe the values of participating in the labor market for firms and workers. The firm value equals the present discounted value of the future profit stream. We denote the value of a vacant firm searching for a worker by $V_{t}$, and the value of an operating firm employing a worker by $J_{t}$. The Bellman equations for each type are given as follows:

$$
\begin{gathered}
r_{t} J_{t}=\left(\bar{y}-w_{t}\right) x_{t}-\delta\left[J_{t}-V_{t}\right]+\dot{J}_{t}, \\
r_{t} V_{t}=-(1-s) k+q\left(\theta_{t}\right)\left[J_{t}-V_{t}\right]+\dot{V}_{t} .
\end{gathered}
$$

Similarly, we denote the present discounted values of the future income streams associated with employment and unemployment by $E_{t}$ and $U_{t}$ respectively. The Bellman equations for both types of household members are given by

$$
r_{t} E_{t}=w_{t} x_{t}-\delta\left[E_{t}-U_{t}\right]+\dot{E}_{t},
$$

\footnotetext{
${ }^{17}$ Note that we assume both functions $q($.$) and p($.$) to be continuously differentiable in [0, \infty)$.
} 


$$
r_{t} U_{t}=z+\theta_{t} q\left(\theta_{t}\right)\left[E_{t}-U_{t}\right]+\dot{U}_{t}
$$

After a vacancy is filled, wages are negotiated between firms and workers through Nash bargaining. Let $\varepsilon \in(0,1)$ denote the bargaining power of workers. Wages are set to maximize the joint surplus of workers and firms given by $\left(E_{t}-U_{t}\right)^{\varepsilon}\left(J_{t}-V_{t}\right)^{1-\varepsilon}$. Using (15) and (17) and taking the derivative with respect to wages, we obtain the following sharing rule of the total matching surplus between the firm and the worker:

$$
(1-\varepsilon)\left(E_{t}-U_{t}\right)=\varepsilon\left(J_{t}-V_{t}\right)
$$

Firms can enter the labor market freely. As a consequence, a firm will enter the labor market and post a vacancy as long as its expected value is greater or equal to zero. The free entry condition therefore implies

$$
V_{t}=0 \text {. }
$$

By applying (20) to (16) and utilizing the property $q^{\prime}(\cdot)<0$ given in (12), we find the value of an operating firm $J_{t}$ to satisfy

$$
J\left(\theta_{t}\right)=\frac{(1-s) k}{q\left(\theta_{t}\right)}, \quad J(0)=(1-s) k>0, \quad J(\infty) \rightarrow \infty, \quad J^{\prime}(.)>0 .
$$

The market entry condition therefore requires that the expected value of a filled job equals the search costs associated with a vacancy. The tighter the labor market, the lower the probability of filling a vacancy and the higher the value of an operating firm.

Using (15), (17), (18), (19), (20) and (21), the solution to the Nash bargaining problem is given by the following real wage rate (see Appendix A for the derivation):

$$
w_{t} x_{t}=\varepsilon\left(\bar{y} x_{t}+(1-s) k \theta_{t}\right)+(1-\varepsilon) z .
$$

All else equal, the negotiated wage $w_{t}$ is increasing in the bargaining power of workers $\varepsilon$, the effective cost of creating a vacancy $(1-s) k$ and unemployment benefits $z$. In addition, the wage increases in labor market tightness $\theta_{t}$ and decreases in effective working hours $x_{t}$.

The free entry condition $V_{t}=0$, applied to the Bellman equation (15), implies that in any equilibrium the real interest rate is determined by the return on equity, i.e. the sum of the net dividend yield and any capital gains on firm ownership. Formally,

$$
r_{t}=\frac{\left(\bar{y}-w_{t}\right) x_{t}}{J_{t}}-\delta+\frac{\dot{J}_{t}}{J_{t}}
$$

From $(21)$ and $(22)$, the dividend yield $\left(\bar{y}-w_{t}\right) x_{t} / J_{t}$ represented by the first term of the righthand side above turns to

$$
\vartheta\left(\theta_{t}, x_{t}\right) \equiv \frac{\left(\bar{y}-w_{t}\right) x_{t}}{J_{t}}=\frac{(1-\varepsilon)\left(\bar{y} x_{t}-z\right)}{(1-s) k} q\left(\theta_{t}\right)-\varepsilon p\left(\theta_{t}\right) .
$$

Let $\vartheta\left(\theta_{t}, 1\right)$ denote the dividend yield when there is no underemployment and $\vartheta_{\theta}\left(\theta_{t}, 1\right)$ its partial derivative with respect to $\theta_{t}$. As $\bar{y}>z$, we have $\vartheta(0,1)>0, \vartheta(\infty, 1)=-\varepsilon<0$ and $\vartheta_{\theta}\left(\theta_{t}, 1\right)<0$. 
Substituting the time derivative of $J_{t}$ derived from (21) and the expression for the dividend yield $\vartheta\left(\theta_{t}, x_{t}\right)$ in $(24)$ into $(23)$ gives the law of motion for $\theta_{t}$ :

$$
\eta_{\theta_{t}} \frac{\dot{\theta}_{t}}{\theta_{t}} \equiv \frac{\dot{J}_{t}}{J_{t}}=r_{t}-\vartheta\left(\theta_{t}, x_{t}\right)+\delta
$$

where $\eta_{\theta_{t}} \equiv-\frac{\theta_{t} q^{\prime}\left(\theta_{t}\right)}{q\left(\theta_{t}\right)}>0$. Intuitively, labor market tightness $\theta_{t}$ adjusts so that the real interest rate $r_{t}$ equals the net return on equity holdings. If $r_{t}$ exceeds the net dividend yield $\vartheta\left(\theta_{t}, x_{t}\right)-\delta$, the labor market tightness $\theta_{t}$ has to increase and thereby raise the firm value $J_{t}$ to fill the difference and to make it sufficiently attractive to invest in firms. If $r_{t}$ is less than $\vartheta\left(\theta_{t}, x_{t}\right)-\delta$, on the contrary, $\theta_{t}$ must decrease so that $J_{t}$ declines, yielding capital losses to firm owners.

\subsection{Market clearing conditions}

The money market perfectly adjusts so that at any point in time, money demand of households equals the money supply. In equilibrium, we have

$$
m_{t}=m_{t}^{S} \equiv \frac{M_{t}^{S}}{P_{t}}
$$

where $M_{t}^{S}$ is the nominal money supply, which is directly controlled by the central bank. Using (8), the dynamics of the real money supply is determined by

$$
\frac{\dot{m}_{t}}{m_{t}}=g_{m}-\pi_{t}=\left\{\begin{array}{l}
0 \text { if } x_{t}=1, \\
g_{m}-\alpha\left(x_{t}-1\right) \text { if } x_{t}<1,
\end{array}\right.
$$

where $g_{m} \geq 0$ denotes the nominal money supply growth rate. Hence, the real money supply is constant in the absence of aggregate demand shortage but expands indefinitely in case of secular stagnation due to the effects of deflation, thereby pushing the economy into a permanent liquidity trap as eventually $m_{t}>\bar{m}$.

The nominal interest rate is endogenously determined in the money market in line with (4). Using the Fisher equation and the expression for the inflation rate in (8), the real interest rate satisfies

$$
r_{t}=R_{t}-\pi_{t}=\left\{\begin{array}{l}
\frac{\mu^{\prime}\left(m_{t}\right)}{\phi^{\prime}\left(c_{t}\right)}-g_{m} \text { if } x_{t}=1, \\
\frac{\mu^{\prime}\left(m_{t}\right)}{\phi^{\prime}\left(c_{t}\right)}-\alpha\left(x_{t}-1\right) \text { if } x_{t}<1 .
\end{array}\right.
$$

Similarly, the stock market perfectly adjusts so that at any point in time the value of equity owned by households $b_{t}$ equals the aggregate firm value. Because the number of operating firms is equal to the number of employed workers, $J_{t}\left(1-u_{t}\right)$ represents the total supply of equities. Using (21), the value of equity and hence the net wealth of the household $a_{t}-m_{t}^{S}$ is given by

$$
b_{t}=\left(1-u_{t}\right) \frac{(1-s) k}{q\left(\theta_{t}\right)}
$$


Finally, the goods market equilibrium condition is derived from the household and government budget equations (see Appendix B) as

$$
\left(1-u_{t}\right) x_{t} \bar{y}=c_{t}+g+k \theta_{t} u_{t}
$$

implying that total output is used for household consumption, government spending and total search costs of firms with vacancies $v_{t}=\theta_{t} u_{t}$. Note that effective output is reduced below the production capacity $\bar{y}$ due to structural (or frictional) unemployment $u_{t}$ and demand-driven underemployment $x_{t}$, when $x_{t}<1$. We can interpret $\left(1-u_{t}\right) \bar{y}$ as a measure of potential output in the presence of structural inefficiencies. By reformulating (30), $x_{t}$ can be expressed as the ratio between effective demand and potential output. Therefore, $x_{t}$ constitutes both a measure of underemployment and a measure of effective demand shortage as reflected in the output gap. In the business cycle literature, output fluctuations around the natural level of output are typically the result of variations in working hours in response to various shocks. In contrast, our framework allows for the possibility of persistent underemployment as a steady state phenomenon, even in the absence of shocks.

\subsection{Equilibrium and steady states}

The equilibrium of the model is defined as follows:

Definition 1 An equilibrium is a set of paths for prices $P_{0}$ and $\left\{r_{t}, R_{t}, w_{t}, \pi_{t}\right\}$ and for quantities $\left\{c_{t}, m_{t}, b_{t}, a_{t}, Y_{t}, y_{t}, x_{t}, u_{t}, v_{t}, \theta_{t}\right\}$ such that

- $\left\{c_{t}, m_{t}, b_{t}, a_{t}\right\}$ solves the consumer's problem given $\left\{r_{t}, R_{t}, w_{t}, u_{t}, \theta_{t}\right\}, a_{0}, m_{0}=M_{0} / P_{0}$ and $a_{t}=b_{t}+m_{t}$ in (1);

- firms produce $y_{t}$ given $\left\{r_{t}, w_{t}, u_{t}, \theta_{t}\right\}$ resulting in aggregate output $Y_{t}$ given by (7);

- $\left\{w_{t}, v_{t}, u_{t}, \theta_{t}\right\}$ solves the Nash bargaining problem in the labor market where $v_{t}=\theta_{t} u_{t}$ according to (11);

- equilibrium prices $P_{0}$ and $\left\{r_{t}, R_{t}, \pi_{t}\right\}$ are consistent with money market equilibrium, stock market equilibrium as well as the No-Arbitrage relation between money and stocks (28), while in the goods market, inflation and working hours are determined by the non-linear Phillips curve (8) and $x_{t} \leq 1$, which hold with complementary slackness.

Equations (3), (14), (25) and (27) form an autonomous dynamic system with respect to $c_{t}$, $u_{t}, \theta_{t}$, and $m_{t}$, where $r_{t}, b_{t}$ and $x_{t}$ are derived from (28), (29) and (30) as functions of these variables. A steady state of this system is defined as follows:

Definition 2 In a stationary steady state consumption, the unemployment rate and labor market tightness are constant, i.e. it has to hold that $\dot{c}_{t}=0, \dot{u}_{t}=0$ and $\dot{\theta}_{t}=0$, while the behavior of $\dot{m}_{t}$ depends on the presence of aggregate demand shortage. 
Applying this definition, we derive the general properties of a steady state equilibrium. In each steady state, the number of newly unemployed has to equal the number of newly filled jobs for the unemployment rate to be constant. Substituting $\dot{u}=0$ into the dynamic equation in (14) yields the steady-state unemployment rate, which satisfies

$$
u(\theta)=\frac{\delta}{\delta+p(\theta)}, \quad u(0)=1, \quad u(\infty)=\frac{\delta}{\delta+1}, \quad u^{\prime}(.)<0, \quad u^{\prime \prime}(.)>0,
$$

where the signs of the derivatives follow from (13). This equation represents the Beveridge curve. A tighter labor market is characterized by a lower structural unemployment rate. In addition, the unemployment rate is increasing in the job separation rate $\delta$ (ceteris paribus) and depends on the shape of the matching function as represented by $p(\theta)$.

Using this expression in (29), the value of equity in steady state, and hence net wealth of households, is also a function of $\theta$ given by

$$
b(\theta)=(1-u(\theta)) \frac{(1-s) k}{q(\theta)}, \quad b(0)=0, \quad b(\infty) \rightarrow \infty, \quad b^{\prime}(.)>0 .
$$

A tighter labor market implies a higher number of operating firms and a higher valuation of these, both of which increase the total equity value. As a consequence, household net wealth is increasing in labor market tightness as well. Equations (31) and (32) show that, all else equal, net wealth increases in net search costs $(1-s) k$ and decreases in the separation rate $\delta$.

Finally, the real interest rate in steady state is determined by the real return on equity, which equals the dividend yield $\vartheta(\theta, x)$ net of the firm separation rate $\delta$ as there are no capital gain or losses due to a constant firm value, which is clear from (25) with $\dot{\theta}=0$, i.e.,

$$
r(\theta, x)=\vartheta(\theta, x)-\delta=\frac{(1-\varepsilon)(\bar{y} x-z)}{(1-s) k} q(\theta)-\varepsilon p(\theta)-\delta .
$$

Hence, all else equal, the real interest rate is increasing in realized working hours $x$ and decreasing in labor market tightness $\theta$, with the partial derivatives $r_{\theta}(\theta, x)<0$ and $r_{x}(\theta, x)>0 .{ }^{18}$ In addition, the real interest rate is increasing in firm productivity and decreasing in unemployment benefits, effective search costs, the firm destruction rate and the bargaining power of workers. Hence, the following partial derivatives hold in (33) for given $x$ and $\theta$ :

$$
r_{\bar{y}}>0, r_{z}<0, r_{\varepsilon}<0, r_{s}>0, r_{k}<0, r_{\delta}<0
$$

Using these properties, a steady state of our model is summarized by two equations representing the equilibrium conditions for the goods market and the asset market that simultaneously determine labor market tightness $\theta$, and hence unemployment $u(\theta)$, and realized working hours $x$, and hence underemployment $1-x$.

\footnotetext{
${ }^{18}$ In principal, we could have $\vartheta_{\theta}(\theta, x)>0$ for sufficiently small values of $x$. Yet, such a scenario is not feasible in any steady state of our model as we either have $x=1$ or $r>0$ if $x<1$, effectively putting a lower bound on any feasible $x$ in steady state.
} 
Goods market equilibrium curve: Consider first the goods market. The Euler Equation (3) with $\dot{c}_{t}=0$ implicitly defines consumption demand of households $c$ as a function of net wealth $b(\theta)$ in $(32)$ and the real interest rate in (33) as

$$
c(\theta, x)^{\text {demand }}: \frac{1}{\phi^{\prime}(c)}=\frac{1}{\omega^{\prime}(b(\theta))}[\rho-r(\theta, x)] .
$$

Consumption demand is increasing in $\theta$ as a consequence of both higher wealth and a lower real interest rate. In addition, a decrease in realized working hours $x$ stimulates consumption demand, all else equal, by lowering the real interest rate in (33). Consumption demand of households is illustrated in panel (a) of Figure 2 as a function of labor market tightness $\theta$ for the case of $x=1$ and a lower value of $x<1$.

The net supply of goods to households is defined as the difference between total output on the one hand and total entry costs of firms and government spending on the other hand. Applying the expression for unemployment in (31) to the goods market clearing condition (30), the net supply of goods is a function of labor market tightness and realized working hours given by

$$
c(\theta, x)^{\text {supply }}=(1-u(\theta)) x \bar{y}-k \theta u(\theta)-g .
$$

The net supply of goods is increasing in realized working hours $x$ as total output increases while there are no changes in entry costs. When it comes to changes in labor market tightness $\theta$, total output net of firms' entry cost shows a hump-shaped pattern for a given $x$. This behavior of the net supply of goods is illustrated in panel (b) of Figure 2 as a function of labor market tightness $\theta$ for the case of $x=1$ and a lower value of $x<1$. Initially, an increase in labor market tightness raises total output by more than it raises total search costs, thereby increasing the net supply of goods. At some point, however, the increase in total search costs exceeds the increase in output, thereby lowering the net supply available for household consumption. ${ }^{19}$ Also note that, all else equal, $c(\theta, x)^{\text {supply }}$ is decreasing in government spending $g$, as a larger fraction of output is diverted to public instead of private uses, and declining in $\delta$ and $k$ due to higher unemployment and higher search costs respectively.

Goods market equilibrium requires consumption demand in (35) to equal the net supply of goods in (36). Put differently, aggregate demand, consisting of consumption demand, government purchases and entry fees of firms has to equal aggregate supply given by total output in (7). In steady state, goods market equilibrium defines a function $x^{g}(\theta)$, which represents all combinations of $\theta$ and $x$ such that

$$
\begin{gathered}
x^{g}(\theta): E D(\theta, x) \equiv c(\theta, x)^{\text {demand }}-c(\theta, x)^{\text {supply }} \\
=\phi^{\prime-1}\left(\frac{\omega^{\prime}\left((1-u(\theta)) \frac{(1-s) k}{q(\theta)}\right)}{\rho+\delta+\varepsilon p(\theta)-\frac{(1-\varepsilon)(\bar{y} x-z)}{(1-s) k} q(\theta)}\right)+k \theta u(\theta)+g-(1-u(\theta)) \bar{y} x=0,
\end{gathered}
$$

\footnotetext{
${ }^{19}$ In a related framework, Michaillat and Saez (2015) refer to a steady state in which the net supply of goods is increasing in labor market tightness as "slack", while the opposite case is labelled "tight". We adopt their notation in this paper accordingly defining a steady state with $\frac{d c}{d \theta}>0$ in (36) as slack and a steady state with $\frac{d c}{d \theta}<0$ as tight. Note, however, that the definition refers to the total (rather than the partial) derivative.
} 
Figure 2: Demand and supply in the goods market
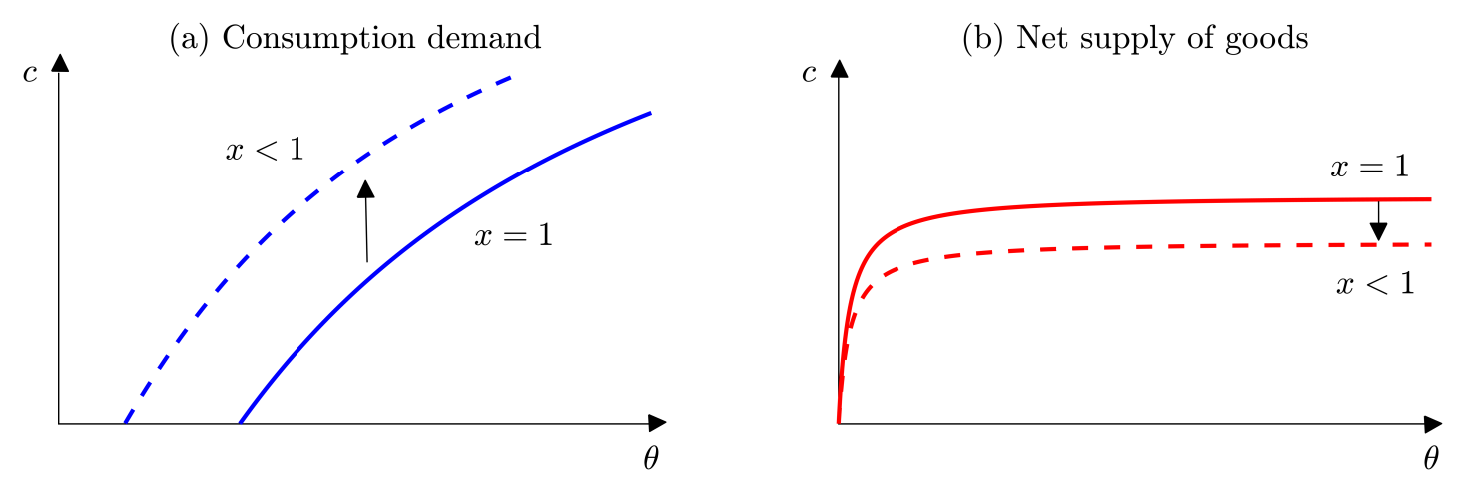

Note: Panel (a) shows consumption demand of households in (35) as a function of $\theta$ for different values of $x$. Panel (b) shows the net supply of goods, i.e. total output net of government purchases and entry costs of firms, in (36) for different $x$.

where $E D$ denotes excess demand. Excess demand is decreasing in $x$ as an increase in working hours reduces consumption demand while increasing total output, i.e. $E D_{x}(\theta, x)<0$. Consumption demand is increasing in $\theta$ as shown in (35), whereas the net supply shows a hump-shaped pattern, but is eventually decreasing in $\theta$. Hence, eventually, excess demand is increasing in $\theta$, while the initial pattern is unclear. The $E D(\theta, x)=0$ curve defines all combinations of $\theta$ and $x$ for which the goods market is in a steady state equilibrium, where $x^{g}(\theta)$ is increasing in $\theta$ for sufficiently high levels of $\theta$. It is illustrated in panel (a) of Figure 3 and satisfies

$$
x_{\varepsilon}^{g}>0, x_{z}^{g}>0, x_{s}^{g}<0, x_{k}^{g}>0, x_{\delta}^{g}>0, x_{\bar{y}}^{g}<0, x_{g}^{g}>0 .
$$

Hence, higher unemployment benefits $z$, a stronger bargaining power of workers $\varepsilon$, higher search costs $k$, a higher job separation rate $\delta$ and higher government purchases cause an upward shift of the $x^{g}(\theta)$ curve, while a higher cost subsidy $s$ and higher labor productivity $\bar{y}$ lead to a downward shift in Figure 3. These properties follow directly from the properties of consumption demand and the net supply of goods discussed above. For a given $\theta$, values of $x$ below the $x^{g}(\theta)$ curve are associated with excess demand giving firms incentives to increase working hours and output, while values of $x$ above the $x^{g}(\theta)$ curve are associated with excess supply giving firms incentives to produce less until equilibrium is restored.

Asset market equilibrium curve: Consider now the asset market equilibrium. In a steady state equilibrium, equities and money have to yield the same return. These are given by (33) and (28) respectively. Any steady state with $x<1$ is characterized by persistent deflation and, hence, an expanding real money supply as is clear from (8) and (27). Eventually, when $m_{t}>\bar{m}$, households' liquidity preferences are satiated and the nominal interest rate is at the zero lower bound as $\mu^{\prime}(m)=0$. Put different, any stagnation steady state also features a (permanent) liquidity trap. ${ }^{20}$ Hence, the following No-arbitrage condition describes all combinations of $x$

\footnotetext{
${ }^{20}$ For such a steady state to exist, the transversality condition (5) needs to be satisfied. This requires a sufficiently low money growth rate $g_{m}$ and a sufficiently low rate of price adjustment $\alpha$. A sufficient restriction is $\rho>g_{m}+\alpha$.
} 
Figure 3: Steady state equilibria

(a) Goods market equilibrium

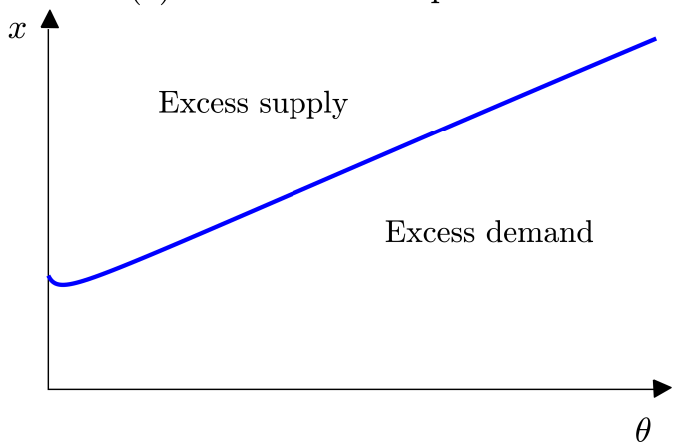

(c) Steady state without underemployment

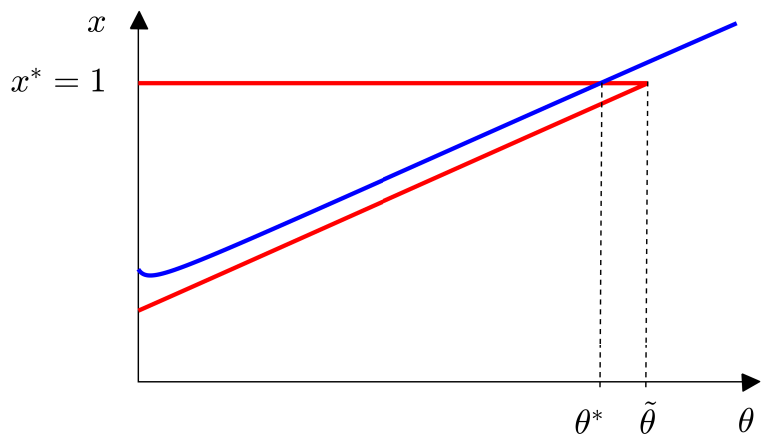

(b) Asset market equilibrium

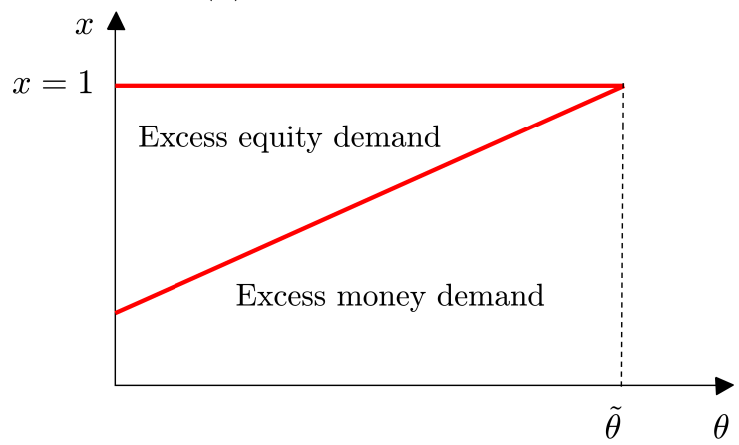

(d) Steady state with underemployment

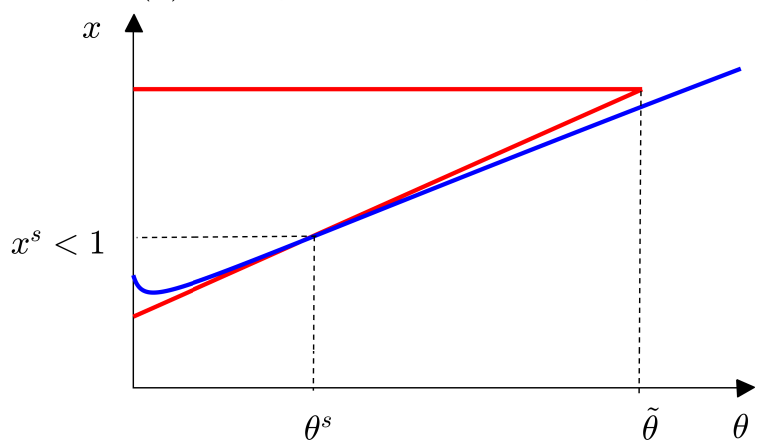

Note: Panel (a) shows the goods market equilibrium curve $x^{g}(\theta)$, i.e. all combinations of $x$ and $\theta$ that result in goods market equilibrium in steady state as defined by (37). Panel (b) shows the asset market equilibrium curve $x^{a}(\theta)$, i.e. all combinations of $x$ and $\theta$ that result in asset market equilibrium in steady state as defined by (39). A steady state without underemployment is denoted by $\left(\theta^{*}, x^{*}=1\right)$ in panel (c), a steady state with underemployment by $\left(\theta^{s}, x^{s}\right)$ in panel $(\mathrm{d})$.

and $\theta$, for which the asset market is in equilibrium in steady state:

$$
\frac{(1-\varepsilon)(\bar{y} x-z)}{(1-s) k} q(\theta)-\varepsilon p(\theta)-\delta=\left\{\begin{array}{l}
\frac{\mu^{\prime}(m)}{\phi^{\prime}(c)}-g_{m} \text { if } x=1 \\
\alpha(1-x) \text { if } x<1
\end{array}\right.
$$

Panel (b) of Figure 3 illustrates this condition in the $(\theta, x)$ space. In the absence of aggregate demand shortage, the net dividend yield associated with firm ownership determines the real interest rate and the nominal rate adjusts endogenously in the money market. This is reflected by the horizontal part of the equilibrium curve in panel (b). The zero lower bound on the nominal interest rate might, however, prevent such an adjustment if the required real interest rate is sufficiently low or equivalently if the labor market is sufficiently tight, as the dividend yield is declining in $\theta$. Specifically, a steady state with $x=1$ is no longer feasible if $\theta>\tilde{\theta}$ where $\tilde{\theta}$ is uniquely defined by $r(\tilde{\theta}, 1)=-g_{m}$, or, using the expression for the real rate in (33), by

$$
\tilde{\theta}: \quad \frac{(1-\varepsilon)(\bar{y}-z)}{(1-s) k} q(\tilde{\theta})-\varepsilon p(\tilde{\theta})-\delta=-g_{m}
$$


With a constant nominal money supply, i.e. $g_{m}=0$, a steady state equilibrium without aggregate demand shortage and a negative real interest rate is not feasible. ${ }^{21}$

In the presence of aggregate demand shortage, the zero lower bound is binding and the real interest rate is determined by the rate of deflation. This in turn determines the net dividend yield of firms. A reduction in realized working hours increases the rate of deflation while at the same time lowering firm profits. Unemployment increases as firms leave the labor market and labor market tightness falls. The following curve captures all combinations of $x$ and $\theta$ for which asset markets are in equilibrium in steady state under demand shortage:

$$
x^{a}(\theta)=\frac{(1-\varepsilon) z q(\theta)+(1-s) k[\varepsilon p(\theta)+\delta+\alpha]}{(1-\varepsilon) \bar{y} q(\theta)+(1-s) k \alpha},
$$

which satisfies $\frac{d x^{a}(\theta)}{d \theta}>0, x^{a}(0)=\frac{(1-\varepsilon) z+(1-s) k(\alpha+\delta)}{(1-\varepsilon) \bar{y}+(1-s) k \alpha}$ and $x^{a}(\tilde{\theta})=1$, with $\tilde{\theta}$ defined in (35). This curve is reflected by the increasing branch of the curve in panel (b). For a given $x$, higher values of $\theta$ are associated with a return on equity below the return on money. Hence, there is excessive demand for money, which makes firms leave the labor market resulting in fewer vacancies and higher unemployment until equilibrium is restored. Similarly, lower values of $\theta$ are associated with a return on equity above the return on money. Hence, there is excessive demand for equity, which induces firms to enter the labor market resulting in more vacancies and lower unemployment until equilibrium is restored. In addition, $x^{a}(\theta)$ in (41) satisfies

$$
x_{\varepsilon}^{a}>0, x_{z}^{a}>0, x_{s}^{a}<0, x_{k}^{a}>0, x_{\delta}^{a}>0, x_{\bar{y}}^{a}<0, x_{g}^{a}=0 .
$$

Any change in parameters that lowers the dividend yield, for a given $x$, leads to firm exit and a reduction in labor market tightness $\theta$ such as to satisfy the free entry condition and the No-arbitrage condition. This is the case for an increase in $\varepsilon, z, k$ and $\delta$. An increase in these parameters causes an upward shift of the $x^{a}(\theta)$ curve in Figure 3. In contrast, an increases in $s$ or $\bar{y}$ leads to a downward shift. ${ }^{22}$

In general equilibrium, unemployment (via labor market tightness) and underemployment are simultaneously determined by the intersection of the goods market equilibrium curve in (37) and the asset market equilibrium curve in (39). Two steady state equilibria are possible: A steady state without underemployment as illustrated in panel (c) or a steady state with the simultaneous occurrence of underemployment and structural unemployment as shown in panel (d) of Figure $3 .{ }^{23}$ We now analyze the properties of these steady state equilibria.

\footnotetext{
${ }^{21}$ The illustration in Figure 3 assumes $g_{m}=0$ for simplicity. With $g_{m}>0$, the horizontal part of the red curve in panel (b) simply extends for larger values of $\theta$ as $\tilde{\theta}$ is increasing in $g_{m}$.

${ }^{22}$ Note that the horizontal part of the line is unaffected by parameter changes. Yet, the threshold $\tilde{\theta}$ defined in (40) changes accordingly.

${ }^{23}$ In theory, there are also the possibilities of multiple steady states and the non-existence of a steady state. We discuss uniqueness and existence conditions in the following sections.
} 


\section{Unemployment and the preference for wealth}

In this section, we analyze the model equilibrium in the absence of aggregate demand shortage, i.e. for $x_{t}=1$. For simplicity, our discussion focuses on the case of a constant nominal money supply with $g_{m}=0$ and hence a steady state with stable prices, but can be generalized to the case of $g_{m}>0$ as discussed among others in Illing et al. (2018) or Michau (2018).

The model equilibrium without demand shortage can be summarized by a system of three differential equations for $u_{t}, \theta_{t}$ and $m_{t}$ as shown in Appendix C. ${ }^{24}$ The steady state of this equilibrium is characterized by $x^{*}=1, \theta^{*}$ determined by (37), $c^{*}$ by (36) and $m^{*}$ by (39). The real interest rate is determined by the net dividend yield of firms and the real money supply adjusts to clear the money market such that holding money yields the same real return. However, since $R \geq 0$ and $\pi=0$ (due to $g_{m}=0$ ), existence requires that the real interest rate is weakly positive as otherwise an oversupply of savings would occur. In that case, holding real money balances is too attractive to be compatible with asset market equilibrium. The following lemma summarizes these existence conditions for the steady state:

Lemma 1 There always exists a solution $\theta^{*}$ to $(37)$ with $x=1$ if $\vartheta(\underline{\theta}, 1)-\delta>\rho>\vartheta(\bar{\theta}, 1)-\delta$, where $\underline{\theta}$ and $\bar{\theta}$ are the two solutions to $c(\theta, 1)=0$ in (36) with $\underline{\theta}<\bar{\theta}$ and $\vartheta(\theta, 1)$ is given by (24) with $x=1$. The steady state without demand shortage exists if and only if

$$
\rho \phi^{\prime}(c(\tilde{\theta}, 1)) \geq \omega^{\prime}(b(\tilde{\theta}))
$$

where $\tilde{\theta}$ is uniquely defined in (35) with $g_{m}=0, b(\theta)$ is given by (32) and $c(\theta, x)$ given by (36).

The proof is in Appendix D. Lemma 1 requires that the return on equity exceeds the time preference rate of the household for low levels of labor market tightness. Put differently, it has to be sufficiently attractive to create new vacancies when unemployment is high. If there are no incentives to establish firms even in case of high unemployment, existence of a steady state is not guaranteed. Low productivity, high unemployment benefits, a high destruction rate or high costs of creating vacancies might violate this existence condition. This is expressed in the requirement $\vartheta(\underline{\theta}, 1)-\delta>\rho>\vartheta(\bar{\theta}, 1)-\delta$. Moreover, the preference for wealth creates additional incentives for savings, which reduce the equilibrium interest rate. If the preference for wealth is sufficiently strong, the real interest rate can be negative in steady state. But then, holding money is too attractive due to the zero lower bound on the nominal interest rate in combination with a ceiling on the inflation rate represented by $g_{m}=0$. This results in an oversupply of savings and asset market disequilibrium at $x=1$, which is not consistent with the existence of a steady state. Hence, Lemma 1 requires a sufficiently weak wealth preference for the steady state without aggregate demand shortage to exist, as expressed in condition (43). Graphically, existence requires that the goods market equilibrium curve intersects the horizontal line of the asset market equilibrium curve. The horizontal part, however, only exists for $\theta \leq \tilde{\theta}$.

\footnotetext{
${ }^{24}$ Since $x_{t}=1$ and $\dot{x}_{t}=0$, we can derive an expression for the real interest rate $r_{t}$ based on the total differential of the goods market clearing condition (36) together with the Euler Equation (3) and the law of motions for $\theta_{t}$ and $u_{t}$ in (14) and (25).
} 
As a corollary, it immediately follows that relative to the standard matching model, the preference for wealth reduces the steady state real interest rate and increases labor market tightness. To see this, note that without the preference for wealth the real rate is simply given by the time preference rate $\rho$ of the household. Compared to this case, the preference for wealth implies that households are willing to accept a lower return on their savings which in turn stimulates firm creation resulting in a tighter labor market.

In principle, there could be multiple steady states consistent with (37) and $x=1$. Yet, it turns out that, similar to Michau et al. (2018), mild technical restrictions on the functional forms of $\phi(),. \omega($.$) and q($.$) are sufficient to establish uniqueness of this steady state (see Appendix$ $\mathrm{D}$ for the derivation). Graphically, uniqueness requires that the slope of the goods market equilibrium curve represented by (37) exceeds the slope of the horizontal part of the asset market equilibrium curve given by (39) at each intersection in Figure $3 .{ }^{25}$ We assume that the steady state without underemployment is unique throughout this paper.

Having established the existence of the steady state of the search and matching model with a preference for wealth, what about its stability patterns? This is summarized in the following lemma, the proof of which is in Appendix E.

Lemma 2 If the steady state without aggregate demand shortage is unique, then it is also saddle-path stable.

The following proposition summarizes how this steady state is affected by various labor market policies related to wages and the cost of creating a vacancy as well as demand and supply shocks ("macro" shocks). The proof is in Appendix F. ${ }^{26}$

Proposition 1 In the steady state without aggregate demand shortage, variations in the model parameters have the following effects on labor market tightness $\theta^{f}$, the unemployment rate $u^{f}$, total output $Y^{f}$ and consumption $c^{f}$ :

\begin{tabular}{cccccc}
\hline & $\theta^{f}$ & $u^{f}$ & $Y^{f}$ & $c^{f}$ & $c^{f}$ \\
\hline Wage Shock: $\varepsilon, z$ & - & + & - & - & + \\
Cost Shock: $k$ & - & + & - & - & $+/-$ \\
Cost Subsidy: $s$ & + & - & + & + & - \\
Supply Shock: $\bar{y}$ & + & - & + & + & $+/-$ \\
Demand Shock: $g$ & - & + & - & - & $+/-$ \\
\hline & & & & $\begin{array}{l}\text { if slack: } \\
\frac{d c^{f}}{d \theta}>0\end{array}$ & $\begin{array}{l}\text { if tight: } \\
\text { de }\end{array}$ \\
& & & & &
\end{tabular}

\footnotetext{
${ }^{25}$ Technically, we assume that the equation $\omega^{\prime}(b(\theta)+\xi)=[\rho+\delta-\vartheta(\theta, 1)] \phi^{\prime}(c(\theta, 1))$, with $\vartheta(\theta, 1), b(\theta)$ and $c(\theta, 1)$ given by $(24),(29)$ and $(36)$, defines $\xi$ as a decreasing function of $\theta$ for all admissible values of $\theta$. This implies that an exogenous increase in wealth $\xi$ reduces households' propensity to save via a reduction in the steady state labor market tightness $\theta^{f}$. Not only is it the natural economic scenario to expect, it is also technically a very mild condition. Totally differentiating this equation with respect to $\theta$ reveals that this assumption must be satisfied provided that the elasticity of the unemployment rate with respect to $\theta$ is sufficiently low.

${ }^{26} \mathrm{We}$ assume that changes in parameters do not violate the existence conditions in Lemma 1.
} 
These effects follow immediately from the properties of the goods market equilibrium curve (37) as the horizontal part of the asset market equilibrium curve is unaffected by parameter variations. An exogenous increase in the real interest rate, given by the net dividend yield, due to lower wages or operating costs for firms (see equation (34)) reduces consumption demand of households in (35), which results in a downward shift of the goods market equilibrium curve and, hence, excess supply. Labor market tightness needs to increase in order to restore equilibrium. This occurs as the higher dividend yield makes it more attractive for firms to enter the labor market. As the number of vacancies increases, labor market tightness increases and the unemployment rate goes down. This also results in a higher level of output as is clear from (7). Yet, the overall effect on household consumption is undetermined due to the hump-shaped patterns of the net supply in (36) allowing for both a "slack" or a "tight" steady state. ${ }^{27}$

These results are in line with the standard search frictions model (cf. Pissarides, 2000), in which a positive shock to firm profits via a decrease in costs or an increase in productivity temporarily increases the value of a vacant firm. As a result, firms enter the market, causing labor market tightness to rise until the value of a vacant firm has returned to zero. In the absence of the preference for wealth, the real interest rate is pinned down to a constant subjective discount rate, $r=\rho$. Then, it is easy to see from the job creation condition $\rho=\vartheta(\theta, 1)-\delta$ in (32), as $r(\theta, x)=\rho$ for $\omega^{\prime}=0$, that wage and cost shocks decrease labor market tightness and increase the unemployment rate, while a higher subsidy or a productivity shock increase labor market tightness and decrease the unemployment rate.

The preference for wealth creates an additional channel through which these shocks operate as exogenous changes in the firm value or consumption feed back into the real interest rate by affecting the wealth premium. Changes in the interest rate in turn affect both labor market tightness and the unemployment rate. Ceteris paribus, cost shocks increase the interest rate, while subsidy and productivity shocks lower it, giving further incentives for market entry or exit. The working of the interest rate channel can reinforce the job creation channel or work opposite to it depending on the shape of the wealth preference.

Finally, demand shocks in the form of higher government expenditures have no effect on the labor market in the standard model without a preference for wealth. However, demand shocks negatively affect labor market tightness and employment in our model. Crowding out of household consumption increases the interest rate, which lowers the firm value, reduces the number of vacancies as firms leave the labor market and increases unemployment.

\footnotetext{
${ }^{27}$ Whether an equilibrium is slack or tight depends on the shape and curvature of the matching function and the steady state level of labor market tightness, which is in turn related to the model parameters and the strength of the preference for wealth. In the literature, Michaillat and Saez (2014) analyze business cycle fluctuations in the slack equilibrium in a model with wealth preferences. This focus seems natural since it implies that an increase in labor market tightness raises total final output $(\bar{y}(1-u))$ by more than total search costs $(k v=k \theta u)$. Pissarides (2000, Chapter 8) provides a general discussion of the interactions of labor market tightness and consumption in a matching model.
} 


\section{Underemployment and secular stagnation}

We now consider the case of aggregate demand shortage. In such a steady state, households' realized working hours upon employment are below their potential and economic slack manifests itself in both structural unemployment $u$ and demand-driven underemployment $x<1$.

Persistent stagnation occurs when saving is too attractive as the nominal interest rate cannot fall below zero. As explained above, the price level under stagnation declines in steady state as a consequence of underemployment in (8) and real money balances continuously increase at rate $\alpha(1-x)$. Eventually, the transaction demand for money becomes satiated such that the nominal interest rate is zero, i.e. $R=0$. The real interest rate is then given by the rate of deflation. Equilibrium conditions $x^{g}(\theta)$ and $x^{a}(\theta)$ in (37) and (39) simultaneously determine $x^{s}$ and $\theta^{s}$. It follows from (39) that the realized return on equity has to be strictly positive in the stagnation steady state. Also, the return on equity at $\theta=\tilde{\theta}$ is zero and we have $\vartheta_{\theta}(\theta, x)<0$. It therefore has to hold that $\theta^{s}<\tilde{\theta}$ in any stagnation steady state. Consumption $c^{s}$ is determined by (36) with $x=x^{s}$ and $\theta=\theta^{s}$. Non-negativity of $c^{s}$ and the restriction $x^{s} \leq 1$ require $\theta \in\left(\underline{\theta}^{s}, \tilde{\theta}\right)$, where $\underline{\theta}^{s}$ is defined by $c\left(\underline{\theta}^{s}, x^{a}\left(\underline{\theta}^{s}\right)\right)=0$ with $x^{a}(\theta)$ given by (41) and $\tilde{\theta}$ defined in (40). ${ }^{28}$ The next lemma summarizes these conditions (see Appendix $\mathrm{G}$ for the proof).

Lemma 3 There always exists a solution $\left(\theta^{s}, x^{s}\right)$ with $x^{s}<1$ to (37) and (39) if $\rho>\alpha$ and

$$
\rho \phi^{\prime}(c(\tilde{\theta}, 1))<\omega^{\prime}(b(\tilde{\theta}))
$$

where $\tilde{\theta}$ is uniquely defined in (35). This solution satisfies $\theta^{s} \in\left(\underline{\theta}^{s}, \tilde{\theta}\right)$, where $\underline{\theta}^{s}$ is defined by $c\left(\underline{\theta}^{s}, x^{a}\left(\underline{\theta}^{s}\right)\right)=0$ in $(36)$ with $x^{a}(\theta)$ given by (41) and with $\underline{\theta}^{s}<\tilde{\theta}$.

The condition $\rho>\alpha$ establishes a lower bound on the rate of deflation and hence an upper bound on the real interest rate thereby preventing a wage-price spiral that is not consistent with the existence of a well-defined steady state. An excessively high rate of deflation in steady state would imply an expansion of real money balances that violates the transversality condition of the household (5). Existence of the secular stagnation steady state further requires the real interest at $\tilde{\theta}$ to be negative. Note that this condition is exactly opposite to condition (43) in Lemma 1 that establishes the feasibility of the steady state without aggregate demand shortage. ${ }^{29}$

Throughout this paper, we assume that the secular stagnation steady state is unique. This holds under mild restrictions on the functional forms of the utility, production and matching functions. Graphically, uniqueness implies that the slope of the asset market equilibrium curve in Figure 3 exceeds the slope of the goods market equilibrium curve at each intersection. ${ }^{30}$

\footnotetext{
${ }^{28}$ Note that $\underline{\theta}$ in Lemma 1 and $\underline{\theta}^{s}$ are identical for $g=0$ and given by $\underline{\theta}=\underline{\theta}^{s}=0$.

${ }^{29}$ Assuming uniqueness of the steady state with $x=1$ and the one with $x<1$, these steady states are mutually exclusive. This no longer holds for $g_{m}>0$. Then both steady states are feasible for some parameter calibrations.

${ }^{30}$ Formally, uniqueness requires that under secular stagnation an exogenous increase in wealth increases households' propensity to save and therefore increases the aggregate equity value via an increase in the steady state labor market tightness $\theta^{s}$. Compared to the previous case, an increase in $\theta$ affects households' propensity to save via two additional channels: First, the induced decrease in the real interest rate is dampened due to the weaker response of the return on equity to increases in $\theta$ as a consequence of the prevalence of persistent deflation. Secondly, there is a stronger effect of changes in $\theta$ on the net supply as a consequence of the induced change in realized labor working hours. Both, higher income and a smaller sensitivity of the return on savings relative the
} 
Whilst the response of consumption to an increase in labor market tightness in the absence of aggregate demand shortage depends on the functional form of the matching function and the preference for wealth, the secular stagnation steady state necessarily has to be slack if the steady state is unique. This is summarized in the following lemma, which follows immediately from the uniqueness condition as shown at the end of Appendix G:

Lemma 4 If the secular stagnation steady state is unique, then it is slack and an increase in labor market tightness raises steady state consumption $c^{s}$, i.e. $\frac{d c\left(\theta, x^{a}(\theta)\right)}{d \theta}>0$ in (36).

How about the stability properties of the secular stagnation steady state? We derive the following lemma in Appendix H.

Lemma 5 If the secular stagnation steady state is unique, then it is also saddle-path stable.

When analyzing the effects of labor market policies and macroeconomic supply and demand shocks, note that most parameter changes shift the goods market equilibrium curve and the asset market equilibrium curve in the same direction. Specifically, recall from (38) and (42) that the following partial derivatives are qualitatively the same for both curves:

$$
x_{\varepsilon}>0, x_{z}>0, x_{s}<0, x_{k}>0, x_{\delta}>0, x_{\bar{y}}<0 .
$$

The following lemma establishes a helpful intermediate result about the magnitude of the associated shifts in both curves (see Appendix I for the proof).

Lemma 6 For a sufficiently small intertemporal elasticity of substitution for consumption $\eta_{c}^{-1}$, an exogenous variation in the net dividend yield triggers a larger vertical shift of the asset market equilibrium curve (39) in absolute terms than in the goods market equilibrium curve (37) for a given $\theta$. Formally,

$$
-\frac{\omega^{\prime}(b) \phi^{\prime \prime}(c)(1-u(\theta)) \bar{y}}{\phi^{\prime}(c)^{2}}-\alpha>0 \text { if } \eta_{c}>\frac{\alpha}{\rho} .
$$

Since $\rho>\alpha$ under stagnation, this is a weak restriction on the intertemporal substitution elasticity for consumption and we will assume that it holds throughout the following analysis. Note that this condition holds irrespective of the properties of the preference for wealth.

Intuitively, an exogenous marginal decline $\Delta$ in the net dividend yield requires working hours to increase by $\Delta / \alpha$ as to reduce the rate of deflation and restore asset market equilibrium in (39). In the goods market, the lower interest rate increases consumption demand. For equilibrium to be restored, more goods have to be produced which requires more working hours. Lemma 6 shows that the required adjustment in the asset market exceeds the one in the goods market.

This implies that starting from the stagnation steady state, a decrease in the net dividend yield following a parameter variation requires a reduction in labor market tightness for general equilibrium to be restored. The same mechanism as in the standard model is at work. The lower return triggers market exit of firms which eventually results in lower vacancies and higher unemployment. Based on this reasoning, we establish the following proposition about the effects of parameter variations on the stagnation steady state. The proof is in Appendix J.

to case of full employment support the assumption of an increase in the propensity to save in response to an exogenous increase in wealth under stagnation. 
Proposition 2 In the secular stagnation steady state, variations in the model parameters have the following effects on labor market tightness $\theta^{s}$, the unemployment rate $u^{s}$, realized working hours $x^{s}$, total output $Y^{s}$ and consumption $c^{s}$ :

\begin{tabular}{lccccc}
\hline & $\theta^{s}$ & $u^{s}$ & $x^{s}$ & $Y^{s}$ & $c^{s}$ \\
\hline Wage Shock: $\varepsilon, z$ & - & + & $+/-$ & $+/-$ & $+/-$ \\
Cost Shock: $k$ & $+/-$ & $+/-$ & $+/-$ & $+/-$ & $+/-$ \\
Cost Subsidy: $s$ & $+/-$ & $+/-$ & $+/-$ & $+/-$ & $+/-$ \\
Supply Shock: $\bar{y}$ & - & + & - & - & - \\
Demand Shock: $g$ & + & - & + & + & + \\
\hline
\end{tabular}

Several conclusions follow from this proposition compared to the case of the standard model in Proposition 1. First, the stagnation steady state behaves in stark contrast to the case without aggregate demand shortage in case of supply and demand shocks. Under stagnation, these "macro" shocks have opposite effects on both labor market variables and macroeconomic variables. Their effects are unambiguous and result in co-movements of the structural unemployment rate and the rate of underemployment in steady state.

Consider an increase in aggregate demand via higher government spending. This results in a tighter labor market with both a lower unemployment rate and higher realized working hours. The reason is as follows. Higher public spending creates demand which leads to an upward shift in the goods market equilibrium curve $x^{g}(\theta)$ in Figure (3), as is clear from (38), while the asset market curve is unaffected. The resulting excess demand for goods allows firms to increase working hours, which in turn results in an excess demand for equity. This implies market entry of firms, which increases labor market tightness, giving further incentive to extend working hours. This in turn stimulates both output and consumption. Hence, there is a crowding-in effect of government spending, which is in stark contrast to the crowding-out effect in the case without aggregate demand shortage. ${ }^{31}$

On the other hand, positive supply shocks in the form of higher productivity cause a downward shift of both the asset market curve $x^{a}(\theta)$ and the goods market curve $x^{g}(\theta)$ in the $(\theta, x)$ diagram. As we show in Appendix $J$, the net effect of these shifts is a reduction in labor market tightness and a reduction in realized working hours. As a consequence, unemployment under stagnation increases and consumption spending of households drops. In fact, the increase in unemployment and the reduction in working hours overcompensate the effect of the productivity shock such that total output actually falls in response to the supply shock. The directions of the effects of both demand and supply shocks are independent of the shape of the wealth preference and the matching function as shown in Appendix. J. The reversal of the effects compared to the standard model is a direct consequence of the shortage of aggregate demand under stagnation. This "paradox of toil" is a common occurrence in models of economic stagnation.

\footnotetext{
${ }^{31}$ Note that this is not related to the notion of deficit spending. In fact, any increase in government spending is budget neutral as the government runs a balanced budget each period by equation (9).
} 
In light of these finding, the simultaneous increase in unemployment and underemployment in Japan during the early 1990s and after 2007 can be attributed to the occurrence of severe negative demand shocks associated with the burst of the bubble economy and the global financial crisis.

When it comes to the effects of "micro shocks" (i.e. wage and cost shocks) or labor market policies, there are interesting interactions between the standard job creation channel of the search and matching model, the interest rate channel associated with the wealth preference and the degree of aggregate demand shortage. In principle, most of these policies can qualitatively have the same effects as in the previous case or opposite ones resulting in either co-movements of unemployment and underemployment or movements in opposite directions. The reason is that both equilibrium curves shift in the same direction in response to micro shocks such that the overall effect on labor market tightness is unclear. In fact, the overall effect is dependent on the degree of aggregate demand shortage, which is in turn related to the strength of the wealth preference and the substitution elasticity in the matching function.

In order to better understand the relative importance of these additional channels, we support our analysis by a numerical simulation of the effects. The parameter calibration and specific functional forms are summarized in Table 1. In particular, the specification and calibration of the matching function closely follows Den Haan et al. (2000) and assumes a matching function with a constant elasticity of substitution between unemployed and vacancies that fulfils all criteria in (10). ${ }^{32}$ When it comes to the preference for wealth, a non-homothetic specification is empirically most plausible as argued by Mian et al. (2019), implying that the marginal utility of wealth decays more slowly than the marginal utility of consumption. The easiest way to implement this feature is via a constant marginal utility of wealth. This is our benchmark specification. As an alternative, we consider a utility from wealth function with constant absolute risk aversion (CARA). ${ }^{33}$

We calibrate the job separation rate at $\delta=0.019$ based on the average values for labor market tightness and unemployment in Japan over the period from 1980 to $2018 .{ }^{34}$ This relatively low value of job separations might reflect the specific features of the Japanese employment system as discussed earlier. It implies a lower bound on the unemployment rate of $1.86 \%$.

In addition, we calibrate the parameters in the profit function such that the model yields a return on equity of $2 \%$ in the absence of aggregate demand shortage for these average values. This requires a combination of a relatively strong bargaining power of workers $(\varepsilon=0.6)$, high unemployment benefits $(z=0.6)$ and non-negligible costs of creating a vacancy $(k=0.3)$ in the absence of government spending or search subsidies.

\footnotetext{
${ }^{32}$ Note that a commonly employed alternative is a Cobb-Douglas function. However, this specification implies that the number of matches can exceed $\min \left\{u_{t}, v_{t}\right\}$, which implies matching probabilities above one.

${ }^{33}$ Mian et al. (2019) do not directly specify the preference for wealth but the marginal utility of wealth relative to a logarithmic specification, which reflects the utility from consumption. Their calibration implies that this measure is always strictly positive in $(0,1)$. Similarly, our benchmark specification implies that this measure is constant at level $\beta$, which we chose in $(0,1)$.

${ }^{34}$ Based on data from the Japan Institute for Labour Policy and Training, we calculate an average active job openings-to-applicants ratio of $\theta=0.85$ for the period 1980-2018, whereas the average unemployment rate has been at $u=3.47 \%$. Given the calibration of $\gamma=1.27$ in the matching function, a value of $\delta=0.019$ supports this data as can be seen from (31).
} 
Table 1: Functional form assumptions and parameter calibration

A: Matching Function based on Den Haan et al. (2000)

\begin{tabular}{ll}
\hline Variable & Functional Form \\
\hline Matching function & $F(u, v)=\left(u^{-\gamma}+v^{-\gamma}\right)^{-1 / \gamma}$ \\
Probability of filling vacancy & $q(\theta)=\left(1+\theta^{\gamma}\right)^{-1 / \gamma}$ \\
Probability of finding a job & $p(\theta)=\theta\left(1+\theta^{\gamma}\right)^{-1 / \gamma}$ \\
Substitution elasticity $=(1+\gamma)^{-1}$ & $\gamma=1.27$ (baseline)
\end{tabular}

The substitution elasticity varies depending on the simulation. Our baseline is $\gamma=1.27$ as suggested by Den Haan et al. (2000). Higher values imply that vacancies and unemployed are complements in producing successful matches, while lower values imply a higher degree of substitutability.

B: Preference for Wealth

\begin{tabular}{ll}
\hline Specification & Functional Form \\
\hline Constant marginal utility & $\omega(a)=\beta a, \omega^{\prime}(a)=\beta \quad$ (baseline) \\
Constant absolute risk aversion & $\omega(a)=1-e^{-\beta a}, \omega^{\prime}(a)=\beta e^{-\beta a}$
\end{tabular}

The parameter $\beta$ of the utility function varies depending on the simulation exercise. A larger value of $\beta$ implies a stronger desire to save.

C: Parameter Calibration

\begin{tabular}{lcl}
\hline Parameter & Calibration & Comment \\
\hline Time preference rate & $\rho=0.1$ & upper bound on real rate: $r \leq 0.1$ \\
Utility from consumption & $\eta_{c}=1$ & logarithmic consumption utility \\
Speed of price adjustment & $\alpha=0.02$ & $\rho>\alpha$ by Lemma 3 \\
Job separation rate & $\delta=0.019$ & average $\theta$ and $u$ in Japan, $1980-2018$ \\
Cost of a vacancy & $k=0.3$ & average return of $2 \% ; \vartheta(\underline{\theta})>\rho+\delta$ \\
Bargaining power of workers & $\varepsilon=0.6$ & average return of $2 \%$ \\
Potential income (normalized) & $\bar{y}=1$ & used to model supply shocks \\
Government spending & $g=0$ & used to model demand shocks \\
Unemployment benefits & $z=0.6$ & average return of $2 \%$, policy variable \\
Search subsidy & $s=0$ & policy variable \\
\hline
\end{tabular}

Figures 4 and 5 illustrate the properties of the stagnation steady state for the calibration summarized in Table 1 depending on the degree of demand shortage and for different values of the parameter $\gamma$ that captures the curvature of the matching function. ${ }^{35}$ Panel (a) shows the effects of an increase in unemployment benefits, panel (b) illustrates the response to an introduction of a search cost subsidy and panel (c) represents the effects of an increase in the cost of a vacancy. ${ }^{36}$ Figure 4 is based on our baseline specification of a constant marginal utility of wealth, Figure 5 on the constant absolute risk aversion specification of the wealth preference.

\footnotetext{
${ }^{35}$ Variations in $1-x$ result from changes in the wealth preference parameter $\beta$, which directly affects the extent of stagnation. Its initial value is chosen such that the economy is close to $x=1$ at the start of the $(1-x)$-axis.

${ }^{36}$ We do not show the effects of variations in the bargaining power $\varepsilon$ since these are qualitatively the same as the effects of an increase in unemployment benefits in panel (a) as shown in Appendix J.
} 
Our simulations support several conclusions. First, the basic search and matching mechanism continues to work even under stagnation. In fact, all parameter variations in Figure 4 have the same qualitative effects on labor market tightness and unemployment as in the standard case provided that the degree of underemployment is sufficiently small, i.e. $x$ is sufficiently close to one. Then, wage and cost shocks reduce labor market tightness and increase unemployment while a search cost subsidy has the opposite effects.

In fact, wage shocks due to increases in unemployment benefits or the bargaining power of workers unanimously reduce labor market tightness and increase structural unemployment under stagnation. This follows immediately from Lemma 6 . Higher wages reduce firm profits and the real return on equity. This exogenous reduction in the dividend yield results in an upward shift of both equilibrium curves, resulting in excess commodity demand and excess money demand. The former makes it more attractive for firms to increase working hours in order to satisfy the additional demand, whereas the latter induces firms to leave the market as firm ownership is less attractive. As shown above, the latter effect dominates as the shift in the asset market equilibrium curve in response to the change in the dividend yield is quantitatively larger, irrespective of the functional form of the preference for wealth. As a consequence, labor market tightness decreases as firms leave the labor market until equilibrium is restored. This implies a higher unemployment rate as is clear from expression (31).

Variations in $z$ and $\varepsilon$ only affect the real interest rate via their direct effect on negotiated wages, which is why their effects can directly be deducted from Lemma 6 . In case of cost shocks or the introduction of a cost subsidy, there are additional effects as changes in these parameters affect the firm value in (21) and hence the wealth premium and the saving patterns of households, unless the marginal utility of wealth is constant. In addition, higher entry costs for firms $k$ also directly affect the net supply in (36), reinforcing the shift in the goods market equilibrium curve. As a consequence, the combined effect of these changes is unclear, but the wealth channel is stronger the higher the curvature of the utility from wealth and the lower the curvature parameter $\gamma$ in the matching function. ${ }^{37}$

To get some further intuition for these results, consider the case of logarithmic utility in consumption, $u(c)=\ln (c)$, and $g=0$. This allows for the goods market equilibrium curve (37) to be written as an explicit functional relationship given by

$$
x^{g}(\theta)=\frac{(1-\varepsilon) z q(\theta)+(1-s) k\left[\varepsilon p(\theta)+\delta+\rho+k \theta u(\theta) \omega^{\prime}\left((1-s) k \frac{1-u(\theta)}{q(\theta)}\right)\right]}{(1-\varepsilon) \bar{y} q(\theta)+(1-s) k(1-u(\theta)) \bar{y} \omega^{\prime}\left((1-s) k \frac{1-u(\theta)}{q(\theta)}\right)} .
$$

In addition to the transmission channel via changes in the dividend yield discussed so far, the $x^{g}(\theta)$ curve shifts in response to changes in household wealth, as given by $\omega^{\prime}$, and changes in total search costs, as given by $k \theta u(\theta)$. Both the wealth-induced and cost-induced shifts reinforce the initial effect of the change in the dividend yield. If these effects are sufficiently strong, the shift

\footnotetext{
${ }^{37}$ Such a case is illustrated in panel (c) of Figure 5. An increase in search costs $k$ results in an increase in labor market tightness and a reduction of unemployment for large values of the wealth preference parameter $\beta$ and low values of $\gamma$. Note that with a constant marginal utility of wealth, as in Figure 4, the effect of introducing a subsidy is unambiguous and follows directly from Lemma 6.
} 
Figure 4: Effects of micro shocks and labor market policies (baseline specification)

(a) Wage shock: Increase in unemployment benefits $z$ (Elasticities)
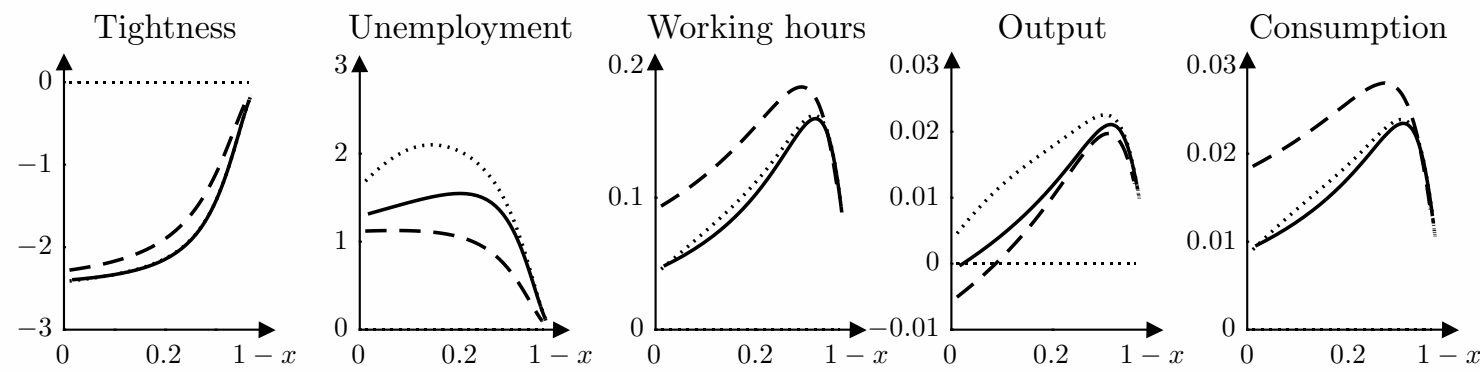

(b) Introduction of a search subsidy $s=10 \%$ (Percentage responses)
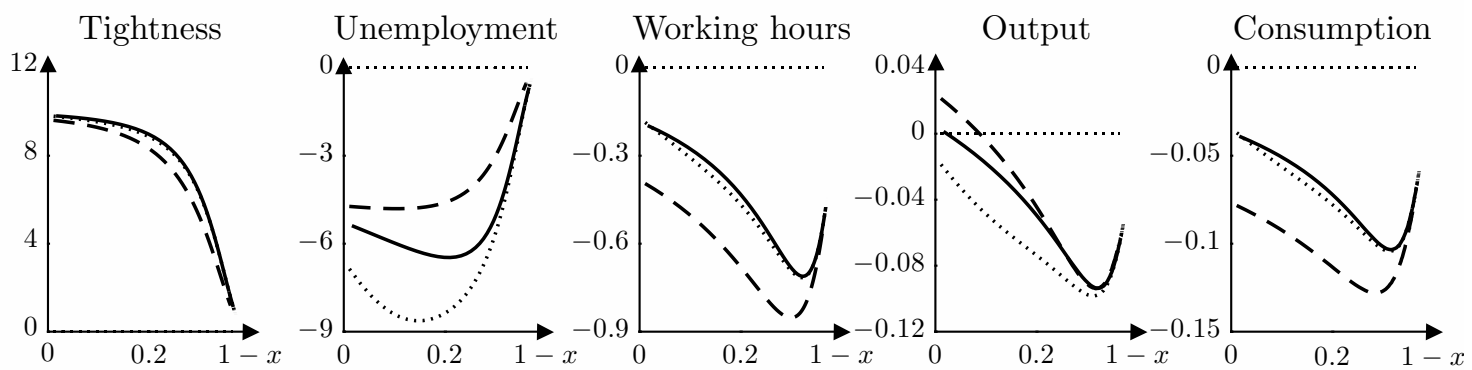

(c) Cost shock: Increase in $k$ (Elasticities)
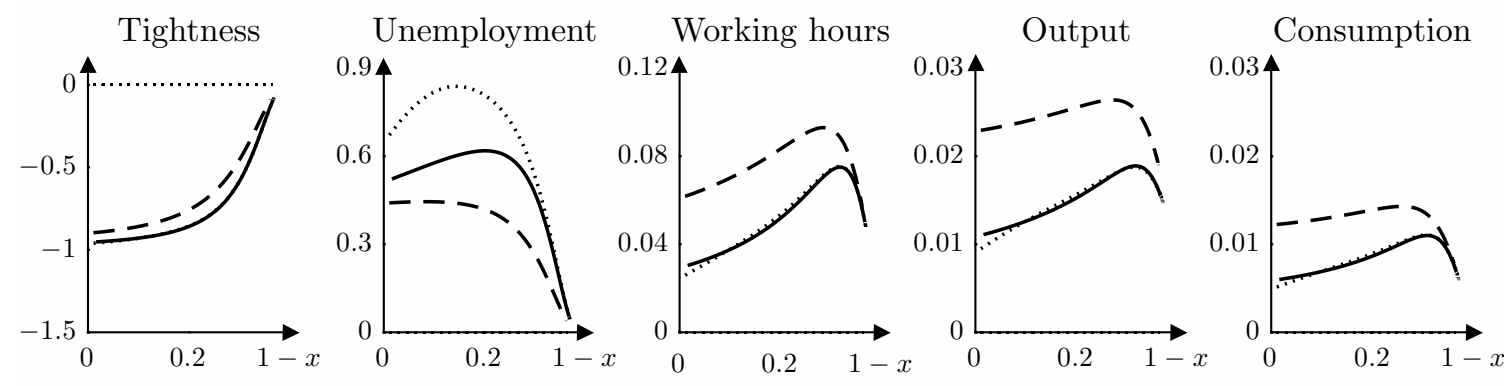

$-\boldsymbol{-} \gamma=0.5$

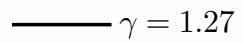

$\gamma=5$

Notes: This figure shows (a) the response to an increase in unemployment benefits expressed as elasticities, (b) the effects of the introduction of a subsidy $s=0.1$ (in percent) and (c) the response to an increase in the cost of a vacancy expressed as elasticities on the secular stagnation steady state. We assume a wealth preference with constant marginal utility of $\beta$. This parameter also determines the degree of aggregate demand shortage. The initial value of $\beta$ is chosen such that the economy is at full employment at the start of the $(1-x)$-axis. The calibration is summarized in Table 1.

in the goods market equilibrium curve can dominate the shift in the asset market equilibrium curve, thereby reversing the effects on labor market tightness and unemployment. The strength of these two channels depends on the shape of the wealth preference $\omega^{\prime}$ and the matching function, which affects the behavior of $u(\theta)$.

Consider now the spillover effects from the labor market to the goods market. In our baseline specification in Figure 4, wage and cost shocks increase realized working hours, output and consumption spending, whereas the introduction of a cost subsidy reduces these variables. Hence, the effects of these shocks are reversed compared to the standard model. 
Figure 5: Effects of micro shocks and labor market policies (CARA specification)

(a) Wage shock: Increase in unemployment benefits $z$ (Elasticities)
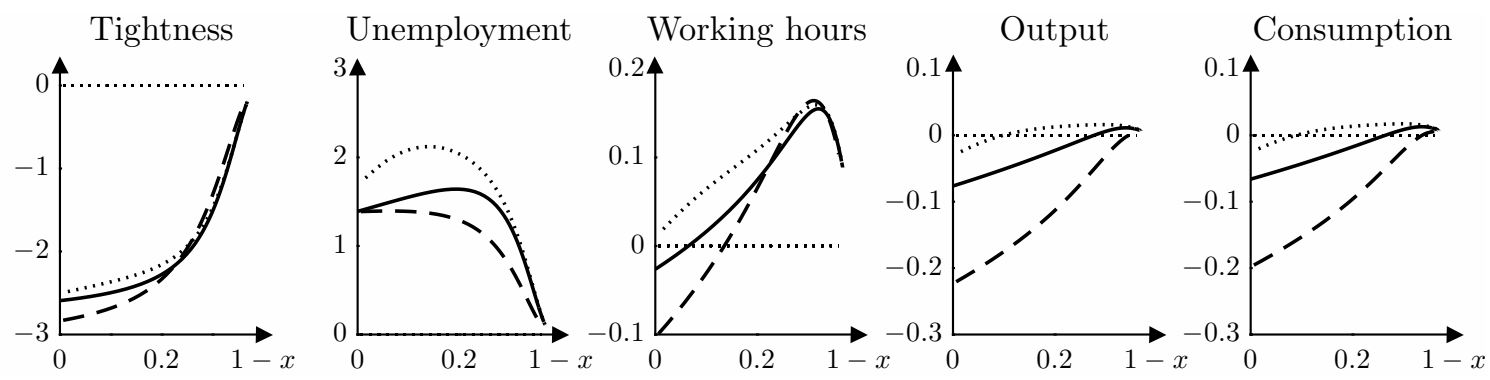

(b) Introduction of a search subsidy $s=10 \%$ (Percentage responses)
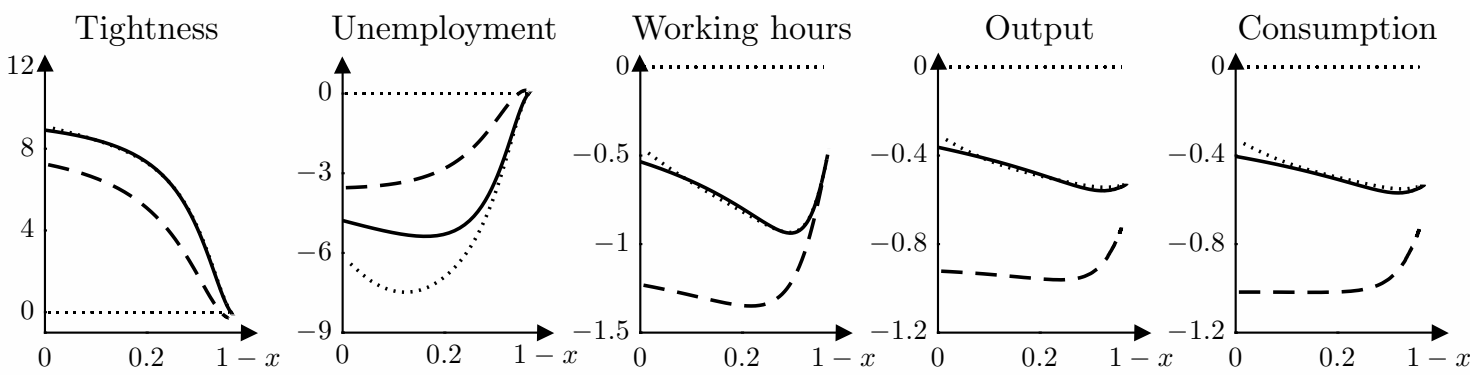

(c) Cost shock: Increase in $k$ (Elasticities)
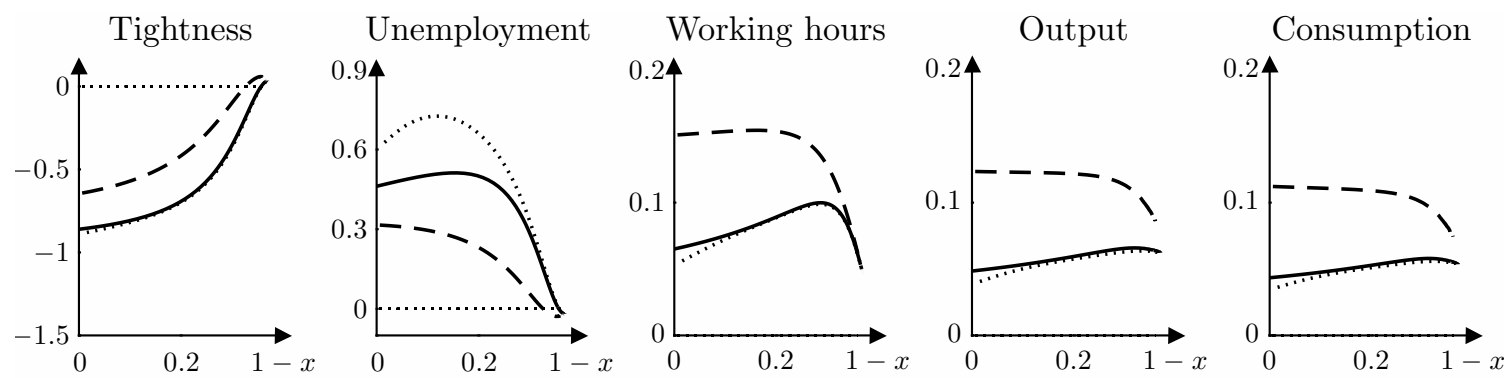

$--\gamma=0.5$

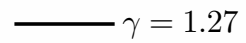

$\gamma=5$

Notes: This figure shows (a) the response to an increase in unemployment benefits expressed as elasticities, (b) the effects of the introduction of a subsidy $s=0.1$ (in percent) and (c) the response to an increase in the cost of a vacancy expressed as elasticities on the secular stagnation steady state. We assume a CARA wealth preference. The parameter $\beta$ determines the degree of demand shortage. Its initial value is chosen such that the economy is close to $x=1$ at the start of the $(1-x)$-axis. The calibration is summarized in Table 1 .

However, in general, these effects depend on the degree of demand shortage, the curvature of the wealth preference and the substitution elasticity in the matching function. Specifically, the model behaves as in the standard case when $x$ is close to one, vacancies and unemployed are closer substitutes in the matching process (i.e. a low value of $\gamma$ ) and for a stronger curvature of the utility from wealth. Then, wage shocks do reduce working hours, output and consumption and a cost subsidy potentially improves these variables, resulting in movements of unemployment and underemployment in the same direction. Panel (a) of Figure 5 is an example of such a situation. However, the effects of these shocks are opposite to the standard model when stagnation is sufficiently severe or for a higher complementarity of vacancies and unemployed as 
can be seen in Figures 4 and 5. Hence, labor market policies or micro shocks cause a movement of unemployment and underemployment in opposite directions in most cases, particularly once the economy suffers already substantially from stagnation. Then, a decline in the unemployment rate occurs with a simultaneous reduction in realized working hours, i.e. an increase in the degree of underemployment.

Why does the degree of demand shortage affect the direction of these effects? Consider the case of an increase in unemployment benefits. This policy causes an upward shift in the $x^{g}(\theta)$ and the $x^{a}(\theta)$ curves in Figure 3 resulting in a reduction in labor market tightness $\theta$ (as discussed). The response of working hours results from the relative magnitude of the vertical shifts of these curves in response to an increase in $z$ for a given $x$. For a constant marginal utility of wealth, the difference in the strength of these shifts depends only on the response of the net supply of goods in (36) to induced changes in $\theta$. When the degree of demand shortage is sufficiently small, a reduction in $\theta$ reduces the net supply of goods for a given $x$ close to unity if the steady state without aggregate demand shortage is slack and it increases the net supply if that steady state is tight. In the former case, the vertical shift in the $x^{g}(\theta)$ curve exceeds the shift in the $x^{a}(\theta)$ curve as demand increases while supply declines. Hence, realized working hours increase in steady state. In the latter case, the opposite holds as both demand and supply increase and working hours actually decline. Yet, when demand shortage worsens, the net supply of goods eventually declines in response to a reduction in $\theta$ implying a stronger vertical shift in the $x^{g}(\theta)$ curve and hence an increase in working hours. ${ }^{38}$

With a standard wealth preference, there are additional effects on consumption demand through changes in household wealth. The reduction in $\theta$ following a wage shock reduces wealth and consumption demand. Equilibrium requires a stronger decline in working hours compared to the case of a constant marginal utility, which explains why the response of realized working hours is negative for low values of underemployment in panel (a) of Figure 5. Nevertheless, our conclusion that the overall effects depend on the degree of demand shortage continues to hold. ${ }^{39}$

The effects of parameter variations on consumption and output follow directly from the above analysis. In fact, for a constant marginal utility of wealth, consumption and working hours have to change in the same direction. ${ }^{40}$ However, it is also evident from Figures 4 and 5 that variations in cost and wage parameters primarily affect labor market variables, such as tightness and unemployment and to some extent the degree of underemployment. The spillover effects into consumption and output are weak. In contrast, macroeconomic demand and supply shocks trigger strong responses in both labor market variables and macroeconomic variables.

\footnotetext{
${ }^{38}$ Note that the steady state without aggregate demand shortage is slack in our simulation so that $x$ increases following a wage shock for low levels of $\beta$ in case of a constant marginal utility of wealth in Figure 4 . In general, the effect of $\theta$ on consumption for a given $x$ depends on the slope of the Beveridge curve, i.e. the curvature of the unemployment function, which in turn depends on the substitution elasticity of the matching function $\gamma$.

${ }^{39}$ In all of our simulations, the partial effect of changes in the labor market tightness on consumption eventually becomes sufficiently positive for large values of $\beta$ to dominate the effects related to changes in the marginal utility from wealth. This implies that working hours have to increase in response to a wage shock. Hence, even in the general case, wage shocks increase working hours once the employment gap under stagnation is sufficiently severe.

${ }^{40}$ Any increase (decrease) in working hours directly lowers (increases) the real interest rate, which requires an increase (a reduction) in the wealth premium. With $\omega^{\prime}(b)=\beta$, consumption has to increase (decrease).
} 
Structural unemployment versus demand-driven underemployment: In our model, slack in the labor market manifests itself in two forms: Structural unemployment as measured by the unemployment rate $u$ and underemployment due to demand shortage given by $(1-u)(1-x)$. We refer to the later as underemployment since it is characterized by a shortfall of realized working hours below potential. Taken together, these two components constitute the total employment gap:

$$
\underbrace{1-\left(1-u_{t}\right) x_{t}}_{\text {Employment gap }}=\underbrace{u_{t}}_{\begin{array}{c}
\text { Structural } \\
\text { unemployment }
\end{array}}+\underbrace{\left(1-u_{t}\right)\left(1-x_{t}\right)}_{\text {Underemployment }} .
$$

The unemployment rate itself is therefore an inadequate indicator of the overall slack in the labor market of an economy that suffers from demand shortage. We have already shown that macro shocks have opposite effects on $u$ and $x$. Supply shocks increase the unemployment rate and reduce realized working hours, while positive demand shocks lower the unemployment rate and increase working hours. In contrast, cost and wage shocks typically result in co-movements of $u$ and $x$, particularly when stagnation is already substantial. We now quantify the relative importance of structural unemployment and underemployment in a stagnating economy.

Using the steady state expression for the unemployment rate in (31), we rewrite decomposition (46) in shares of the steady state employment gap as

$$
1=\underbrace{\frac{\delta}{\delta+p(\theta)(1-x)}}_{\begin{array}{c}
\text { Unemployment } \\
\text { share }
\end{array}}+\underbrace{\frac{p(\theta)(1-x)}{\delta+p(\theta)(1-x)}}_{\begin{array}{c}
\text { Underemployment } \\
\text { share }
\end{array}} .
$$

The relative importance of underemployment is determined by the behavior of $p(\theta)(1-x)$ in response to (exogenous) variations in $(1-x)$. Underemployment becomes relatively more important if this term is increasing the more an economy suffers from stagnation and relatively less important otherwise. The share of underemployment in the total employment gap increases under stagnation if

$$
x^{\prime}(\theta) \frac{p(\theta)}{p^{\prime}(\theta)}>1-x(\theta),
$$

where $x(\theta)$ is defined in (41) with $x^{\prime}(\theta)>0$. It is easy to see that this inequality has to hold when $x$ is sufficiently close to unity. As an economy falls into stagnation and the stagnation is getting more severe, underemployment initially becomes relatively more important than unemployment. ${ }^{41}$ As realized working hours fall further, underemployment worsens. However, the fall in working hours also implies an increase in labor market tightness, which decreases the likelihood for unemployed workers to find a new job and hence contributes to higher structural unemployment. The strength of the unemployment response depends on both the relationship between $x$ and $\theta$ in the asset market equilibrium condition (41), captured by $x^{\prime}(\theta)$ in (48), and the shape of the matching function. Yet, the increase in underemployment is substantially

\footnotetext{
${ }^{41}$ In fact, unemployment might actually decrease since the response of the unemployment rate depends on the specific shock that causes aggregate demand shortage to appear. If stagnation is caused by macroeconomic shocks, which is most likely the case, then unemployment will increase as well. Yet, the share of underemployment in the total employment gap initially widens.
} 
Figure 6: Unemployment and underemployment under stagnation
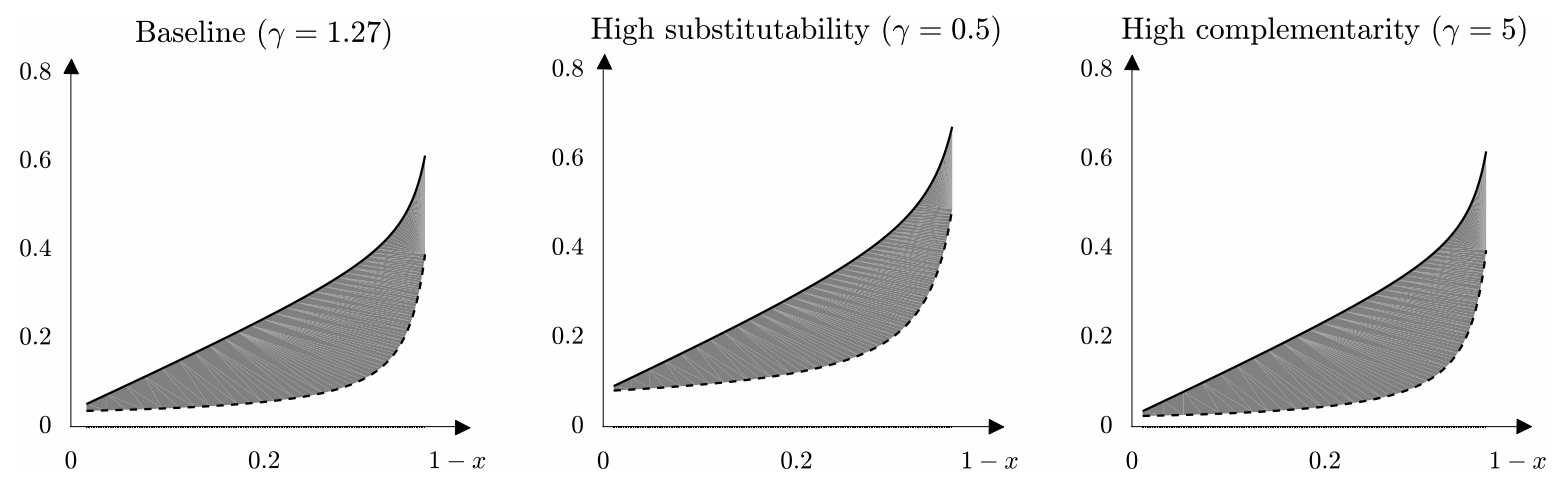

Note: This figure shows the allocation of the total employment gap $1-(1-u) x$ among the unemployment rate $u$ (dashed line) and underemployment $(1-u)(1-x)$ (shaded area) as a function of the degree of demand shortage $(1-x)$ (generated by variations in $\beta$ for different values of $\gamma$ in the matching function.

stronger than the increase in unemployment for plausible calibrations.

For illustration, Figure 6 visualizes the decomposition of the employment gap into unemployment (dashed line) and underemployment (shaded area) depending on the degree of demand shortage $(1-x)$ for the baseline calibration and alternative specifications of the matching function. Variations in $x$ are generated by variations in the wealth preference parameter $\beta$.

When the degree of stagnation is still minor, the unemployment rate increases only slightly, while underemployment rises substantially as demand shortage worsens. This holds for all calibrations of $\gamma$ in the matching function, even though there are stronger increases in unemployment when vacancies and unemployed become closer substitutes. Note, however, that the associated small values of $\gamma$ imply a relatively high rate of unemployment in the absence of demand shortage. ${ }^{42}$ Underemployment accounts for more than half of the total employment gap once realized working hours have fallen by $3.8 \%$ (i.e. at $1-x=0.038$ in the first panel of Figure 6 ) in our baseline specification (by $10.5 \%$ for $\gamma=0.5$ and by $2.5 \%$ for $\gamma=5$ respectively).

It is only when the economy suffers from a substantial degree of demand shortage that the unemployment rate starts rising sharply. The reason is that the No-Arbitrage condition (41) establishes a lower bound on realized working hours. Once $x$ approaches this value, the derivative $x^{\prime}(\theta)$ becomes sufficiently small such that the inequality in (48) no longer holds. ${ }^{43}$ Yet, within these ranges, it is demand-driven underemployment rather than structural unemployment that constitutes the bulk of the slack in the labor market under stagnation.

\section{Conclusion}

We have presented a model of secular stagnation that distinguishes between structural unemployment and demand-driven underemployment as a manifestation of economic slack in the labor market. If the unemployment rate is primarily determined by institutional features of the

\footnotetext{
${ }^{42}$ Specifically, $\gamma=0.5$ implies an unemployment rate of $u=8 \%$ at the margin when the real interest rate is zero. This is certainly not compatible with the low unemployment rate in Japan as described in the introduction.

${ }^{43}$ The lower bound on $x$ is given by $x(0)=\frac{(1-\varepsilon) z+(1-s) k(\alpha+\delta)}{(1-\varepsilon) \bar{y}+(1-s) k \alpha}$, which equals $x(0)=0.643$ for our baseline calibration.
} 
labor market, as seems to be the case in Japan, it becomes an insufficient indicator of the extent of the aggregate demand problem in a permanent liquidity trap leading to inadequate policy conclusions. Under stagnation, the lack of demand can express itself in various forms of underemployment, such as part-time or non-regular employment. These provide better indicators of the stance of the macroeconomy and the further need for policies in support of demand.

Our findings also suggest that traditional labor market policies aiming to improve the supply side succeed in lowering unemployment, while at the same time contributing to more widespread underemployment in a stagnating economy. Put differently, albeit these policies succeed in creating new jobs, these are non-regular ones such as part-time jobs. As a consequence, increases in the employment rate are not reflected in an expansion in total output but might in fact be hurtful for both output and consumption. This insight helps to explain the continued sluggishness in the Japanese economy despite the seemingly decent employment record. Examples of such policies include reductions in unemployment benefits, job-creation subsidies to firms or policies aimed at reducing the bargaining power of workers in wage negotiations. In contrast, our model highlights the need for policies that improve aggregate demand as such measures both create new jobs and decrease the degree of underemployment. 


\section{Appendix}

\section{Appendix A: Derivation of the wage rate under Nash bargaining}

From the Bellman equations (17) and (18), we have:

$$
\left(r_{t}+\delta+\theta_{t} q\left(\theta_{t}\right)\right)\left[E_{t}-U_{t}\right]=w_{t} x_{t}-z+\left[E_{t} \dot{-} U_{t}\right] .
$$

Using the optimal sharing rule (19), the above equation is rewritten as:

$$
\left(r_{t}+\delta+\theta_{t} q\left(\theta_{t}\right)\right) \frac{\varepsilon}{1-\varepsilon} J_{t}=w_{t} x_{t}-z+\frac{\varepsilon}{1-\varepsilon} \dot{J}_{t}
$$

Using the Bellman equation (15) and the free entry condition (20), the value of an operating firm is given as:

$$
\dot{J}_{t}=\left(r_{t}+\delta\right) J_{t}-\left(\bar{y}-w_{t}\right) x_{t} .
$$

Substituting this equation for $\dot{J}_{t}$ into (A.2) gives:

$$
\theta_{t} q\left(\theta_{t}\right) \frac{\varepsilon}{1-\varepsilon} J_{t}=w_{t} x_{t}-z-\frac{\varepsilon}{1-\varepsilon}\left(\bar{y}-w_{t}\right) x_{t} .
$$

Using expression (21) for the value of an operating firm $J_{t}$, the above equation gives the wage rate under Nash bargaining as equation (22).

\section{Appendix B: Derivation of the goods market clearing condition}

Substituting the dynamics of the money supply (27) and the government budget constraint (9) into the flow of funds constraint (2) gives

$$
\dot{b}_{t}=r_{t} b_{t}+w_{t} x_{t}\left(1-u_{t}\right)-c_{t}-s k v_{t}-g .
$$

Differentiating $b_{t}=J_{t}\left(1-u_{t}\right)$ from the asset market clearing condition (29) with respect to time, we also have

$$
\dot{b}_{t}=\dot{J}_{t}\left(1-u_{t}\right)-J_{t} \dot{u}_{t} .
$$

Substituting (B.2) and $b_{t}=J_{t}\left(1-u_{t}\right)$ into equation (B.1) gives

$$
\dot{J}_{t}\left(1-u_{t}\right)-J_{t} \dot{u}_{t}=r_{t} J_{t}\left(1-u_{t}\right)+w_{t} x_{t}\left(1-u_{t}\right)-c_{t}-g-s k_{t} v_{t} .
$$

Using the dynamic equations (14) and (A.3) to substitute for $\dot{u}_{t}$ and $\dot{J}_{t}$ in (B.3), we get

$$
\left(1-u_{t}\right) \bar{y} x_{t}=J_{t} p\left(\theta_{t}\right) u_{t}+c_{t}+g+s k_{t} v_{t} .
$$

Finally, using expression (21) for the value of an operating firm $J_{t}$ and the identities $v_{t} \equiv \theta_{t} u_{t}$ and $p\left(\theta_{t}\right) \equiv \theta_{t} q\left(\theta_{t}\right)$, equation (B.4) gives the goods market clearing condition as equation (36).

\section{Appendix C: Derivation of the dynamic system when $x_{t}=1$}

Without aggregate demand shortage, we have $x_{t}=1$ and $\dot{x}_{t}=0$. The goods market clearing condition (36) then defines consumption at any time $t$ as a function of the unemployment rate $u_{t}$ and the labor market tightness $\theta_{t}$ as

$$
c_{t}\left(\theta_{t}, u_{t}\right)=\left(1-u_{t}\right) \bar{y}-k \theta_{t} u_{t}-g,
$$


where the partial derivatives are given by $c_{u}=-(\bar{y}+k \theta)<0$ and $c_{\theta}=-k u_{t}<0$. Differentiating this function with respect to $t$ implies

$$
\dot{c}_{t}=-\dot{u}_{t}\left(\bar{y}+k \theta_{t}\right)-k u_{t} \dot{\theta}_{t}
$$

Using (3), (14) and (25) to substitute for $\dot{c}_{t}, \dot{u}_{t}$ and $\dot{\theta}_{t}$, we derive the following expression for the real interest rate $r_{t}$ at any time $t$ :

$$
\begin{aligned}
& \frac{c_{t}}{\eta_{c}}\left[r_{t}-\rho+\frac{\omega^{\prime}\left(b_{t}\right)}{\phi^{\prime}\left(c_{t}\right)}\right]=-\frac{k u_{t} \theta_{t}}{\eta_{\theta_{t}}}\left[r_{t}-\vartheta\left(\theta_{t}, 1\right)+\delta\right]-\left(\bar{y}+k \theta_{t}\right)\left[\delta\left(1-u_{t}\right)-p\left(\theta_{t}\right) u_{t}\right], \\
& r_{t}\left(\theta_{t}, u_{t}\right)=\varphi_{t}\left[\rho-\frac{\omega^{\prime}\left(b_{t}\right)}{\phi^{\prime}\left(c_{t}\right)}\right]+\left(1-\varphi_{t}\right)\left[\vartheta\left(\theta_{t}, 1\right)-\delta\right]-\tilde{\varphi}_{t}\left[\delta\left(1-u_{t}\right)-p\left(\theta_{t}\right) u_{t}\right],
\end{aligned}
$$

where

$$
\varphi_{t}=\frac{c_{t} / \eta_{c}}{c_{t} / \eta_{c}+k u_{t} \theta_{t} / \eta_{\theta_{t}}} \quad, \quad \tilde{\varphi}_{t}=\frac{\bar{y}+k \theta_{t}}{c_{t} / \eta_{c}+k u_{t} \theta_{t} / \eta_{\theta_{t}}} .
$$

From (C.1), $c_{t}$ is a function of $\theta_{t}$ and $u_{t}$. Hence, the real rate $r_{t}$ is also a function of $\theta_{t}$ and $u_{t}$ as $b_{t}$ depends on the same variables by (19). Using these expressions, we can rewrite the model as a system of three differential equations in $m_{t}, u_{t}$ and $\theta_{t}$ :

$$
\begin{gathered}
\dot{m}_{t}=\left[g_{m}-\frac{\mu^{\prime}\left(m_{t}\right)}{\phi^{\prime}\left(c_{t}\left(\theta_{t}, u_{t}\right)\right)}+r_{t}\left(\theta_{t}, u_{t}\right)\right] m_{t}, \\
\dot{u}_{t}=\left(1-u_{t}\right) \delta-p\left(\theta_{t}\right) u_{t}, \\
\dot{\theta}_{t}=\frac{\theta_{t}}{\eta_{\theta_{t}}}\left[r_{t}\left(\theta_{t}, u_{t}\right)-\vartheta\left(\theta_{t}, 1\right)+\delta\right] .
\end{gathered}
$$

\section{Appendix D: Proof of Lemma 1}

Reformulate (37) with $x_{t}=1$ to define the function $H(\theta)$ as

$$
H(\theta)=\rho+\delta+\varepsilon p(\theta)-\frac{(1-\varepsilon)(\bar{y}-z)}{(1-s) k} q(\theta)-\frac{\omega^{\prime}\left((1-u(\theta)) \frac{(1-s) k}{q(\theta)}\right)}{\phi^{\prime}((1-u(\theta)) \bar{y}-k \theta u(\theta)-g)} .
$$

The function $c(\theta, 1)=(1-u(\theta)) \bar{y}-k \theta u(\theta)-g$ in (36) with $x=1$ defines consumption as a continuous function of $\theta$ with a hump-shaped pattern that attains a maximum at a strictly positive value. ${ }^{44}$ Define $\underline{\theta}$ and $\bar{\theta}$ by $c(\underline{\theta}, 1)=c(\bar{\theta}, 1)=0$ with $\underline{\theta}<\bar{\theta}$. Note that $\underline{\theta}=0$ for $g=0$. Then $c(\theta, 1) \geq 0$ and $H(\theta)$ is a continuous function of $\theta$ for $\theta \in(\underline{\theta}, \bar{\theta})$. As $\omega^{\prime}()<.\infty$, we have

$$
\begin{aligned}
& H(\underline{\theta})=\rho+\delta+\varepsilon p(\underline{\theta})-\frac{(1-\varepsilon)(\bar{y}-z)}{(1-s) k} q(\underline{\theta})=\rho+\delta-\vartheta(\underline{\theta}, 1), \\
& H(\bar{\theta})=\rho+\delta+\varepsilon p(\bar{\theta})-\frac{(1-\varepsilon)(\bar{y}-z)}{(1-s) k} q(\bar{\theta})=\rho+\delta-\vartheta(\bar{\theta}, 1) .
\end{aligned}
$$

Note that $H(\underline{\theta})<H(\bar{\theta})$ since $\vartheta_{\theta}(\theta, 1)<0$. Without any other restrictions, a steady state with $H\left(\theta^{*}\right)=0$ always exists for $\theta^{*} \in(\underline{\theta}, \bar{\theta})$ if $H(\underline{\theta})<0<H(\bar{\theta})$ or equivalently if

$$
\vartheta(\underline{\theta}, 1)-\delta>\rho>\vartheta(\bar{\theta}, 1)-\delta .
$$

Money market equilibrium requires a positive real interest rate in steady state. Define $\tilde{\theta}$ by

\footnotetext{
${ }^{44}$ We ensure this by choosing the parameters $g$ and $k$ sufficiently low relative to $\bar{y}$.
} 
$\vartheta(\tilde{\theta}, 1)=\delta$ as in (40), which implies a zero net return on equity by (33) with $x=1$ and hence a real interest rate of zero. Since $\vartheta_{\theta}(\theta, 1)<0$, equilibrium requires $\theta^{*} \leq \tilde{\theta}$. The steady state without aggregate demand shortage exists in $(\underline{\theta}, \tilde{\theta})$ if the following condition holds: ${ }^{45}$

$$
H(\tilde{\theta}) \geq H\left(\theta^{*}\right)=0 \quad \leftrightarrow \quad \rho \phi^{\prime}(c(\tilde{\theta}, 1)) \geq \omega^{\prime}(b(\tilde{\theta}))
$$

Conditions (D.2) and (D.3) are the necessary existence conditions of Lemma 1. Uniqueness of the steady state requires $H^{\prime}(\theta)>0$ for all $\theta$ with $H(\theta)=0$. Intuitively, the slope of the goods market equilibrium curve has to exceed the slope of the asset market equilibrium curve (which is zero) at each intersection in the $(\theta, x)$ diagram. This derivative is given by:

$$
H^{\prime}(\theta)=\frac{\omega^{\prime \prime}(b)}{\phi^{\prime}(c)}\left[-\frac{\phi^{\prime}(c)}{\omega^{\prime \prime}(b)} \vartheta_{\theta}(\theta, 1)-b^{\prime}(\theta)+\frac{\omega^{\prime}(b)}{\omega^{\prime \prime}(b)} \frac{\phi^{\prime \prime}(c)}{\phi^{\prime}(c)} \frac{d c(\theta, 1)}{d \theta}\right] .
$$

We assume that $H^{\prime}\left(\theta^{*}\right)>0$ so that the steady state with $x=1$ is unique.

\section{Appendix E: Proof of Lemma 2}

The dynamic system is given by (C.4), (C.5) and (C.6). The unemployment rate $u_{t}$ is a predetermined state variables, while labor market tightness $\theta_{t}$ (via vacancies $v_{t}$ ) and the money supply (for $x=1$ ) are control variables and can jump. Stability of the dynamic system therefore requires one negative and two positive eigenvalues. The Jacobian of this system evaluated at the steady state with $x=1$ is given by

$$
\left[\begin{array}{ccc}
-\frac{\mu^{\prime \prime}(m)}{\phi^{\prime}(c)} m & {\left[\frac{\mu^{\prime}(m) \phi^{\prime \prime}(c) c_{u}}{\phi^{\prime}(c)^{2}}+r_{u}\right] m} & {\left[\frac{\mu^{\prime}(m) \phi^{\prime \prime}(c) c_{\theta}}{\phi^{\prime}(c)^{2}}+r_{\theta}\right] m} \\
0 & -[\delta+p(\theta)] & -p^{\prime}(\theta) u \\
0 & \frac{\theta}{\eta_{\theta}} r_{u} & \frac{\theta}{\eta_{\theta}}\left[r_{\theta}-\vartheta_{\theta}(\theta, 1)\right]
\end{array}\right],
$$

where $r_{\chi}$ denotes the partial derivative of the real rate defined in (C.1) with respect to variable $\chi$. The eigenvalues of this system solve the following characteristic equation:

$$
\Omega(\lambda)=\left[-\frac{\mu^{\prime \prime}(m)}{\phi^{\prime}(c)} m-\lambda\right] \cdot\left|\begin{array}{cc}
-[\delta+p(\theta)]-\lambda & -p^{\prime}(\theta) u \\
\frac{\theta}{\eta_{\theta}} r_{u} & \frac{\theta}{\eta_{\theta}}\left[r_{\theta}-\vartheta_{\theta}(\theta, 1)\right]-\lambda
\end{array}\right|=0 .
$$

It is clear that $\lambda_{1}=-\mu^{\prime \prime}(m) m / \phi^{\prime}(c)>0$ is one solution. The other two eigenvalues solve:

$$
\lambda^{2}-\left(\frac{\theta}{\eta_{\theta}}\left[r_{\theta}-\vartheta_{\theta}(\theta, 1)\right]-\delta-p(\theta)\right) \lambda+\frac{\theta}{\eta_{\theta}} r_{u} p^{\prime}(\theta) u-\frac{\theta}{\eta_{\theta}}[\delta+p(\theta)]\left(r_{\theta}-\vartheta_{\theta}(\theta, 1)\right)=0 .
$$

We can recover the sign of the eigenvalues from

$$
\lambda_{2} \lambda_{3}=\frac{\theta}{\eta_{\theta}}\left[r_{u} p^{\prime}(\theta) u-[\delta+p(\theta)]\left(r_{\theta}-\vartheta_{\theta}\right)(\theta, 1)\right],
$$

From (C.3), we get the following expression for the partial derivative of $r_{t}$ with respect to $u_{t}$ and $\theta_{t}$ in steady state:

$$
r_{u}=-\varphi\left[\frac{\omega^{\prime \prime}(b) \phi^{\prime}(c) b_{u}-\omega^{\prime}(b) \phi^{\prime \prime}(c) c_{u}}{\phi^{\prime}(c)^{2}}\right]+\tilde{\varphi}[\delta+p(\theta)]
$$

\footnotetext{
${ }^{45}$ We assume a constant nominal money supply and hence zero inflation, i.e. $g_{m}=0$. For $g_{m}>0, \bar{\theta}$ becomes a function of $g_{m}$ as the real interest rate cannot fall below $-g_{m}$.
} 


$$
r_{\theta}=-\varphi\left[\frac{\omega^{\prime \prime}(b) \phi^{\prime}(c) b_{\theta}-\omega^{\prime}(b) \phi^{\prime \prime}(c) c_{\theta}}{\phi^{\prime}(c)^{2}}\right]+(1-\varphi) \vartheta_{\theta}(\theta, 1)+\tilde{\varphi} p^{\prime}(\theta) u
$$

Also note that the unemployment rate in steady state is a function of labor market tightness from equation (31) with $d u / d \theta \equiv u^{\prime}(\theta)=-p^{\prime}(\theta) u(\theta) /(\delta+p(\theta))$. Using this expression, we can relate the partial derivatives $c_{u}$ and $c_{\theta}$ to the total derivative $d c(\theta, 1) / d \theta=c^{\prime}(\theta, 1)$ in steady state as follows (and equivalently for $b(\theta))^{46}$

$$
\begin{gathered}
\frac{d c(\theta, u)}{d \theta} \equiv \frac{d c(\theta, 1)}{d \theta}=c_{\theta}+c_{u} u^{\prime}(\theta)=c_{\theta}-c_{u} \frac{p^{\prime}(\theta) u(\theta)}{\delta+p(\theta)} \\
\frac{d b(\theta, u)}{d \theta} \equiv b^{\prime}(\theta)=b_{\theta}+b_{u} u^{\prime}(\theta)=b_{\theta}-b_{u} \frac{p^{\prime}(\theta) u(\theta)}{\delta+p(\theta)}
\end{gathered}
$$

Using these properties, we rewrite the above equation as:

$$
\begin{gathered}
\lambda_{2} \lambda_{3}=\frac{\theta}{\eta_{\theta}}\left[-\varphi\left[\frac{\omega^{\prime \prime}(b) \phi^{\prime}(c) b_{u}-\omega^{\prime}(b) \phi^{\prime \prime}(c) c_{u}}{\phi^{\prime}(c)^{2}}\right] p^{\prime}(\theta) u+\tilde{\varphi}[\delta+p(\theta)] p^{\prime}(\theta) u\right. \\
\left.-[\delta+p(\theta)]\left(-\varphi\left[\frac{\omega^{\prime \prime}(b) \phi^{\prime}(c) b_{\theta}-\omega^{\prime}(b) \phi^{\prime \prime}(c) c_{\theta}}{\phi^{\prime}(c)^{2}}\right]+(1-\varphi) \vartheta_{\theta}(\theta, 1)+\tilde{\varphi} p^{\prime}(\theta) u-\vartheta_{\theta}\right)\right], \\
=\frac{\theta}{\eta_{\theta}}\left[-\varphi\left[\frac{\omega^{\prime \prime}(b) \phi^{\prime}(c) b_{u}-\omega^{\prime}(b) \phi^{\prime \prime}(c) c_{u}}{\phi^{\prime}(c)^{2}}\right] p^{\prime}(\theta) u\right. \\
\left.+[\delta+p(\theta)]\left(\varphi\left[\frac{\omega^{\prime \prime}(b) \phi^{\prime}(c) b_{\theta}-\omega^{\prime}(b) \phi^{\prime \prime}(c) c_{\theta}}{\phi^{\prime}(c)^{2}}\right]+\varphi \vartheta_{\theta}(\theta, 1)\right)\right] \\
=\frac{\theta}{\eta_{\theta}} \varphi[\delta+p(\theta)]\left[\frac{\omega^{\prime \prime}(b)}{\phi^{\prime}(c)}\left(b_{\theta}-b_{u} \frac{p^{\prime}(\theta) u}{\delta+p(\theta)}\right)-\frac{\omega^{\prime}(b) \phi^{\prime \prime}(c)}{\phi^{\prime}(c)^{2}}\left(c_{\theta}-c_{u} \frac{p^{\prime}(\theta) u}{\delta+p(\theta)}\right)+\vartheta_{\theta}(\theta, 1)\right], \\
=\frac{\theta}{\eta_{\theta}} \varphi[\delta+p(\theta)]\left[\frac{\omega^{\prime \prime}(b)}{\phi^{\prime}(c)} b^{\prime}(\theta)-\frac{\omega^{\prime}(b) \phi^{\prime \prime}(c)}{\phi^{\prime}(c)^{2}} \frac{d c(\theta, 1)}{d \theta}+\vartheta_{\theta}(\theta, 1)\right], \\
=-\frac{\theta}{\eta_{\theta}} \varphi[\delta+p(\theta)] \frac{\omega^{\prime \prime}(b)}{\phi^{\prime}(c)}\left[-\frac{\phi^{\prime}(c)}{\omega^{\prime \prime}(b)} \vartheta_{\theta}(\theta, 1)-b^{\prime}(\theta)+\frac{\omega^{\prime}(b)}{\phi^{\prime}(c)} \frac{\phi^{\prime \prime}(c)}{\omega^{\prime \prime}(b)} \frac{d c(\theta, 1)}{d \theta}\right] .
\end{gathered}
$$

The term in brackets is identical to expression (D.4) in Appendix D. Hence, we can rewrite this equation as:

$$
\lambda_{2} \lambda_{3}=-\frac{\theta}{\eta_{\theta}} \varphi[\delta+p(\theta)] H^{\prime}(\theta)<0 .
$$

If the steady state is unique, it holds that $H^{\prime}(\theta)>0$. It then follows that $\lambda_{2} \lambda_{3}<0$, which implies one negative and one positive eigenvalue. Together with $\lambda_{1}>0$, the dynamic system has one negative and two positive eigenvalues and therefore exhibits saddle-path stability around the steady state without demand shortage.

\section{Appendix F: Proof of Proposition 1}

Use (37) with $x_{t}=1$ to define the function $H(\theta, \chi)$, where $\chi$ denotes any parameter in the model, as follows:

$$
H(\theta, \chi)=\rho+\delta+\varepsilon p(\theta)-\frac{(1-\varepsilon)(\bar{y}-z)}{(1-s) k} q(\theta)-\frac{\omega^{\prime}\left((1-u(\theta)) \frac{(1-s) k}{q(\theta)}\right)}{\phi^{\prime}(c(\theta, 1))},
$$

\footnotetext{
${ }^{46}$ Note that $d \vartheta(\theta, 1) / d \theta \equiv \vartheta_{\theta}(\theta, 1)=\vartheta_{\theta}$ in the absence of aggregate demand shortage.
} 
with $H\left(\theta^{*}\right)=0$ and $H^{\prime}\left(\theta^{*}\right)>0$ in a unique steady state where $H_{\theta}$ denotes the derivative with respect to $\theta$ evaluated in steady state (see Appendix D). $c(\theta, 1)$ is defined in (36). The effects of changes in a parameter $\chi$ on the labor market tightness $\theta$ can be recovered from (F.1) as

$$
\frac{d \theta}{d \chi}=-\frac{H_{\chi}}{H_{\theta}} .
$$

It holds that:

$$
\begin{gathered}
H_{\varepsilon}=\frac{(\bar{y}-z+\theta(1-s) k) q}{(1-s) k}>0, \\
H_{z}=\frac{(1-\varepsilon) q}{(1-s) k}>0, \\
H_{s}=\frac{\omega^{\prime \prime}(b)(1-u) k}{\phi^{\prime}(c) q}-\frac{(1-\varepsilon)(\bar{y}-z) q}{(1-s)^{2} k}<0, \\
H_{k}=-\frac{\omega^{\prime \prime}(b)(1-u)(1-s)}{\phi^{\prime}(c) q}-\frac{\omega^{\prime}(b) \phi^{\prime \prime}(c) \theta u}{\phi^{\prime}(c)^{2}}+\frac{(1-\varepsilon)(\bar{y}-z) q}{(1-s) k^{2}}>0, \\
H_{\bar{y}}=\frac{\omega^{\prime}(b) \phi^{\prime \prime}(c)(1-u)}{\phi^{\prime}(c)^{2}}-\frac{(1-\varepsilon) q}{(1-s) k}<0, \\
H_{g}=-\frac{\omega^{\prime}(b) \phi^{\prime \prime}(c)}{\phi^{\prime}(c)^{2}}>0 .
\end{gathered}
$$

This implies the following relationship between the steady state labor market tightness and the model parameters:

$$
\theta^{f}=\theta(\underbrace{\varepsilon}_{-}, \underbrace{z}_{-}, \underbrace{s}_{+}, \underbrace{k}_{-}, \underbrace{\bar{y}}_{+}, \underbrace{g}_{-}),
$$

From the Beveridge curve in (31), it immediately follows that the effects on the unemployment rate are opposite to those on the labor market tightness, i.e.

$$
u^{f}=u(\underbrace{\varepsilon}_{+}, \underbrace{z}_{+}, \underbrace{s}_{-}, \underbrace{k}_{+}, \underbrace{\bar{y}}_{-}, \underbrace{g}_{+}),
$$

In addition, total output $Y=(1-u(\theta)) \bar{y}$ is affected by the model parameters in the same way as the labor market tightness, except that changes in productivity are reinforced, i.e.

$$
Y^{f}=Y(\underbrace{\varepsilon}_{-}, \underbrace{z}_{-}, \underbrace{s}_{+}, \underbrace{k}_{-}, \underbrace{\bar{y}}_{+}, \underbrace{g}_{-})
$$

Finally, the effects on household consumption can be derived from the goods market clearing condition (36). Specifically, it holds that

$$
\frac{d c(\theta, 1)}{d \chi}=\frac{d c(\theta, 1)}{d \theta} \frac{d \theta}{d \chi}+\frac{\partial c(\theta, 1)}{\partial \chi}
$$

where $\frac{\partial c}{\partial \chi}=0$ for $\chi=\varepsilon, z, s, \frac{\partial c}{\partial \chi}=-\theta u$ for $\chi=k, \frac{\partial c}{\partial \chi}=1-u$ for $\chi=\bar{y}$ and $\frac{\partial c}{\partial \chi}=-1$ for $\chi=g$. Moreover, $d c(\theta, 1) / d \theta=-u^{\prime}(\theta)(\bar{y}+k \theta)-k u(\theta)$ and its sign is not uniquely determined. For $d c(\theta, 1) / d \theta>0$ ("slack" steady state), the sign of the effects of all parameter changes are identical to those of the labor market tightness. For $d c(\theta, 1) / d \theta<0$ ("tight" steady state), the sign of the effects of changes in $\varepsilon, z$ and $s$ is opposite to those on $\theta$, while the effects of variations in $k, \bar{y}$ and $g$ are indeterminate. 


\section{Appendix G: Proof of Lemma 3 and Lemma 4}

Equations (37) and (39) define the function $G(\theta)$ as

$$
G(\theta)=\rho-\frac{\omega^{\prime}\left((1-u(\theta)) \frac{(1-s) k}{q(\theta)}\right)}{\phi^{\prime}\left(x^{a}(\theta)(1-u(\theta)) \bar{y}-k \theta u(\theta)-g\right)}-\alpha\left(1-x^{a}(\theta)\right),
$$

where $x^{a}(\theta)$ is the increasing part of the asset market equilibrium curve given by (41). A well-defined steady state requires non-negative consumption. Define $\underline{\theta}^{s}$ as the smallest value of $\theta$ such that $c\left(\underline{\theta}^{s}, x^{a}\left(\underline{\theta}^{s}\right)\right)=0$, where $c\left(\theta, x^{a}(\theta)\right) \equiv x^{a}(\theta)(1-u(\theta)) \bar{y}-k \theta u(\theta)-g$. Note that $\underline{\theta}^{s}=\underline{\theta}=0$ for $g=0$, where $\underline{\theta}$ is defined in Appendix D. ${ }^{47}$ In addition, let $\tilde{\theta}$ by defined as before by $\vartheta(\tilde{\theta}, 1)=\delta$ in $(40)$, which implies $x^{a}(\tilde{\theta})=1$ in (41). We then have:

$$
\begin{gathered}
G\left(\underline{\theta}^{s}\right)=\rho-\alpha\left(1-x^{a}\left(\underline{\theta}^{s}\right)\right)=\rho-\alpha \frac{\vartheta\left(\underline{\theta}^{s}, 1\right)-\delta}{\alpha+\frac{(1-\varepsilon) \bar{y}}{(1-s) k} q\left(\underline{\theta}^{s}\right)}>0, \\
G(\tilde{\theta})=\rho-\frac{\omega^{\prime}\left((1-u(\tilde{\theta})) \frac{(1-s) k}{q(\tilde{\theta})}\right)}{\phi^{\prime}((1-u(\tilde{\theta})) \bar{y}-k \tilde{\theta} u(\tilde{\theta})-g)}=\rho-\frac{\omega^{\prime}(b(\tilde{\theta}))}{\phi^{\prime}(c(\tilde{\theta}, 1))} .
\end{gathered}
$$

Note that $G\left(\underline{\theta}^{s}\right)>0$ if $\rho>\alpha$ since the ratio $\frac{\vartheta\left(\theta^{s}, 1\right)-\delta}{\left.\alpha+\frac{(1-\varepsilon) \bar{y}}{(1-s) k} q \underline{(}^{s}\right)}$ is always strictly smaller than unity. Existence of the secular stagnation steady state then requires $G(\tilde{\theta})<0$ or equivalently

$$
\rho \phi^{\prime}(c(\tilde{\theta}, 1))<\omega^{\prime}(b(\tilde{\theta})) .
$$

Whenever full employment is not feasible, we have $G(\tilde{\theta})=H(\tilde{\theta})<0$ by Lemma 1 as shown in Appendix D. It then follows that there exists $\theta^{s}$ such that $G\left(\theta^{s}\right)=0$.

Uniqueness of the steady state requires $G^{\prime}(\theta)<0$ for all $\theta$ with $G(\theta)=0$. Intuitively, the slope of the goods market equilibrium curve has to be smaller than the slope of the asset market equilibrium curve at each intersection in the $(\theta, x)$ diagram. This derivative is given by:

$$
G^{\prime}(\theta)=\frac{\omega^{\prime \prime}(b)}{\phi^{\prime}(c)}\left[-b^{\prime}(\theta)+\frac{\omega^{\prime}(b)}{\omega^{\prime \prime}(b)} \frac{\phi^{\prime \prime}(c)}{\phi^{\prime}(c)} \frac{d c\left(\theta, x^{a}(\theta)\right)}{d \theta}+\frac{\phi^{\prime}(c)}{\omega^{\prime \prime}(b)} \alpha \frac{d x^{a}(\theta)}{d \theta}\right] .
$$

Throughout this paper, we assume that $G^{\prime}\left(\theta^{s}\right)<0$ so that the steady state is unique. Uniqueness in turn implies that the secular stagnation steady state is slack. Reformulating $G^{\prime}(\theta)<0$ implies:

$$
\frac{\omega^{\prime}(b)}{\omega^{\prime \prime}(b)} \frac{\phi^{\prime \prime}(c)}{\phi^{\prime}(c)} \frac{d c\left(\theta, x^{a}(\theta)\right)}{d \theta}>b^{\prime}(\theta)-\alpha \frac{\phi^{\prime}(c)}{\omega^{\prime \prime}(b)} \frac{d x^{a}(\theta)}{d \theta}>0
$$

since $\frac{d x^{a}(\theta)}{d \theta}>0$ in steady state, which can be seen in (41). It follows that $\frac{d c\left(\theta, x^{a}(\theta)\right)}{d \theta}>0$.

\section{Appendix H: Proof of Lemma 5}

In the stagnation steady state, the liquidity preference of households is satiated such that $R_{t}=0$ and hence $r_{t}=R_{t}-\pi_{t}=\alpha\left(1-x_{t}\right)$. The goods market clearing condition (36) defines realized working hours $x_{t}$ at any time $t$ as a function of $c_{t}, \theta_{t}$ and $u_{t}$ as

$$
x_{t}=\frac{c_{t}+k \theta_{t} u_{t}+g}{\left(1-u_{t}\right) \bar{y}}
$$

\footnotetext{
${ }^{47}$ We ensure non-negativity in consumption in steady state by choosing the parameters $g$ and $k$ sufficiently low relative to $\bar{y}$.
} 
where the partial derivatives satisfy $x_{c}>0, x_{\theta}>0$ and $x_{u}>0$. Define $\tilde{m}_{t} \equiv 1 / m_{t}$ with $\tilde{m}=0$ in steady state. The dynamic system is given by the following differential equations for $\tilde{m}_{t}, c_{t}$, $\theta_{t}$ and $u_{t}$ :

$$
\begin{gathered}
\dot{\tilde{m}}_{t}=\alpha\left(x_{t}-1\right) \tilde{m}_{t}, \\
\dot{c}_{t}=\left[\alpha\left(1-x_{t}\right)-\rho+\frac{\omega^{\prime}\left(b\left(\theta_{t}, u_{t}\right)\right)}{\phi^{\prime}\left(c_{t}\right)}\right] \frac{c_{t}}{\eta_{c}}, \\
\dot{\theta}_{t}=\left[\alpha\left(1-x_{t}\right)-\vartheta\left(\theta_{t}, x_{t}\right)+\delta\right] \frac{\theta_{t}}{\eta_{\theta_{t}}}, \\
\dot{u}_{t}=\delta\left(1-u_{t}\right)-p\left(\theta_{t}\right) u_{t},
\end{gathered}
$$

where $b\left(\theta_{t}, u_{t}\right)$ and $\vartheta\left(\theta_{t}, x_{t}\right)$ are given by (29) and (24) respectively. Let $\vartheta_{\theta}$ and $\vartheta_{x}$ denote the partial derivatives of $\vartheta\left(\theta_{t}, x_{t}\right)$ with respect to $\theta_{t}$ and $x_{t}$. Since the price level cannot adjust freely, the money supply grows with the rate of deflation and is hence a predetermined variable. In addition, the unemployment rate is a state variable whereas consumption and labor market tightness are jump variables. Stability of the system therefore requires two positive and two negative eigenvalues. The Jacobian of this system evaluated at the secular stagnation steady state is as follows:

$$
\left[\begin{array}{cccc}
\alpha(x-1) & \alpha x_{c} \tilde{m} & \alpha x_{\theta} \tilde{m} & \alpha x_{u} \tilde{m} \\
0 & \frac{c}{\eta_{c}}\left[-\alpha x_{c}-\frac{\omega^{\prime}(b) \phi^{\prime \prime}(c)}{\phi^{\prime}(c)^{2}}\right] & \frac{c}{\eta_{c}}\left[-\alpha x_{\theta}+\frac{\omega^{\prime \prime}(b) b_{\theta}}{\phi^{\prime}(c)}\right] & \frac{c}{\eta_{c}}\left[-\alpha x_{u}+\frac{\omega^{\prime \prime}(b) b_{u}}{\phi^{\prime}(c)}\right] \\
0 & \frac{\theta}{\eta_{\theta}}\left[-\alpha x_{c}-\vartheta_{x} x_{c}\right] & \frac{\theta}{\eta_{\theta}}\left[-\alpha x_{\theta}-\vartheta_{x} x_{\theta}-\vartheta_{\theta}\right] & \frac{\theta}{\eta_{\theta}}\left[-\alpha x_{u}-\vartheta_{x} x_{u}\right] \\
0 & 0 & -p^{\prime}(\theta) u & -[\delta+p(\theta)]
\end{array}\right] .
$$

The eigenvalues of this system solve the following characteristic equation:

$$
\begin{aligned}
& \Omega(\lambda)=[\alpha(x-1)-\lambda] . \\
& \begin{array}{ccc}
\frac{c}{\eta_{c}}\left[-\alpha x_{c}-\frac{\omega^{\prime}(b) \phi^{\prime \prime}(c)}{\phi^{\prime}(c)^{2}}\right]-\lambda & \frac{c}{\eta_{c}}\left[-\alpha x_{\theta}+\frac{\omega^{\prime \prime}(b) b_{\theta}}{\phi^{\prime}(c)}\right] & \frac{c}{\eta_{c}}\left[-\alpha x_{u}+\frac{\omega^{\prime \prime}(b) b_{u}}{\phi^{\prime}(c)}\right] \\
\frac{\theta}{\eta_{\theta}}\left[-\alpha x_{c}-\vartheta_{x} x_{c}\right] & \frac{\theta}{\eta_{\theta}}\left[-\alpha x_{\theta}-\vartheta_{x} x_{\theta}-\vartheta_{\theta}\right]-\lambda & \frac{\theta}{\eta_{\theta}}\left[-\alpha x_{u}-\vartheta_{x} x_{u}\right] \\
0 & -p^{\prime}(\theta) u & -[\delta+p(\theta)]-\lambda
\end{array} \mid=0 .
\end{aligned}
$$

It is clear that $\lambda_{1}=\alpha(x-1)<0$ is one solution. The other eigenvalues solve:

$$
\begin{aligned}
& \tilde{\Omega}(\lambda)=p^{\prime}(\theta) u \cdot\left|\begin{array}{cc}
-\frac{c}{\eta_{c}}\left[\alpha x_{c}+\frac{\omega^{\prime}(b) \phi^{\prime \prime}(c)}{\phi^{\prime}(c)^{2}}\right]-\lambda & -\frac{c}{\eta_{c}}\left[\alpha x_{u}-\frac{\omega^{\prime \prime}(b) b_{u}}{\phi^{\prime}(c)}\right] \\
-\frac{\theta}{\eta_{\theta}}\left[\alpha+\vartheta_{x}\right] x_{c} & -\frac{\theta}{\eta_{\theta}}\left[\alpha+\vartheta_{x}\right] x_{u}
\end{array}\right|
\end{aligned}
$$

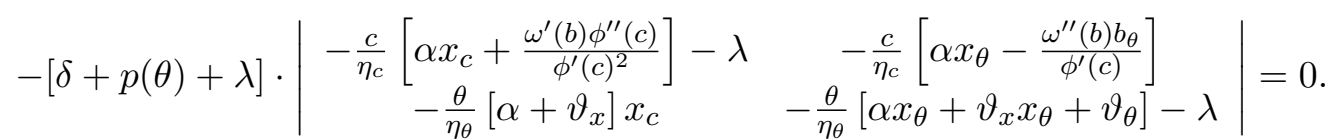

We rewrite this expression as:

$$
\tilde{\Omega}(\lambda)=-\lambda^{3}+A_{2} \lambda^{2}-A_{1} \lambda+A_{0}=0,
$$

where

$$
\begin{gathered}
A_{2}=-\frac{c}{\eta_{c}}\left(\alpha x_{c}+\frac{\omega^{\prime}(b) \phi^{\prime \prime}(c)}{\phi^{\prime}(c)^{2}}\right)-\frac{\theta}{\eta_{\theta}}\left(\alpha x_{\theta}+\vartheta_{x} x_{\theta}+\vartheta_{\theta}\right)-\delta-p(\theta), \\
A_{1}=-p^{\prime}(\theta) u \frac{\theta}{\eta_{\theta}}\left(\alpha+\vartheta_{x}\right) x_{u}+[\delta+p(\theta)]\left[\frac{c}{\eta_{c}}\left(\alpha x_{c}+\frac{\omega^{\prime}(b) \phi^{\prime \prime}(c)}{\phi^{\prime}(c)^{2}}\right)+\frac{\theta}{\eta_{\theta}}\left(\alpha x_{\theta}+\vartheta_{x} x_{\theta}+\vartheta_{\theta}\right)\right] \\
+\frac{c}{\eta_{c}} \frac{\theta}{\eta_{\theta}}\left(\alpha x_{c}+\frac{\omega^{\prime}(b) \phi^{\prime \prime}(c)}{\phi^{\prime}(c)^{2}}\right)\left(\alpha x_{\theta}+\vartheta_{x} x_{\theta}+\vartheta_{\theta}\right)-\frac{c}{\eta_{c}} \frac{\theta}{\eta_{\theta}}\left(\alpha+\vartheta_{x}\right) x_{c}\left(\alpha x_{\theta}-\frac{\omega^{\prime \prime}(b) b_{\theta}}{\phi^{\prime}(c)}\right),
\end{gathered}
$$




$$
\begin{gathered}
A_{0}=p^{\prime}(\theta) u \frac{c}{\eta_{c}} \frac{\theta}{\eta_{\theta}}\left(\alpha+\vartheta_{x}\right)\left[\left(\alpha x_{c}+\frac{\omega^{\prime}(b) \phi^{\prime \prime}(c)}{\phi^{\prime}(c)^{2}}\right) x_{u}-\left(\alpha x_{u}-\frac{\omega^{\prime \prime}(b) b_{u}}{\phi^{\prime}(c)}\right) x_{c}\right] \\
-[\delta+p(\theta)] \frac{c}{\eta_{c}} \frac{\theta}{\eta_{\theta}}\left[\left(\alpha x_{c}+\frac{\omega^{\prime}(b) \phi^{\prime \prime}(c)}{\phi^{\prime}(c)^{2}}\right)\left(\alpha x_{\theta}+\vartheta_{x} x_{\theta}+\vartheta_{\theta}\right)-\left(\alpha+\vartheta_{x}\right) x_{c}\left(\alpha x_{\theta}-\frac{\omega^{\prime \prime}(b) b_{\theta}}{\phi^{\prime}(c)}\right)\right] .
\end{gathered}
$$

Noting that $u^{\prime}(\theta)=-p^{\prime}(\theta) u /[\delta+p(\theta)]$ and $b^{\prime}(\theta)=b_{\theta}+b_{u} u^{\prime}(\theta)$, we can modify $A_{0}$ as follows:

$$
\begin{gathered}
A_{0}=[\delta+p(\theta)] \frac{c}{\eta_{c}} \frac{\theta}{\eta_{\theta}}\left[\frac{p^{\prime}(\theta) u}{\delta+p(\theta)}\left(\alpha+\vartheta_{x}\right)\left(\alpha x_{c} x_{u}+\frac{\omega^{\prime}(b) \phi^{\prime \prime}(c)}{\phi^{\prime}(c)^{2}} x_{u}-\alpha x_{u} x_{c}+\frac{\omega^{\prime \prime}(b) b_{u}}{\phi^{\prime}(c)} x_{c}\right)\right. \\
\left.-\left(\alpha x_{c}+\frac{\omega^{\prime}(b) \phi^{\prime \prime}(c)}{\phi^{\prime}(c)^{2}}\right)\left(\alpha x_{\theta}+\vartheta_{x} x_{\theta}+\vartheta_{\theta}\right)+\left(\alpha+\vartheta_{x}\right) x_{c}\left(\alpha x_{\theta}-\frac{\omega^{\prime \prime}(b) b_{\theta}}{\phi^{\prime}(c)}\right)\right] \\
=[\delta+p(\theta)] \frac{c}{\eta_{c}} \frac{\theta}{\eta_{\theta}}\left(\alpha+\vartheta_{x}\right)\left[-\frac{\omega^{\prime}(b) \phi^{\prime \prime}(c)}{\phi^{\prime}(c)^{2}} x_{u} u^{\prime}(\theta)-\frac{\omega^{\prime \prime}(b) b_{u}}{\phi^{\prime}(c)} x_{c} u^{\prime}(\theta)-\frac{\omega^{\prime \prime}(b) b_{\theta}}{\phi^{\prime}(c)} x_{c}+x_{c} \alpha x_{\theta}\right. \\
\left.-\alpha x_{c}\left(x_{\theta}+\frac{\vartheta_{\theta}}{\alpha+\vartheta_{x}}\right)-\frac{\omega^{\prime}(b) \phi^{\prime \prime}(c)}{\phi^{\prime}(c)^{2}}\left(x_{\theta}+\frac{\vartheta_{\theta}}{\alpha+\vartheta_{x}}\right)\right] \\
=[\delta+p(\theta)] \frac{c}{\eta_{c}} \frac{\theta}{\eta_{\theta}}\left(\alpha+\vartheta_{x}\right) x_{c}\left[-\frac{\omega^{\prime}(b) \phi^{\prime \prime}(c)}{\phi^{\prime}(c)^{2}}\left(\frac{x_{u}}{x_{c}} u^{\prime}(\theta)+\frac{x_{\theta}}{x_{c}}+\frac{\vartheta_{\theta}}{\left(\alpha+\vartheta_{x}\right) x_{c}}\right)\right. \\
\left.-\frac{\omega^{\prime \prime}(b)}{\phi^{\prime}(c)} b^{\prime}(\theta)-\frac{\alpha \vartheta_{\theta}}{\alpha+\vartheta_{x}}\right] .
\end{gathered}
$$

Using the partial derivatives of $x$ defined in (H.1), we can rewrite the term in brackets as follows:

$$
\begin{gathered}
\frac{x_{u}}{x_{c}} u^{\prime}(\theta)+\frac{x_{\theta}}{x_{c}}+\frac{\vartheta_{\theta}}{\left(\alpha+\vartheta_{x}\right) x_{c}}=(\bar{y} x+k \theta) u^{\prime}(\theta)+k u-(1-u) \bar{y} \frac{-\vartheta_{\theta}}{\left(\alpha+\vartheta_{x}\right)} \\
=(\bar{y} x+k \theta) u^{\prime}(\theta)+k u-(1-u) \bar{y} \frac{d x^{a}(\theta)}{d \theta} \equiv \frac{d c\left(\theta, x^{a}(\theta)\right)}{d \theta},
\end{gathered}
$$

where $\frac{d x^{a}(\theta)}{d \theta}=-\frac{\vartheta_{\theta}}{\left(\alpha+\vartheta_{x}\right)}$ follows from the No-Arbitrage condition (41) and $c\left(\theta, x^{a}(\theta)\right)$ is defined in (36). It then follows that $A_{0}$ can be rewritten as:

$$
A_{0}=[\delta+p(\theta)] \frac{c}{\eta_{c}} \frac{\theta}{\eta_{\theta}}\left(\alpha+\vartheta_{x}\right) x_{c} \frac{\omega^{\prime \prime}(b)}{\phi^{\prime}(c)}\left[-b^{\prime}(\theta)+\frac{\omega^{\prime}(b)}{\omega^{\prime \prime}(b)} \frac{\phi^{\prime \prime}(c)}{\phi^{\prime}(c)} \frac{d c\left(\theta, x^{a}(\theta)\right)}{d \theta}-\frac{\phi^{\prime}(c)}{\omega^{\prime \prime}(b)} \frac{\alpha \vartheta_{\theta}}{\alpha+\vartheta_{x}}\right] .
$$

Using the expressions for $\vartheta_{x}, \vartheta_{\theta}$ and $\frac{d x^{a}(\theta)}{d \theta}$, it is easy to see that the last part of this term is identical to expression (G.3) in Appendix F. Hence, we can rewrite this equation as:

$$
A_{0}=[\delta+p(\theta)] \frac{c}{\eta_{c}} \frac{\theta}{\eta_{\theta}}\left(\alpha+\vartheta_{x}\right) x_{c} G^{\prime}(\theta) .
$$

If the secular stagnation steady state is unique, it holds that $G^{\prime}(\theta)<0$ and it follows immediately that we have $A_{0}<0$. Since $A_{0}$ can be rewritten as the product of the three remaining eigenvalues, i.e. $A_{0}=\lambda_{2} \lambda_{3} \lambda_{4}<0$, we either have one or three additional negative eigenvalues.

Stability requires two positive and two negative eigenvalues. Since $A_{2}=\lambda_{2}+\lambda_{3}+\lambda_{4}$ and $A_{1}=\lambda_{2} \lambda_{3}+\lambda_{2} \lambda_{4}+\lambda_{3} \lambda_{4}$, we require either $A_{2}>0$ and/or $A_{1}<0$.

Suppose $A_{2}>0$, then stability immediately follows. Suppose instead $A_{2} \leq 0$. This implies

$$
-\frac{c}{\eta_{c}}\left(\alpha x_{c}+\frac{\omega^{\prime}(b) \phi^{\prime \prime}(c)}{\phi^{\prime}(c)^{2}}\right)-\frac{\theta}{\eta_{\theta}}\left(\alpha+\vartheta_{x}\right) x_{\theta} \leq \delta+p(\theta)+\frac{\theta}{\eta_{\theta}} \vartheta_{\theta},
$$


which we use to show that $A_{1}<0$ in this case, from which stability follows. Reformulate $A_{1}$ as:

$$
\begin{aligned}
& A_{1}=[\delta+p(\theta)] \frac{\theta}{\eta_{\theta}}\left(\alpha+\vartheta_{x}\right)\left(\frac{-p^{\prime}(\theta) u}{\delta+p(\theta)} x_{u}+x_{\theta}+\frac{\vartheta_{\theta}}{\alpha+\vartheta_{x}}\right)+[\delta+p(\theta)] \frac{c}{\eta_{c}}\left(\alpha x_{c}+\frac{\omega^{\prime}(b) \phi^{\prime \prime}(c)}{\phi^{\prime}(c)^{2}}\right) \\
& +\frac{c}{\eta_{c}} \frac{\theta}{\eta_{\theta}}\left[\left(\alpha x_{c}+\frac{\omega^{\prime}(b) \phi^{\prime \prime}(c)}{\phi^{\prime}(c)^{2}}\right) \vartheta_{\theta}+\left(\alpha+\vartheta_{x}\right)\left[\left(\alpha x_{c}+\frac{\omega^{\prime}(b) \phi^{\prime \prime}(c)}{\phi^{\prime}(c)^{2}}\right) x_{\theta}-x_{c}\left(\alpha x_{\theta}-\frac{\omega^{\prime \prime}(b) b_{\theta}}{\phi^{\prime}(c)}\right)\right]\right] \\
& =[\delta+p(\theta)] \frac{\theta}{\eta_{\theta}}\left(\alpha+\vartheta_{x}\right) x_{c}\left(\frac{x_{u}}{x_{c}} u^{\prime}(\theta)+\frac{x_{\theta}}{x_{c}}+\frac{\vartheta_{\theta}}{x_{c}\left(\alpha+\vartheta_{x}\right)}\right)+[\delta+p(\theta)] \frac{c}{\eta_{c}}\left(\alpha x_{c}+\frac{\omega^{\prime}(b) \phi^{\prime \prime}(c)}{\phi^{\prime}(c)^{2}}\right) \\
& +\frac{c}{\eta_{c}} \frac{\theta}{\eta_{\theta}}\left(\alpha x_{c}+\frac{\omega^{\prime}(b) \phi^{\prime \prime}(c)}{\phi^{\prime}(c)^{2}}\right) \vartheta_{\theta}+\frac{c}{\eta_{c}} \frac{\theta}{\eta_{\theta}}\left(\alpha+\vartheta_{x}\right)\left[\frac{\omega^{\prime}(b) \phi^{\prime \prime}(c)}{\phi^{\prime}(c)^{2}} x_{\theta}+\frac{\omega^{\prime \prime}(b) b_{\theta}}{\phi^{\prime}(c)} x_{c}\right] \\
& =-[\delta+p(\theta)] \frac{\theta}{\eta_{\theta}}\left(\alpha+\vartheta_{x}\right) x_{c} \frac{d c\left(\theta, x^{a}(\theta)\right)}{d \theta}+\frac{c}{\eta_{c}} \alpha x_{c}\left(\delta+p(\theta)+\frac{\theta}{\eta_{\theta}} \vartheta_{\theta}\right) \\
& +\frac{c}{\eta_{c}} \frac{\omega^{\prime}(b) \phi^{\prime \prime}(c)}{\phi^{\prime}(c)^{2}}\left(\delta+p(\theta)+\frac{\theta}{\eta_{\theta}} \vartheta_{\theta}\right)+\frac{c}{\eta_{c}} \frac{\theta}{\eta_{\theta}}\left(\alpha+\vartheta_{x}\right)\left(\frac{\omega^{\prime}(b) \phi^{\prime \prime}(c)}{\phi^{\prime}(c)^{2}} x_{\theta}+\frac{\omega^{\prime \prime}(b) b_{\theta}}{\phi^{\prime}(c)} x_{c}\right) \\
& =-[\delta+p(\theta)] \frac{\theta}{\eta_{\theta}}\left(\alpha+\vartheta_{x}\right) x_{c} \frac{d c\left(\theta, x^{a}(\theta)\right)}{d \theta}+\left(\delta+p(\theta)+\frac{\theta}{\eta_{\theta}} \vartheta_{\theta}\right)\left(\frac{c}{\eta_{c}} \alpha x_{c}-\frac{\omega^{\prime}(b)}{\phi^{\prime}(c)}\right) \\
& +\frac{c}{\eta_{c}} \frac{\theta}{\eta_{\theta}}\left(\alpha+\vartheta_{x}\right)\left(\frac{\omega^{\prime}(b) \phi^{\prime \prime}(c)}{\phi^{\prime}(c)^{2}} x_{\theta}+\frac{\omega^{\prime \prime}(b) b_{\theta}}{\phi^{\prime}(c)} x_{c}\right) .
\end{aligned}
$$

For sufficiently high values of $\eta_{c}$, specifically for all $\eta_{c}>\frac{\alpha}{\rho}$, it holds that $\left(\frac{c}{\eta_{c}} \alpha x_{c}-\frac{\omega^{\prime}(b)}{\phi^{\prime}(c)}\right)<0$. We formally show this in Lemma 6 . It then follows that for $A_{2} \leq 0$, we have

$$
\begin{gathered}
A_{1} \leq-[\delta+p(\theta)] \frac{\theta}{\eta_{\theta}}\left(\alpha+\vartheta_{x}\right) x_{c} \frac{d c\left(\theta, x^{a}(\theta)\right)}{d \theta}-\left(\frac{c}{\eta_{c}} \alpha x_{c}-\frac{\omega^{\prime}(b)}{\phi^{\prime}(c)}+\frac{\theta}{\eta_{\theta}}\left(\alpha+\vartheta_{x}\right) x_{\theta}\right)\left(\frac{c}{\eta_{c}} \alpha x_{c}-\frac{\omega^{\prime}(b)}{\phi^{\prime}(c)}\right) \\
+\frac{c}{\eta_{c}} \frac{\theta}{\eta_{\theta}}\left(\alpha+\vartheta_{x}\right)\left(\frac{\omega^{\prime}(b) \phi^{\prime \prime}(c)}{\phi^{\prime}(c)^{2}} x_{\theta}+\frac{\omega^{\prime \prime}(b) b_{\theta}}{\phi^{\prime}(c)} x_{c}\right) \\
=-[\delta+p(\theta)] \frac{\theta}{\eta_{\theta}}\left(\alpha+\vartheta_{x}\right) x_{c} \frac{d c\left(\theta, x^{a}(\theta)\right)}{d \theta}-\left(\frac{c}{\eta_{c}} \alpha x_{c}-\frac{\omega^{\prime}(b)}{\phi^{\prime}(c)}\right)^{2}-\frac{\theta}{\eta_{\theta}}\left(\alpha+\vartheta_{x}\right) x_{\theta} \frac{c}{\eta_{c}} \alpha x_{c} \\
+\frac{\theta}{\eta_{\theta}}\left(\alpha+\vartheta_{x}\right) x_{\theta} \frac{\omega^{\prime}(b)}{\phi^{\prime}(c)}-\frac{\theta}{\eta_{\theta}}\left(\alpha+\vartheta_{x}\right) \frac{\omega^{\prime}(b)}{\phi^{\prime}(c)} x_{\theta}+\frac{c}{\eta_{c}} \frac{\theta}{\eta_{\theta}}\left(\alpha+\vartheta_{x}\right) \frac{\omega^{\prime \prime}(b) b_{\theta}}{\phi^{\prime}(c)} x_{c} \\
=-[\delta+p(\theta)] \frac{\theta}{\eta_{\theta}}\left(\alpha+\vartheta_{x}\right) x_{c} \frac{d c\left(\theta, x^{a}(\theta)\right)}{d \theta}-\left(\frac{c}{\eta_{c}} \alpha x_{c}-\frac{\omega^{\prime}(b)}{\phi^{\prime}(c)}\right)^{2}-\frac{c}{\eta_{c}} \frac{\theta}{\eta_{\theta}}\left(\alpha+\vartheta_{x}\right) x_{c}\left(x_{\theta}-\frac{\omega^{\prime \prime}(b) b_{\theta}}{\phi^{\prime}(c)}\right) .
\end{gathered}
$$

Since $\frac{d c\left(\theta, x^{a}(\theta)\right)}{d \theta}>0$ by Lemma 4 in the stagnation steady state, all three terms are negative and we have $A_{1}<0$. Therefore, we cannot have three negative eigenvalues, which together with $A_{0}<0$ and $\lambda_{1}>0$ implies that there are exactly two positive and two negative eigenvalues. It follows that the dynamic system is saddle path stable around the stagnation steady state.

\section{Appendix I: Proof of Lemma 6}

We want to derive the conditions under which, in the stagnation steady state, we have

$$
\Upsilon(\theta) \equiv-\frac{\omega^{\prime}(b) \phi^{\prime \prime}(c)(1-u) \bar{y}}{\phi^{\prime}(c)^{2}}-\alpha>0 .
$$


Consider the following modifications using the definition of $\eta_{c}$ and $c$

$$
\begin{gathered}
\Upsilon(\theta)=\frac{\omega^{\prime}(b)}{\phi^{\prime}(c)} \frac{(1-u) \bar{y} \eta_{c}}{c}-\alpha=\frac{(1-u) \bar{y}}{c}\left[\rho \eta_{c}-\alpha(1-x) \eta_{c}-\alpha \frac{c}{(1-u) \bar{y}}\right] \\
=\frac{(1-u) \bar{y}}{c}\left[\rho \eta_{c}-\alpha(1-x) \eta_{c}-\alpha \frac{(1-u) \bar{y} x-k u \theta-g}{(1-u) \bar{y}}\right] \\
=\frac{(1-u) \bar{y}}{c}\left[(\rho-\alpha) \eta_{c}+\alpha x\left(\eta_{c}-1\right)+\alpha \frac{k u \theta+g}{(1-u) \bar{y}}\right] .
\end{gathered}
$$

It is easy to see that $\Upsilon(\theta)>0$ for $\eta_{c} \geq 1$. Suppose $\eta_{c}<1$, then $x=1$ establishes a lower bound on the right hand side:

$$
\Upsilon(\theta)>\frac{(1-u) \bar{y}}{c}\left[\rho \eta_{c}-\alpha+\alpha \frac{k u \theta+g}{(1-u) \bar{y}}\right]>\frac{(1-u) \bar{y}}{c}\left[\rho \eta_{c}-\alpha\right] .
$$

It follows directly that $\Upsilon(\theta)>0$ for $\eta_{c}>\frac{\alpha}{\rho}$ or

$$
-\frac{\omega^{\prime}(b) \phi^{\prime \prime}(c)(1-u) \bar{y}}{\phi^{\prime}(c)^{2}}-\alpha>0 \text { if } \eta_{c}>\frac{\alpha}{\rho} .
$$

\section{Appendix J: Proof of Proposition 2}

(i) Effects on labor market tightness and unemployment: Use the steady state conditions (37) and (39) to define $G(\theta, \chi)$, where $x^{a}(\theta)$ is given by (41) as $x<1$ and $\chi$ denotes any parameter as follows:

$$
G(\theta, \chi)=\rho-\frac{\omega^{\prime}\left((1-u(\theta)) \frac{(1-s) k}{q(\theta)}\right)}{\phi^{\prime}\left(c\left(\theta, x^{a}(\theta)\right)\right)}-\alpha\left(1-x^{a}(\theta)\right),
$$

with $G\left(\theta^{s}, \chi\right)=0$ and $G_{\theta^{s}}<0$ in steady state where $G_{\theta^{s}}$ denotes the total derivative with respect to $\theta$ evaluated in steady state. The negative sign follows from the uniqueness of the steady state as shown in Appendix G. $c\left(\theta, x^{a}(\theta)\right)$ is given by (36) with $x=x^{a}(\theta)$. The effects of changes in a parameter $\chi$ on the labor market tightness $\theta$ can be recovered from (J.1) as

$$
\frac{d \theta}{d \chi}=-\frac{G_{\chi}}{G_{\theta^{s}}}
$$

In addition, we derive the following partial derivatives from $x^{a}(\theta, \chi)$ in $(41)$ :

$$
x_{\varepsilon}>0, x_{z}>0, x_{s}<0, x_{k}>0, x_{\bar{y}}<0, x_{g}=0, x+\bar{y} x_{\bar{y}}>0 .
$$

Using (J.1) to (J.3) and Lemma 6, we derive the following total derivatives:

$$
\begin{gathered}
\frac{d \theta}{d \varepsilon}=-\left[\frac{\omega^{\prime}(b) \phi^{\prime \prime}(c)(1-u) \bar{y}}{\phi^{\prime}(c)^{2}}+\alpha\right] \frac{x_{\varepsilon}}{G_{\theta^{s}}}<0, \\
\frac{d \theta}{d z}=-\left[\frac{\omega^{\prime}(b) \phi^{\prime \prime}(c)(1-u) \bar{y}}{\phi^{\prime}(c)^{2}}+\alpha\right] \frac{x_{z}}{G_{\theta^{s}}}<0, \\
\frac{d \theta}{d s}=\underbrace{-\frac{\omega^{\prime \prime}(b) b(\theta)}{(1-s) \phi^{\prime}(c)} \frac{1}{G_{\theta^{s}}}}_{\text {wealth channel }(-)}-\underbrace{\left[\frac{\omega^{\prime}(b) \phi^{\prime \prime}(c)(1-u) \bar{y}}{\phi^{\prime}(c)^{2}}+\alpha\right] \frac{x_{s}}{G_{\theta^{s}}}}_{\text {interest rate channel (+) }},
\end{gathered}
$$




$$
\begin{gathered}
\frac{d \theta}{d k}=\underbrace{\frac{\omega^{\prime \prime}(b) b(\theta)}{k \phi^{\prime}(c)} \frac{1}{G_{\theta^{s}}}}_{\text {wealth channel (+) }}+\underbrace{\frac{\omega^{\prime}(b) \phi^{\prime \prime}(c) \theta u}{\phi^{\prime}(c)^{2}} \frac{1}{G_{\theta^{s}}}}_{\text {cost channel }(+)}-\underbrace{\left[\frac{\omega^{\prime}(b) \phi^{\prime \prime}(c)(1-u) \bar{y}}{\phi^{\prime}(c)^{2}}+\alpha\right] \frac{x_{k}}{G_{\theta^{s}}}}_{\text {interest rate channel (-) }}, \\
\frac{d \theta}{d \bar{y}}=-\frac{\omega^{\prime}(b) \phi^{\prime \prime}(c)(1-u)}{\phi^{\prime}(c)^{2}} \frac{x+\bar{y} x_{\bar{y}}}{G_{\theta^{s}}}-\alpha \frac{x_{\bar{y}}}{G_{\theta^{s}}}<0, \\
\frac{d \theta}{d g}=\frac{\omega^{\prime}(b) \phi^{\prime \prime}(c)}{\phi^{\prime}(c)^{2}} \frac{1}{G_{\theta^{s}}}>0 .
\end{gathered}
$$

Expressions (J.4) to (J.9) imply the following response of labor market tightness to parameter variations. The response of the unemployment rate is opposite as is clear from the Beveridge curve in (31):

$$
\begin{aligned}
& \theta^{s}=\theta(\underbrace{\varepsilon}_{-}, \underbrace{z}_{-}, \underbrace{s}_{?}, \underbrace{k}_{?}, \underbrace{\bar{y}}_{-}, \underbrace{g}_{+}), \\
& u^{s}=u(\underbrace{\varepsilon}_{+}, \underbrace{z}_{?}, \underbrace{s}_{?}, \underbrace{\bar{y}}_{+}, \underbrace{g}_{-}) .
\end{aligned}
$$

(ii) Effects on realized working hours: From the asset market equilibrium curve (41), we recover the effects of parameter changes on realized working hours as follows:

$$
\frac{d x^{a}(\theta, \chi)}{d \chi}=x_{\chi}^{a}+\frac{d x^{a}(\theta)}{d \theta} \frac{d \theta}{d \chi}=x_{\chi}^{a}-\frac{d x^{a}(\theta)}{d \theta} \frac{G_{\chi}}{G_{\theta^{s}}}=\left[G_{\theta^{s}}-\frac{d x^{a}(\theta)}{d \theta} \frac{G_{\chi}}{x_{\chi}}\right] \frac{x_{\chi}^{a}}{G_{\theta^{s}}},
$$

where $\frac{d x^{a}(\theta)}{d \theta}>0$ and $G_{\chi}$ are the partial derivatives of $G(\theta, \chi)$ with respect to any parameter $\chi$. Using the expressions above for $\frac{d \theta}{d \chi}$ and $\frac{d c\left(\theta, x^{a}(\theta)\right)}{d \theta}=(1-u) \bar{y} \frac{d x^{a}(\theta)}{d \theta}-\left(\bar{y} x^{a}(\theta)+k \theta\right) u^{\prime}(\theta)-k u$ from (36), we get the following results:

$$
\begin{gathered}
\frac{d x}{d \varepsilon}=\left[\frac{-\omega^{\prime \prime}(b) b^{\prime}(\theta)}{\phi^{\prime}(c)}-\frac{\omega^{\prime}(b)}{\phi^{\prime}(c)} \frac{\phi^{\prime \prime}(c)}{\phi^{\prime}(c)}\left[k u+(\bar{y} x+k \theta) u^{\prime}(\theta)\right]\right] \frac{x_{\varepsilon}}{G_{\theta^{s}}}, \\
\frac{d x}{d z}=\left[\frac{-\omega^{\prime \prime}(b) b^{\prime}(\theta)}{\phi^{\prime}(c)}-\frac{\omega^{\prime}(b)}{\phi^{\prime}(c)} \frac{\phi^{\prime \prime}(c)}{\phi^{\prime}(c)}\left[k u+(\bar{y} x+k \theta) u^{\prime}(\theta)\right]\right] \frac{x_{z}}{G_{\theta^{s}}}, \\
\frac{d x}{d s}=\left[\frac{\omega^{\prime \prime}(b)}{\phi^{\prime}(c)}\left[-\frac{d x^{a}(\theta)}{d \theta} \frac{b(\theta)}{x_{s}(1-s)}-b^{\prime}(\theta)\right]-\frac{\omega^{\prime}(b)}{\phi^{\prime}(c)} \frac{\phi^{\prime \prime}(c)}{\phi^{\prime}(c)}\left[k u+(\bar{y} x+k \theta) u^{\prime}(\theta)\right]\right] \frac{x_{s}}{,} G_{\theta^{s}} \\
\frac{d x}{d k}=\left[\frac{\omega^{\prime \prime}(b)}{\phi^{\prime}(c)}\left[\frac{d x^{a}(\theta)}{d \theta} \frac{b(\theta)}{k x_{k}}-b^{\prime}(\theta)\right]-\frac{\omega^{\prime}(b)}{\phi^{\prime}(c)} \frac{\phi^{\prime \prime}(c)}{\phi^{\prime}(c)}\left[k u+(\bar{y} x+k \theta) u^{\prime}(\theta)-\frac{d x^{a}(\theta)}{d \theta} \frac{\theta u}{x_{k}}\right]\right] \frac{x_{k}}{G_{\theta^{s}}}, \\
\frac{d x}{d \bar{y}}=\left[-\frac{\omega^{\prime \prime}(b) b^{\prime}(\theta)}{\phi^{\prime}(c)}-\frac{\omega^{\prime}(b) \phi^{\prime \prime}(c)}{\phi^{\prime}(c)^{2}}\left[k u+(\bar{y} x+k \theta) u^{\prime}(\theta)+\frac{d x^{a}(\theta)}{d \theta} \frac{(1-u) x(\theta)}{x_{\bar{y}}}\right]\right] \frac{x_{\bar{y}}}{G_{\theta^{s}}} \\
=\left[-\frac{\omega^{\prime \prime}(b) b^{\prime}(\theta)}{\phi^{\prime}(c)}-\frac{\omega^{\prime}(b) \phi^{\prime \prime}(c)}{\phi^{\prime}(c)^{2}}\left[\frac{d x^{a}(\theta)}{d \theta} \frac{(1-u)}{x_{\bar{y}}}\left(x+\bar{y} x_{\bar{y}}\right)-\frac{d c\left(\theta, x^{a}(\theta)\right)}{d \theta}\right]\right] \frac{x_{\bar{y}}}{G_{\theta^{s}}}
\end{gathered}
$$

From $G_{\theta^{s}}<0$, we derive the following upper bound for the first term in brackets:

$$
-\frac{\omega^{\prime \prime}(b) b^{\prime}(\theta)}{\phi^{\prime}(c)}<-\frac{\omega^{\prime}(b) \phi^{\prime \prime}(c)}{\phi^{\prime}(c)^{2}} \frac{d c\left(\theta, x^{a}(\theta)\right)}{d \theta}-\alpha \frac{d x^{a}(\theta)}{d \theta} .
$$

Since $x_{\bar{y}}<0$ and $G_{\theta^{s}}<0$, it follows that:

$$
\begin{gathered}
\frac{d x}{d \bar{y}}<\left[-\frac{\omega^{\prime}(b) \phi^{\prime \prime}(c)}{\phi^{\prime}(c)^{2}} \frac{d c\left(\theta, x^{a}(\theta)\right)}{d \theta}-\alpha \frac{d x^{a}(\theta)}{d \theta}-\frac{\omega^{\prime}(b) \phi^{\prime \prime}(c)}{\phi^{\prime}(c)^{2}}\left[\frac{d x^{a}(\theta)}{d \theta} \frac{(1-u)}{x_{\bar{y}}}\left(x+\bar{y} x_{\bar{y}}\right)-\frac{d c\left(\theta, x^{a}(\theta)\right)}{d \theta}\right]\right] \frac{x_{\bar{y}}}{G_{\theta^{s}}} \\
=-\frac{d x^{a}(\theta)}{d \theta}\left[\alpha+\frac{\omega^{\prime}(b) \phi^{\prime \prime}(c)}{\phi^{\prime}(c)^{2}} \frac{(1-u)}{x_{\bar{y}}}\left(x+\bar{y} x_{\bar{y}}\right)\right] \frac{x_{\bar{y}}}{G_{\theta^{s}}}<0,
\end{gathered}
$$




$$
\frac{d x}{d g}=\frac{d x^{a}(\theta)}{d \theta} \frac{d \theta}{d g}>0
$$

Taken together, we have derived the following effects of parameter changes in (J.13) to (J.18):

$$
x^{s}=x(\underbrace{\varepsilon}_{?}, \underbrace{z}_{?}, \underbrace{s}_{?}, \underbrace{k}_{?}, \underbrace{\bar{y}}_{-}, \underbrace{g}_{+}) .
$$

(iii) Effects on total output: The effects of parameter changes on total output follow from the total differential of $Y(\theta)=(1-u(\theta)) x^{a}(\theta) \bar{y}$ as:

$$
\frac{d Y}{d \chi}=-x^{a}(\theta) \bar{y} \frac{d u}{d \chi}+(1-u) \bar{y} \frac{d x}{d \chi}+Y_{\chi}
$$

where $Y_{\chi}=(1-u) x$ for $\chi=\bar{y}$ and zero otherwise. It then follows that these effects are given by:

$$
\begin{gathered}
\frac{d Y}{d \varepsilon}=\underbrace{(1-u) \bar{y} x_{\varepsilon}}_{+}+\underbrace{\left[(1-u) \bar{y} \frac{d x^{a}(\theta)}{d \theta}-x \bar{y} u^{\prime}(\theta)\right] \frac{d \theta}{d \varepsilon}}_{-}, \\
\frac{d Y}{d z}=\underbrace{(1-u) \bar{y} x_{z}}_{+}+\underbrace{\left[(1-u) \bar{y} \frac{d x^{a}(\theta)}{d \theta}-x \bar{y} u^{\prime}(\theta)\right] \frac{d \theta}{d z}}_{-}, \\
\frac{d Y}{d s}=\underbrace{(1-u) \bar{y} x_{s}}_{-}+\underbrace{\left[(1-u) \bar{y} \frac{d x^{a}(\theta)}{d \theta}-x \bar{y} u^{\prime}(\theta)\right] \frac{d \theta}{d s}}_{+/-}, \\
\frac{d Y}{d k}=\underbrace{(1-u) \bar{y} x_{k}}_{+}+\underbrace{\left[(1-u) \bar{y} \frac{d x^{a}(\theta)}{d \theta}-x \bar{y} u^{\prime}(\theta)\right] \frac{d \theta}{d k}}_{+/-}, \\
=\left[-(1-u)\left(\bar{y}+\frac{d Y}{x_{\bar{y}}}\right) \frac{\omega^{\prime \prime}(b) b^{\prime}(\theta)}{\phi^{\prime}(c)}+\alpha x^{a}(\theta)\left(\bar{y} u^{\prime}(\theta)+\frac{d x^{a}(\theta)}{d \theta} \frac{1-u}{x_{\bar{y}}}\right)\right. \\
\left.-(1-u) \frac{\omega^{\prime}(b) \phi^{\prime \prime}(c)}{\phi^{\prime}(c)^{2}}\left(\bar{y}+\frac{x}{x_{\bar{y}}}\right)\left(k u+k \theta u^{\prime}(\theta)\right)\right] \frac{x_{\bar{y}}}{G_{\theta^{s}}}
\end{gathered}
$$

As above, we apply an upper bound on $-\frac{\omega^{\prime \prime}(b) b^{\prime}(\theta)}{\phi^{\prime}(c)}$ that results from $G_{\theta^{s}}<0$. Since $x_{\bar{y}}<0$ and $G_{\theta^{s}}<0$, it follows that:

$$
\begin{gathered}
\frac{d Y}{d \bar{y}}<\left[-(1-u)\left(\bar{y}+\frac{x^{a}(\theta)}{x_{\bar{y}}}\right)\left[\frac{\omega^{\prime}(b) \phi^{\prime \prime}(c)}{\phi^{\prime}(c)^{2}} \frac{d c\left(\theta, x^{a}(\theta)\right)}{d \theta}+\alpha \frac{d x^{a}(\theta)}{d \theta}\right]+\alpha x\left(\bar{y} u^{\prime}(\theta)+\frac{d x^{a}(\theta)}{d \theta} \frac{1-u}{x_{\bar{y}}}\right)\right. \\
\left.-(1-u) \frac{\omega^{\prime}(b) \phi^{\prime \prime}(c)}{\phi^{\prime}(c)^{2}}\left(\bar{y}+\frac{x^{a}(\theta)}{x_{\bar{y}}}\right)\left(k u+k \theta u^{\prime}(\theta)\right)\right] \frac{x_{\bar{y}}}{G_{\theta^{s}}} \\
=\left[-(1-u)\left(\bar{y}+\frac{x^{a}(\theta)}{x_{\bar{y}}}\right) \frac{\omega^{\prime}(b) \phi^{\prime \prime}(c)}{\phi^{\prime}(c)^{2}} \bar{y}\left((1-u) \frac{d x^{a}(\theta)}{d \theta}-u^{\prime}(\theta) x^{a}(\theta)\right)\right. \\
\left.-\alpha \bar{y}\left((1-u) \frac{d x^{a}(\theta)}{d \theta}-x^{a}(\theta) u^{\prime}(\theta)\right)\right] \frac{x_{\bar{y}}}{G_{\theta^{s}}} \\
=-\underbrace{\left[(1-u) \frac{d x^{a}(\theta)}{d \theta}-u^{\prime}(\theta) x^{a}(\theta)\right]}_{+} \underbrace{\left[(1-u)\left(\bar{y}+\frac{x^{a}(\theta)}{x_{\bar{y}}}\right) \frac{\omega^{\prime}(b) \phi^{\prime \prime}(c)}{\phi^{\prime}(c)^{2}}+\alpha\right]}_{\bar{y}} \underbrace{\frac{x_{\bar{y}}}{G_{\theta^{s}}}}_{+}<0,
\end{gathered}
$$




$$
\frac{d Y}{d g}=\left[\frac{p^{\prime}(\theta)}{p(\theta)} u x^{a}(\theta)+\frac{d x^{a}(\theta)}{d \theta}\right] \frac{p(\theta) \bar{y}}{\delta+p(\theta)} \frac{d \theta}{d g}>0 .
$$

Taken together, we have derived the following effects of parameter changes from (J.21) to (J.26):

$$
Y^{s}=Y(\underbrace{\varepsilon}_{?}, \underbrace{z}_{?}, \underbrace{s}_{?}, \underbrace{k}_{?}, \underbrace{\bar{y}}_{-}, \underbrace{g}_{+}) .
$$

(iv) Effects on consumption: Finally, the effects on consumption are given by the differential of (36) with $x=x^{a}(\theta)$ given by (41) using the expressions above as:

$$
\frac{d c}{d \chi}=\left[-[\bar{y} x+k \theta] u^{\prime}(\theta)-k u\right] \frac{d \theta}{d \chi}+(1-u) \bar{y} \frac{d x}{d \chi}+c_{\chi}=\frac{d c\left(\theta, x^{a}(\theta)\right)}{d \theta} \frac{d \theta}{d \chi}+(1-u) \bar{y} x_{\chi}+c_{\chi}
$$

where $\frac{d c\left(\theta, x^{a}(\theta)\right)}{d \theta}>0, c_{\varepsilon}=c_{z}=c_{s}=0, c_{k}=-\theta u<0, c_{\bar{y}}=(1-u) x>0$ and $c_{g}=-1<0$.

$$
\begin{aligned}
& \frac{d c}{d \varepsilon}=\underbrace{\frac{d c\left(\theta, x^{a}(\theta)\right)}{d \theta} \frac{d \theta}{d \varepsilon}}_{-}+\underbrace{(1-u) \bar{y} x_{\varepsilon}}_{+}=\left[\left[(\bar{y} x+k \theta) u^{\prime}(\theta)+k u\right] \alpha-(1-u) \bar{y} \frac{\omega^{\prime \prime}(b) b^{\prime}(\theta)}{\phi^{\prime}(c)}\right] \frac{x_{\varepsilon}}{G_{\theta^{s}}}, \\
& \frac{d c}{d z}=\underbrace{\frac{d c\left(\theta, x^{a}(\theta)\right)}{d \theta} \frac{d \theta}{d z}}_{-}+\underbrace{(1-u) \bar{y} x_{z}}_{+}=\left[\left[(\bar{y} x+k \theta) u^{\prime}(\theta)+k u\right] \alpha-(1-u) \bar{y} \frac{\omega^{\prime \prime}(b) b^{\prime}(\theta)}{\phi^{\prime}(c)}\right] \frac{x_{z}}{G_{\theta^{s}}}, \\
& \frac{d c}{d s}=\underbrace{\frac{d c\left(\theta, x^{a}(\theta)\right)}{d \theta} \frac{d \theta}{d s}}_{+/-}+\underbrace{(1-u) \bar{y} x_{s}}_{-}, \\
& \frac{d c}{d k}=\underbrace{\frac{d c\left(\theta, x^{a}(\theta)\right)}{d \theta} \frac{d \theta}{d k}}_{+/-}+\underbrace{(1-u) \bar{y} x_{k}}_{+} \underbrace{-u \theta}_{-}, \\
& \frac{d c}{d \bar{y}}=(1-u) x\left[1-\frac{\omega^{\prime}(b) \phi^{\prime \prime}(c)}{\phi^{\prime}(c)^{2} G_{\theta^{s}}} \frac{d c\left(\theta, x^{a}(\theta)\right)}{d \theta}\right]+\left[\left[(\bar{y} x+k \theta) u^{\prime}(\theta)+k u(\theta)\right] \alpha-(1-u) \bar{y} \frac{\omega^{\prime \prime}(b) b^{\prime}(\theta)}{\phi^{\prime}(c)}\right] \frac{x_{\bar{y}}}{G_{\theta^{s}}} \\
& =(1-u) x \frac{\phi^{\prime 2} \alpha \frac{d x^{a}(\theta)}{d \theta}-\omega^{\prime \prime}(b) b^{\prime}(\theta) \phi^{\prime}(c)}{\phi^{\prime}(c)^{2} G_{\theta^{s}}}+\left[\left[(1-u) \frac{d x^{a}(\theta)}{d \theta} \bar{y}-\frac{d c\left(\theta, x^{a}(\theta)\right)}{d \theta}\right] \alpha-(1-u) \bar{y} \frac{\omega^{\prime \prime}(b) b^{\prime}(\theta)}{\phi^{\prime}(c)}\right] \frac{x_{\bar{y}}}{G_{\theta^{s}}} \\
& =\left[\alpha\left((1-u) \frac{d x^{a}(\theta)}{d \theta}\left(\bar{y} x_{\bar{y}}+x\right)-\frac{d c\left(\theta, x^{a}(\theta)\right)}{d \theta} x_{\bar{y}}\right)-(1-u)\left(\bar{y} x_{\bar{y}}+x\right) \frac{\omega^{\prime \prime}(b) b^{\prime}(\theta)}{\phi^{\prime}(c)}\right] \frac{1}{G_{\theta^{s}}} \\
& =[\underbrace{-\alpha \frac{d c\left(\theta, x^{a}(\theta)\right)}{d \theta} x_{\bar{y}}}_{+ \text {as } x_{\bar{y}}<0}+\underbrace{(1-u)\left(\bar{y} x_{\bar{y}}+x\right)}_{+ \text {as } \bar{y} x_{\bar{y}}+x>0}\left(\alpha \frac{d x^{a}(\theta)}{d \theta}-\frac{\omega^{\prime \prime}(b) b^{\prime}(\theta)}{\phi^{\prime}(c)}\right)] \frac{1}{G_{\theta^{s}}}<0, \\
& \frac{d c}{d g}=-\left[\alpha \frac{d x^{a}(\theta)}{d \theta}-\frac{\omega^{\prime \prime}(b) b^{\prime}(\theta)}{\phi^{\prime}(c)}\right] \frac{1}{G_{\theta^{s}}}>0 .
\end{aligned}
$$

Taken together, (J.29) to (J.34) imply the following effects of parameter changes:

$$
c=c(\underbrace{\varepsilon}_{?}, \underbrace{z}_{?}, \underbrace{s}_{?}, \underbrace{k}_{?}, \underbrace{\bar{y}}_{-}, \underbrace{g}_{+}) .
$$




\section{References}

Andolfatto, David, "Business Cycles and Labor-market Search," American Economic Review, 1996, 86 (1), 112-132.

Ball, Laurence M., Daniel Leigh, and Prakash Loungani, "Okun's Law: Fit at Fifty?," Technical Report No. 18668, NBER Working Paper 2013.

Benhabib, Jess and Alberto Bisin, "Skewed Wealth Distributions: Theory and Empirics," Journal of Economic Literature, 2018, 56 (4), 1261-1291.

Caballero, Ricardo J. and Emmanuel Farhi, "The Safety Trap," Review of Economic Studies, 2018, 85 (1), 223-274.

_, _, and Pierre-Olivier Gourinchas, "Global Imbalances and Currency Wars at the ZLB," Working Paper No. 344401, Harvard University OpenScholar 2016.

Diamond, Peter A., "Wage Determination and Efficiency in Search Equilibrium," Review of Economic Studies, 1982, 49 (2), 217-227.

Eggertsson, Gauti B., Neil R. Mehrotra, and Jacob Robbins, "A Model of Secular Stagnation: Theory and Quantitative Evaluation," American Economic Journal: Macroeconomics, 2019, 11 (1), 1-48.

_ , _ , and Lawrence H. Summers, "Secular Stagnation in the Open Economy," American Economic Review, 2016, 106 (5), 503-507.

Fagereng, Andreas, Martin Blomhoff Holm, Benjamin Moll, and Gisle Natvik, "Saving Behavior Across the Wealth Distribution: The Importance of Capital Gains," Working Paper, Oslo University and Princeton University 2019.

Fang, Lei and Richard Rogerson, "Policy Analysis in a Matching Model with Intensive and Extensive Margins," International Economic Review, 2009, 50, 1153-1168.

Haan, Wouter J. Den, Garey Ramey, and Joel Watson, "Job Destruction and Propagation of Shocks," American Economic Review, 2000, 90 (3), 482-498.

Hamaaki, Junya, Masahiro Hori, Saeko Maeda, and Keiko Murata, "Changes in the Japanese Employment System in the Two Lost Decades," Industrial and Labor Relations Review, 2012, 65 (4), 810-846.

Hansen, Alvin, "Economic Progress and Declining Population Growth," American Economic Review, 1939, 29 (1), 1-15.

Hashimoto, Masanori and John Raisian, "Employment Tenure and Earnings Profiles in Japan and the United States," American Economic Review, 1985, 75 (4), 721-735.

Homburg, Stefan, "Understanding Benign Liquidity Traps: The Case of Japan," German Economic Review, 2017, 18 (3), 267-282.

Illing, Gerhard, Yoshiyasu Ono, and Matthias Schlegl, "Credit Booms, Debt Overhang and Secular Stagnation," European Economic Review, 2018, 108, 78-104.

Japan Institute for Labour Policy and Training, "Trends in Non-regular Employment in Japan and Analysis of Several Related Themes," in "Labor Situation in Japan and Its Analysis: Detailed Exposition 2014/2015," Japan Institute for Labour Policy and Training, 2015, chapter 1, pp. 1-21. 
Kambayashi, Ryo and Takao Kato, "The Japanese Employment System after the Bubble Burst: New Evidence," in Anil Kashyap Hamada, Koichi and David Weinstein, eds., Japan's Bubble, Deflation and Long-term Stagnation, MIT Press, Cambridge, 2011, chapter 7, pp. 217-261.

Kudoh, Noritaka, Hiroaki Miyamoto, and Masaru Sasaki, "Employment and Hours over the Business Cycle in a Model with Search Frictions," Review of Economic Dynamics, 2019, 31, 436-461.

Kumhof, Michael, Romain Rancière, and Pablo Winant, "Inequality, Leverage, and Crises," American Economic Review, 2015, 105 (3), 1217-1245.

Landais, Camille, Pascal Michaillat, and Emmanuel Saez, "A Macroeconomic Approach to Optimal Unemployment Insurance: Application," American Economic Journal: Economic Policy, 2015, 10 (2), 182-216.

_ , _ , and _ , "A Macroeconomic Approach to Optimal Unemployment Insurance: Theory," American Economic Journal: Economic Policy, 2015, 10 (2), 152-181.

Merz, Monika, "Search in the Labor Market and the Real Business Cycle," Journal of Monetary Economics, 1995, 36 (2), 269-300.

Mian, Atif, Ludwig Straub, and Amir Sufi, "Indebted Demand," November 2019. Working Paper.

Michaillat, Pascal, "Do Matching Frictions Explain Unemployment? Not in Bad Times," American Economic Review, 2012, 102 (4), 1721-1750.

- and Emmanuel Saez, "An Economic Business-Cycle Model," NBER Working Paper No. 19777, National Bureau of Economic Research 2014.

_ and _ , "Aggregate Demand, Idle Time, and Unemployment," The Quarterly Journal of Economics, 2015, 130 (2), 507-569.

_ and _, "Resolving New Keynesian Anomalies with Wealth in the Utility Function," 2019. Working Paper, Brown University and UC Berkeley.

Michau, Jean-Baptiste, "Secular Stagnation: Theory and Remedies," Journal of Economic Theory, 2018, 176, 552-618.

_ , "Helicopter Drops of Money under Secular Stagnation," 2019. Working Paper, Ecole Polytechnique.

_ , "The Preference for Net Wealth," 2019. Working Paper, Ecole Polytechnique.

_, Yoshiyasu Ono, and Matthias Schlegl, "Wealth Preference and Rational Bubbles," Technical Report No. 7148, CESifo Working Paper 2018.

_ , , and _ , "Wealth Preference and Inequality," 2019. unpublished manuscript.

Mortensen, Dale T., "The Matching Process as a Noncooperative Bargaining Game," in "The Economics of Information and Uncertainty" NBER Chapters, National Bureau of Economic Research, Inc, May 1982, pp. 233-258.

Ono, Yoshiyasu, Money, Interest, and Stagnation - Dynamic Theory and Keynes's Economics, Oxford: Clarendon Press, 1994. 
_ , "A Reinterpretation of Chapter 17 of Keynes's General Theory: Effective Demand Shortage under Dynamic Optimization," International Economic Review, 2001, 42 (1), 207-236.

_ , "International Economic Interdependence and Exchange-rate Adjustment under Persistent Stagnation," Japanese Economic Review, 2014, 65 (1), 70-92.

_, "Growth, Secular Stagnation and Wealth Preference," ISER Discussion Paper No. 946, Institute of Social and Economic Research, Osaka University 2015.

- and Junichiro Ishida, "On Persistent Demand Shortages: A Behavioral Approach," Japanese Economic Review, 2014, 65 (1), 42-69.

Pissarides, Christopher A., "Short-run Equilibrium Dynamics of Unemployment Vacancies, and Real Wages," American Economic Review, 1985, 75 (4), 676-690.

_, Equilibrium Unemployment Theory, 2nd ed., MIT Press, Cambridge, MA, 2000.

Rogerson, Richard, Robert Shimer, and Randall Wright, "Search-theoretic Models of the Labor Market: A Survey," Journal of Economic Literature, 2007, 43, 959-988.

Saez, Emmanuel and Stefanie Stantcheva, "A Simpler Theory of Optimal Capital Taxation," Journal of Public Economics, 2018, 162, 120-142.

Schlegl, Matthias, "Secular Stagnation in an Economy with Land," ISER Discussion Paper No. 1032, Institute of Social and Economic Research, Osaka University 2018.

Schmitt-Grohé, Stephanie and Martín Uribe, "Downward Nominal Wage Rigidity, Currency Pegs, and Involuntary Unemployment," Journal of Political Economy, 2016, 124 (5), $1466-1514$.

_ and _, "Liquidity Traps and Jobless Recoveries," American Economic Journal: Macroeconomics, 2017, 9 (1), 165-204.

Shimizutani, Satoshi and Izumi Yokoyama, "Japan's Long-term Employment Practice Survived? Developments since the 1990s," Industrial and Labor Relations Review, 2009, 62 (3), 313-326.

Summers, Lawrence H., "Conference Address," 2013. IMF Fourteenth Annual Research Conference in Honor of Stanley Fischer.

Zou, Heng-fu, "“The Spirit of Capitalism" and Long-Run Growth," European Journal of Political Economy, 1994, 10, 279-293. 